\title{
Trends in Pesticide Concentrations in Corn-Belt Streams, 1996-2006
}

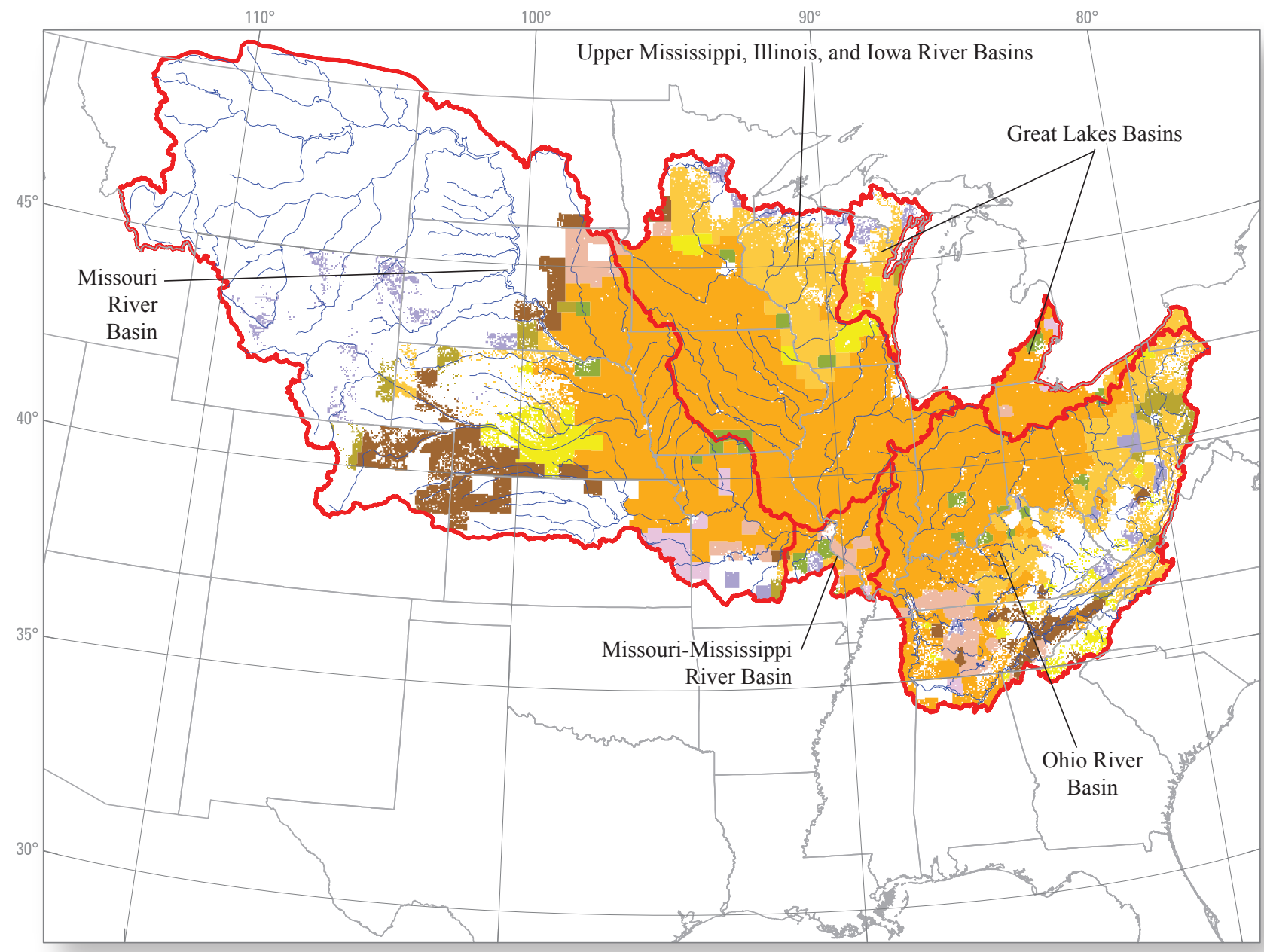

Scientific Investigations Report 2009-5132 
Cover: Major drainage basins and cropping patterns in corn-belt streams, 1996-2006. 


\section{Trends in Pesticide Concentrations in Corn-Belt Streams, 1996-2006}

By Daniel J. Sullivan, Aldo V. Vecchia, David L. Lorenz, Robert J. Gilliom, and Jeffrey D. Martin

National Water-Quality Assessment Program

Scientific Investigations Report 2009-5132 


\title{
U.S. Department of the Interior \\ KEN SALAZAR, Secretary \\ U.S. Geological Survey \\ Marcia K. McNutt, Director
}

\section{U.S. Geological Survey, Reston, Virginia: 2009}

\author{
For more information on the USGS — the Federal source for science about the Earth, its natural and living resources, \\ natural hazards, and the environment, visit http://www.usgs.gov or call 1-888-ASK-USGS \\ For an overview of USGS information products, including maps, imagery, and publications, \\ visit http://www.usgs.gov/pubprod \\ To order this and other USGS information products, visit http://store.usgs.gov
}

\begin{abstract}
Any use of trade, product, or firm names is for descriptive purposes only and does not imply endorsement by the U.S. Government.

Although this report is in the public domain, permission must be secured from the individual copyright owners to reproduce any copyrighted materials contained within this report.
\end{abstract}

Suggested reference:

Sullivan, D.J., Vecchia, A.V., Lorenz, D.L., Gilliom, R.J., and Martin, J.D., 2009, Trends in pesticide concentrations in corn-belt streams, 1996-2006: U.S. Geological Survey Scientific Investigations Report 2009-5132, 75 p. 


\section{Foreword}

The U.S. Geological Survey (USGS) is committed to providing the Nation with credible scientific information that helps to enhance and protect the overall quality of life and that facilitates effective management of water, biological, energy, and mineral resources (http://www.usgs.gov/). Information on the Nation's water resources is critical to ensuring long-term availability of water that is safe for drinking and recreation and is suifor industry, irrigation, and fish and wildlife. Population growth and increasing demands for water make the availability of that water, now measured in terms of quantity and quality, even more essential to the long-term sustainability of our communities and ecosystems.

The USGS implemented the National Water-Quality Assessment (NAWQA) Program in 1991 to support national, regional, State, and local information needs and decisions related to water-quality management and policy (http:// water.usgs.gov/nawqa). The NAWQA Program is designed to answer: What is the condition of our Nation's streams and ground water? How are conditions changing over time? How do natural features and human activities affect the quality of streams and ground water, and where are those effects most pronounced? By combining information on water chemistry, physical characteristics, stream habitat, and aquatic life, the NAWQA Program aims to provide science-based insights for current and emerging water issues and priorities. During 1991-2001, the NAWQA Program completed interdisciplinary assessments and established a baseline understanding of water-quality conditions in 51 of the Nation's river basins and aquifers, referred to as Study Units (http://water.usgs.gov/nawqa/studyu.html).

In the second decade of the Program (2001-2012), a major focus is on regional assessments of water-quality conditions and trends. These regional assessments are based on major river basins and principal aquifers, which encompass larger regions of the country than the Study Units. Regional assessments extend the findings in the Study Units by filling critical gaps in characterizing the quality of surface water and ground water, and by determining status and trends at sites that have been consistently monitored for more than a decade. In addition, the regional assessments continue to build an understanding of how natural features and human activities affect water quality. Many of the regional assessments employ modeling and other scientific tools, developed on the basis of data collected at individual sites, to help extend knowledge of water quality to unmonitored, yet comparable areas within the regions. The models thereby enhance the value of our existing data and our understanding of the hydrologic system. In addition, the models are useful in evaluating various resource-management scenarios and in predicting how our actions, such as reducing or managing nonpoint and point sources of contamination, land conversion, and altering flow and (or) pumping regimes, are likely to affect water conditions within a region.

Other activities planned during the second decade include continuing national syntheses of information on pesticides, volatile organic compounds (VOCs), nutrients, selected trace elements, and aquatic ecology; and continuing national topical studies on the fate of agricultural chemicals, effects of urbanization on stream ecosystems, bioaccumulation of mercury in stream ecosystems, effects of nutrient enrichment on stream ecosystems, and transport of contaminants to public-supply wells.

The USGS aims to disseminate credible, timely, and relevant science information to address practical and effective water-resource management and strategies that protect and restore water quality. We hope this NAWQA publication will provide you with insights and information to meet your needs, and will foster increased citizen awareness and involvement in the protection and restoration of our Nation's waters.

The USGS recognizes that a national assessment by a single program cannot address all water-resource issues of interest. External coordination at all levels is critical for cost-effective management, regulation, and conservation of our Nation's water resources. The NAWQA Program, therefore, depends on advice and information from other agencies_-Federal, State, regional, interstate, Tribal, and local—as well as nongovernmental organizations, industry, academia, and other stakeholder groups. Your assistance and suggestions are greatly appreciated.

Matthew C. Larsen

Associate Director for Water 
This page intentionally left blank. 


\section{Contents}

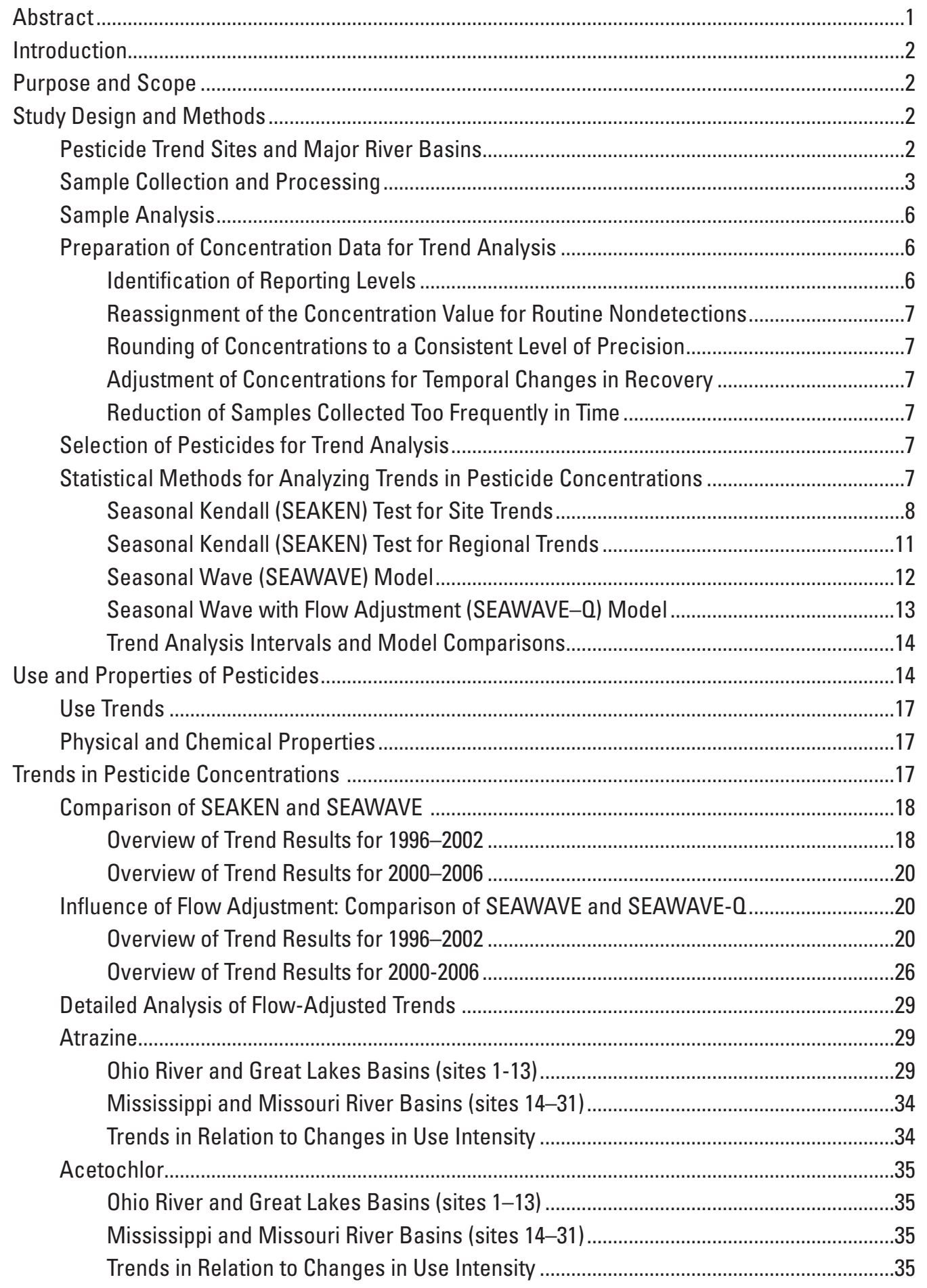




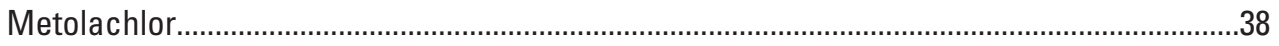

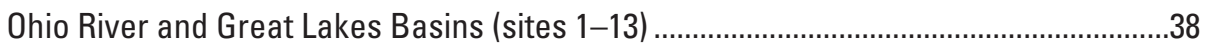

Mississippi and Missouri River Basins (sites 14-31) ..........................................................38

Trends in Relation to Changes in Use Intensity .............................................................. 40

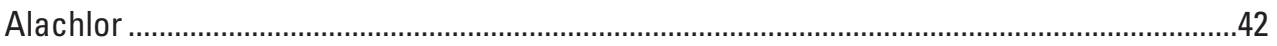

Ohio River and Great Lakes Basins (sites 1-13) ..............................................................42

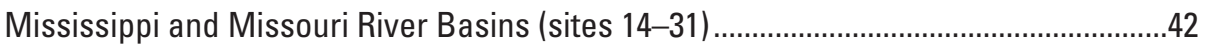

Trends in Relation to Changes in Use Intensity .........................................................42

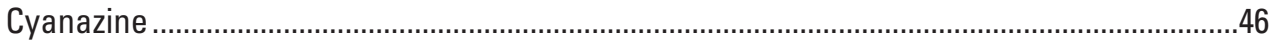

Trends in Relation to Changes in Use Intensity ..............................................................46

EPTC

Trends in Relation to Changes in Use Intensity ...........................................................50

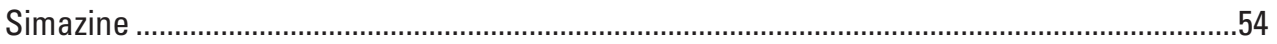

Ohio River and Great Lakes Basins (sites 1-13) ...............................................................54

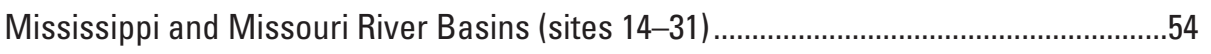

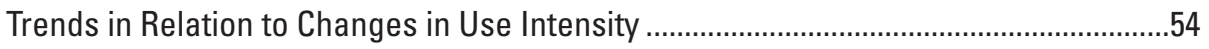

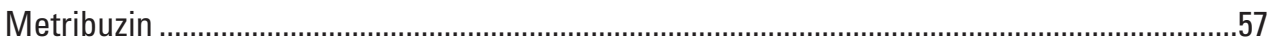

Trends in Relation to Changes in Use Intensity .............................................................57

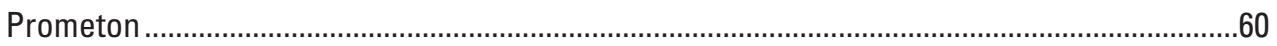

Ohio River and Great Lakes Basins (sites 1-13) .............................................................60

Mississippi and Missouri River Basins (sites 14-31) .....................................................60

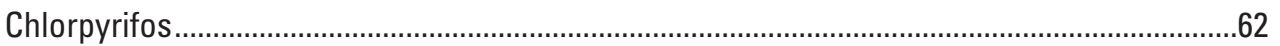

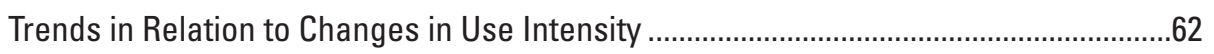

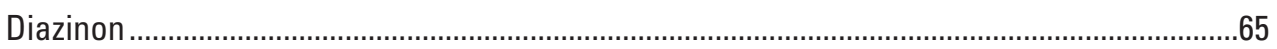

Trends in Relation to Changes in Use Intensity ...........................................................65

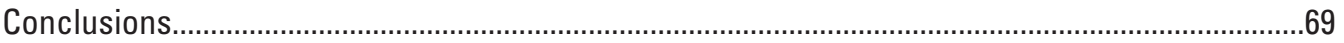

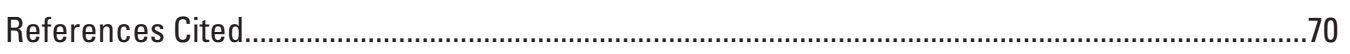

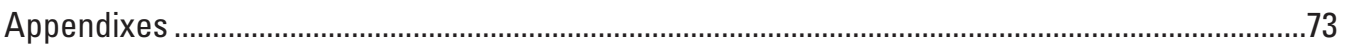

Appendix 1. Left-Censored Seasonal Kendall Trend Test and Approach for Estimating

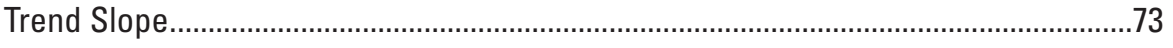

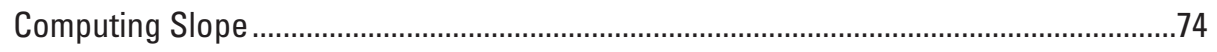

Appendix 2. Methods for Fitting SEAWAVE and SEAWAVE-0 models ..................................75 


\section{Figures}

1. Map of trends sites, major drainage basins, and cropping patterns.................................

2. Trends in total annual pesticide use in major river basins of the Corn Belt, 1992-2006

3. Observed and fitted acetochlor concentrations for selected sites for the 1996-2002 analysis period using SEAWAVE (left) and SEAWAVE-0 (right)

4. Observed and fitted acetochlor concentrations for selected sites for the 2000-2006 analysis period using SEAWAVE (left) and SEAWAVE-0 (right)

5. Observed and fitted simazine concentrations for selected sites for the 2000-2006 analysis period using SEAWAVE (left) and SEAWAVE-Q (right)

6. Observed and fitted prometon concentrations for selected sites for the 2000-2006 analysis period using SEAWAVE (left) and SEAWAVE-Q (right)

7. Flow-adjusted trends in atrazine concentration for 1996-2002 and 2000-2006 analysis periods

8. Atrazine use intensity and stream-water concentrations for selected trend sites in the Corn Belt, 1996-2006

9. Flow-adjusted trends in acetochlor concentrations for 1996-2002 and 2000-2006 analysis periods

10. Acetochlor use intensity and stream-water concentrations for selected trend sites in the Corn Belt, 1996-2006

11. Flow-adjusted trends in metolachlor concentration for 1996-2002 and 2000-2006 analysis periods

12. Metolachlor use intensity and stream-water concentrations for selected trend sites in the Corn Belt, 1996-2006

13. Flow-adjusted trends in alachlor concentration for 1996-2002 and 2000-2006 analysis periods

14. Alachlor use intensity and stream-water concentrations for selected trend sites in the Corn Belt, 1996-2006

15. Flow-adjusted trends in cyanazine concentration for 1996-2002 and 2000-2006 analysis periods.

16. Cyanazine use intensity and stream-water concentrations for selected trend sites in the Corn Belt, 1996-2006

17. Flow-adjusted trends in EPTC concentration for 1996-2002 and 2000-2006 analysis periods

18. EPTC use intensity and stream-water concentrations for selected trend sites in the Corn Belt, 1996-2006

19. Flow-adjusted trends in simazine concentration for 1996-2002 and 2000-2006 analysis periods

20. Simazine use intensity and stream-water concentrations for selected trend sites in the Corn Belt, 1996-2006

21. Flow-adjusted trends in metribuzin concentration for 1996-2002 and 2000-2006 analysis periods.

22. Metribuzin use intensity and stream-water concentrations for selected trend sites in the Corn Belt, 1996-2006 
23. Flow-adjusted trends in prometon concentration for 1996-2002 and 2000-2006 analysis periods 61

24. Flow-adjusted trends in chlorpyrifos concentration for 1996-2002 and 2000-2006 analysis periods.

25. Chlorpyrifos use intensity and stream-water concentrations for selected trend sites in the Corn Belt, 1996-2006.

26. Flow-adjusted trends in diazinon concentration for 1996-2002 and 2000-2006 analysis periods.

27. Diazinon use intensity and stream-water concentrations for selected trend sites in the Corn Belt, 1996-2006.

\section{Tables}

1. Selected information for sampling sites in the study area ..............................................

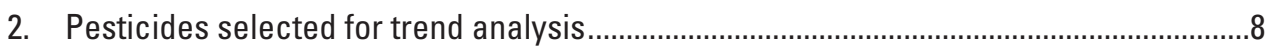

3. Number of uncensored samples and total number of samples for 1996-2002 and

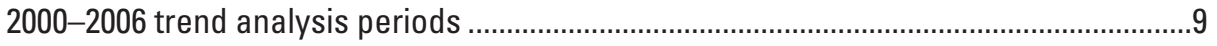

4. Properties affecting the transport and fate of selected pesticides .................................18

5. Comparison of SEAKEN and SEAWAVE trend results for 1996-2002 …..........................19

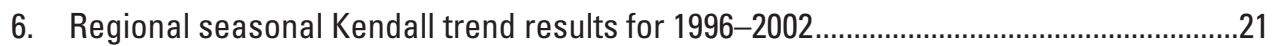

7. Comparison of SEAKEN and SEAWAVE trend results for 2000-2006.............................22

8. Comparison of SEAWAVE and SEAWAVE- $Q$ trend results for 1996-2002 …...................23

9. Comparison of SEAWAVE and SEAWAVE- $Q$ trend results for 2000-2006 .......................24

10. Statistical comparison of unadjusted and flow-adjusted trend magnitudes for atrazine, acetochlor, and metolachlor for the 1996-2002 analysis period.

11. Flow-adjusted trends in atrazine concentration and changes in atrazine use intensity for selected sites for the 1996-2002 and 2000-2006 trend analysis periods.

12. Flow-adjusted trends in acetochlor concentration and changes in acetochlor use intensity for selected sites for the 1996-2002 and 2000-2006 trend analysis periods..

13. Flow-adjusted trends in metolachlor concentration and changes in metolachlor use intensity for selected sites for the 1996-2002 and 2000-2006 trend analysis periods..

14. Flow-adjusted trends in alachlor concentration and changes in alachlor use intensity for selected sites for the 1996-2002 and 2000-2006 trend analysis periods.

15. Flow-adjusted trends in cyanazine concentration and changes in cyanazine use intensity for selected sites for the 1996-2002 and 2000-2006 trend analysis periods

16. Flow-adjusted trends in EPTC concentration and changes in EPTC use intensity for selected sites for the 1996-2002 and 2000-2006 trend analysis periods. 
17. Flow-adjusted trends in simazine concentration and changes in simazine use intensity for selected sites for the 1996-2002 and 2000-2006 trend analysis periods.

18. Flow-adjusted trends in metribuzin concentration and changes in metribuzin use intensity for selected sites for the 1996-2002 and 2000-2006 trend analysis periods

19. Flow-adjusted trends in chlorpyrifos concentration and changes in chlorpyrifos use intensity for selected sites for the 1996-2002 and 2000-2006 trend analysis periods.

20. Flow-adjusted trends in diazinon concentration and changes in diazinon use intensity for selected sites for the 1996-2002 and 2000-2006 trend analysis periods

A2-1. Choices for the input function describing seasonal variability of pesticide application rates (equation A2-1) 


\section{Conversion Factors}

SI to Inch/Pound

\begin{tabular}{lll}
\hline \multicolumn{1}{c}{ Multiply } & By & \multicolumn{1}{c}{ To obtain } \\
\hline micrometer (um) & Length & \\
meter (m) & 0.00003937 & inch (in) \\
meter (m) & 3.281 & foot (ft) \\
& 1.094 & yard (yd) \\
\hline square kilometer $\left(\mathrm{km}^{2}\right)$ & Area & acre \\
square kilometer $\left(\mathrm{km}^{2}\right)$ & 247.1 & square mile (mi $\left.{ }^{2}\right)$ \\
\hline & 0.3861 & \\
\hline gram (g) & Mass & ounce, avoirdupois (oz) \\
kilogram $(\mathrm{kg})$ & 0.03527 & pound avoirdupois (lb) \\
\hline
\end{tabular}

Temperature in degrees Celsius $\left({ }^{\circ} \mathrm{C}\right)$ may be converted to degrees Fahrenheit $\left({ }^{\circ} \mathrm{F}\right)$ as follows:

$$
{ }^{\circ} \mathrm{F}=\left(1.8 \times{ }^{\circ} \mathrm{C}\right)+32
$$

Horizontal coordinate information is referenced to the North American Datum of 1983 (NAD 83).

Specific conductance is given in microsiemens per centimeter at 25 degrees Celsius $\left(\mu \mathrm{S} / \mathrm{cm}\right.$ at $\left.25^{\circ} \mathrm{C}\right)$

Concentrations of chemical constituents in water are given in micrograms per liter $(\mu \mathrm{g} / \mathrm{L})$. 


\title{
Trends in Pesticide Concentrations in Corn-Belt Streams, 1996-2006
}

\author{
By Daniel J. Sullivan, Aldo V. Vecchia, David L. Lorenz, Robert J. Gilliom, and Jeffrey D. Martin
}

\section{Abstract}

Trends in the concentrations of pesticides that commonly occur in streams and rivers of the Corn Belt of the United States were assessed, and the performance and application of several statistical methods for trend analysis were evaluated. Trends in the concentrations of 11 pesticides with sufficient data for trend assessment were assessed at up to 31 stream sites for two time periods: 1996-2002 and 2000-2006. Pesticides included in the trend analyses were atrazine, acetochlor, metolachlor, alachlor, cyanazine, EPTC, simazine, metribuzin, prometon, chlorpyrifos, and diazinon.

The statistical methods applied and compared were (1) a modified version of the nonparametric seasonal Kendall test (SEAKEN), (2) a modified version of the Regional Kendall test, (3) a parametric regression model with seasonal wave (SEAWAVE), and (4) a version of SEAWAVE with adjustment for streamflow (SEAWAVE-Q). The SEAKEN test is a statistical hypothesis test for detecting monotonic trends in seasonal time-series data, such as pesticide concentrations at a particular site. Trends across a region, represented by multiple sites, were evaluated using the regional seasonal Kendall test, which computes a test for an overall trend within a region by computing a score for each season at each site and adding the scores to compute the total for the region. The SEAWAVE model is a parametric regression model specifically designed for analyzing seasonal variability and trends in pesticide concentrations. The SEAWAVE-Q model accounts for the effect of changing flow conditions in order to separate changes caused by hydrologic trends from changes caused by other factors, such as pesticide use.

There was broad, general agreement between unadjusted trends (no adjustment for streamflow effects) identified by the SEAKEN and SEAWAVE methods, including the regional seasonal Kendall test. Only about 9 percent of the paired comparisons between SEAKEN and SEAWAVE indicated a difference in the direction of trend, and only one of these had differences significant at the 10-percent significance level. This consistency of results supports the validity and robustness of all three approaches as trend analysis tools. The SEAWAVE method is favored, however, because it has less restrictive data requirements, enabling analysis for more site/pesticide combinations, and can incorporate adjustment for streamflow
(SEAWAVE-Q) with substantially fewer measurements than the flow-adjustment procedure used with SEAKEN. Analysis of flow-adjusted trends is preferable to analysis of nonadjusted trends for evaluating potential effects of changes in pesticide use or management practices because flow-adjusted trends account for the influence of flow-related variability.

Analysis of flow-adjusted trends showed that most of the pesticides assessed were dominated by concentration downtrends in one or both analysis periods. Atrazine, metolachlor, alachlor, cyanazine, EPTC, and metribuzin - all major corn herbicides - showed more prevalent concentration downtrends during 1996-2002 compared to 2000-2006. The downtrends in concentrations generally correspond to regional downtrends in their use resulting from a variety of regulatory, market, and new-product forces that reduced their use in the Corn Belt during all or part of the study period. The insecticide diazinon had no clear trends during 1996-2002, but the trends were predominantly downward during 2000-2006, likely due to reductions in nonagricultural uses because of a regulatory phaseout. Simazine concentrations trended upward at most sites during both 1996-2002 and 2000-2006, a pattern explained by increasing agricultural use at some sites, but also likely by nonagricultural use in some of the watersheds.

Comparisons of concentration and watershed use trends at 11 sites showed that concentration trends for atrazine, acetochlor, metolachlor, alachlor, cyanazine, EPTC, simazine, and metribuzin generally were similar to use trends for 50 percent or more of trend comparisons for use-trend sites evaluated. There were more frequent differences between concentration trends and agricultural use trends for chlorpyrifos and diazinon. Overall, combined study results indicate that trends in pesticide concentrations in Corn Belt streams and rivers during 1996-2006 were explained largely by corresponding trends in annual use and that major reductions in the use of some pesticides resulting from regulatory actions or market forces generally resulted in corresponding declines in stream and river concentrations. Further evaluation of the causes of concentration trends will require more quantitative comparisons to use trends, given the uncertainty in use estimates, and more information is needed on the timing of changes in factors other than annual use, such as conservation tillage and buffer strips. 


\section{Introduction}

More than 450 million kilograms $(\mathrm{kg})$ of pesticides are used each year in the United States to control weeds, insects, and other pests in agricultural areas, urban areas, and a variety of other land-use settings. The use of pesticides has resulted in a range of benefits, including increased food production and reduction of insect-borne disease, but also raises questions about possible adverse effects on the environment, including water quality. Once released into the environment, pesticides can move through the hydrologic system to streams and groundwater, where they may have unintended effects on humans, aquatic life, or wildlife. In particular, pesticides frequently were detected in streams that drain agricultural and urban areas throughout the Nation during 1992-2001, and concentrations in many of these streams were greater than water-quality benchmarks for aquatic life (Larson and others, 1999; Gilliom and others, 2006).

The use of pesticides has a long history and is changing constantly in response to such factors as regulations, market forces, and the development of new pesticides and genetically engineered crops. Pesticide use on agricultural crops began in the United States in the late 1800s, accelerated during the late 1940 s with the introduction of synthetic organic pesticides, such as 2, 4-D for weed control and DDT for insect control, and has evolved constantly to the present time (Timmons, 2005). The annual use of pesticides in the United States was about 227 million $\mathrm{kg}$ in the 1930s, increased to nearly 454 million $\mathrm{kg}$ by the late $1940 \mathrm{~s}$, peaked at nearly 680 million $\mathrm{kg}$ in the late 1970s, and was relatively steady in the range of 544 million kg during the 1990s (Aspelin, 2003). Although total use has been relatively constant during the past 10-20 years, major changes have occurred in the use of many individual pesticides, as some have been reduced or phased out and others have been introduced. Evaluation of the effects of these changes in use on trends in pesticide concentrations in streams, as well as the additional influences of other changes, such as changes in management practices or streamflow conditions, is vital to understanding how the potential effects of pesticides on water quality may be changing over time.

Assessment of long-term trends in pesticide concentrations in stream water is difficult because there are relatively few streams with long-term records of concentrations, most such streams have had data gaps and sporadic sampling intensities over time, and most data on pesticide concentrations have high proportions of nondetections, resulting in highly censored data sets. These characteristics present unique challenges for statistical analysis. There is a need for methods that can be applied to these types of data in a statistically rigorous manner and that allow a balance of flexibility in application to sites with different types of monitoring data, thereby enabling consistent comparisons of trends among pesticides, streams, and regions.

\section{Purpose and Scope}

The purpose of this report is (1) to assess trends in the concentrations of commonly occurring pesticides in selected streams in the Corn Belt, an agricultural region that accounts for a major portion of national pesticide use, and (2) to evaluate the performance and application of statistical trend-assessment methods for subsequent application to other regions. Trends in the concentrations of 11 pesticides with sufficient data for trend analysis were assessed at 31 stream sites for two time periods: 1996-2002 and 2000-2006. The 31 sites have drainage areas that range from about 45 to $1,840,000$ square kilometers $\left(\mathrm{km}^{2}\right)$, and the percentage of land used for rowcrop production in the basins ranges from 4.3 to 91 percent. All water-quality data were collected as part of the USGS National Water-Quality Assessment (NAWQA) Program (U.S. Geological Survey, 2006a) or the USGS National Stream Quality Accounting Network (NASQAN) (U.S. Geological Survey, 2006b). The statistical methods applied and compared were (1) a modified version of the nonparametric seasonal Kendall test described by Hirsch and Slack (1984), including a seasonal Kendall test for regional trends, and (2) the parametric SEAWAVE regression model specifically designed for analyzing seasonal variability and trends in pesticide concentrations (Vecchia and others, 2008), including a version of SEAWAVE with adjustment for streamflow.

\section{Study Design and Methods}

The combined objectives of providing a comprehensive analysis of trends in Corn Belt streams and developing a prototype of an approach that can be used more broadly required a systematic approach to site selection, data preparation, and statistical analysis. Each part of the approach is described below.

\section{Pesticide Trend Sites and Major River Basins}

Stream sites sampled for this study are distributed among five major drainages that include most of the Corn Belt (fig. 1). The Corn Belt is an intensively farmed agricultural region of the central United States that includes Iowa, Illinois, and parts of Indiana, Minnesota, South Dakota, Nebraska, Kansas, Missouri, and Ohio (Pickett and others, 2000).

Corn and soybeans are the primary crops in the Corn Belt and are two of the most important crops produced in the United States, with estimated values of \$15.1 and \$12.5 billion, respectively, in 2000 (U.S. Environmental Protection Agency, 2005). As of 1996, more than 80 percent of national corn acreage was in the Corn Belt and the top three soybeanproducing states in 1996-Iowa, Illinois, and Minnesotaaccounted for 44 percent of the total U.S. production of soybeans (U.S. Department of Agriculture, 1997). 


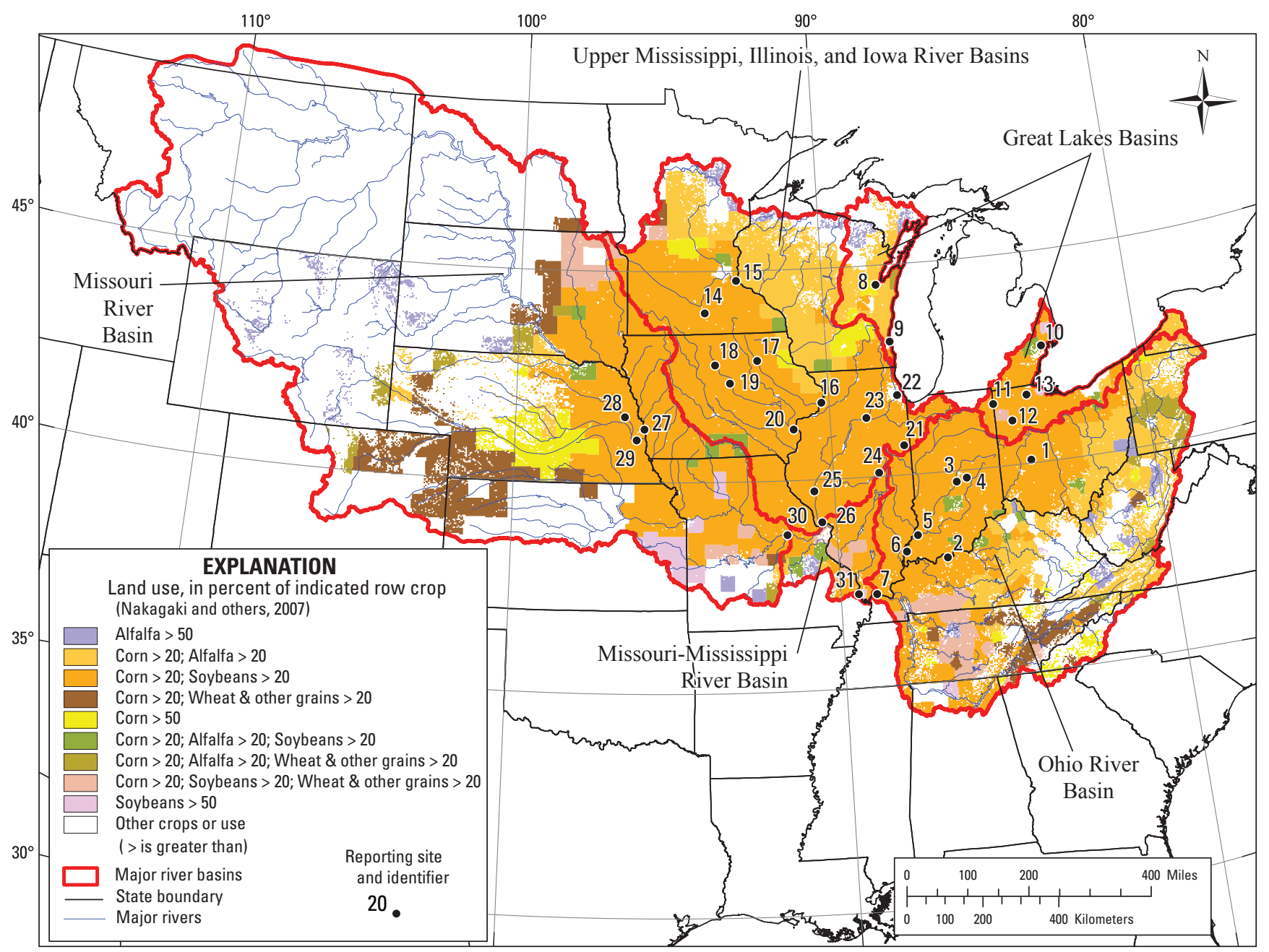

Figure 1. Map of trends sites, major drainage basins, and cropping patterns.

The 31 stream sites analyzed in this study are a subset of 201 sites that were sampled as part of the USGS National Water-Quality Assessment Program and/or the National Stream Quality Accounting Network, which were selected as part of a national effort to identify stream-monitoring sites that have adequate pesticide data for trend analysis (Martin, 2009). For the national screening, sites were required to have had samples analyzed at the USGS National Water Quality Laboratory (NWQL) by Gas Chromatography/Mass Spectrometry (GCMS), a minimum of 3 water years of data, and at least six samples per year. Of the 201 sites nationally, 49 were located within the Corn Belt. For this report, 31 sites with at least 5 years of pesticide data and associated daily streamflow data were selected for trend analysis (table 1). Sites in the Corn Belt were partitioned into major drainage basins for regional trend analysis: the Ohio River Basin; the Upper Mississippi, Illinois, and Iowa River Basins; the Great Lakes Basins; the
Missouri River Basin; and the combined Upper Mississippi and Missouri River Basin (fig. 1).

\section{Sample Collection and Processing}

Sampling strategies varied by site and among some years, but followed guidelines established by NAWQA or NASQAN. Samples were collected using a combination of fixed-interval and high-flow sampling procedures. The fixed-interval sampling was more frequent during the growing season when pesticide concentrations usually are greatest. In general, small streams were sampled more frequently than large streams and rivers. The typical frequency of sampling during the growing season was one to four samples per month and commonly was once a month or once every other month during other times of the year. 


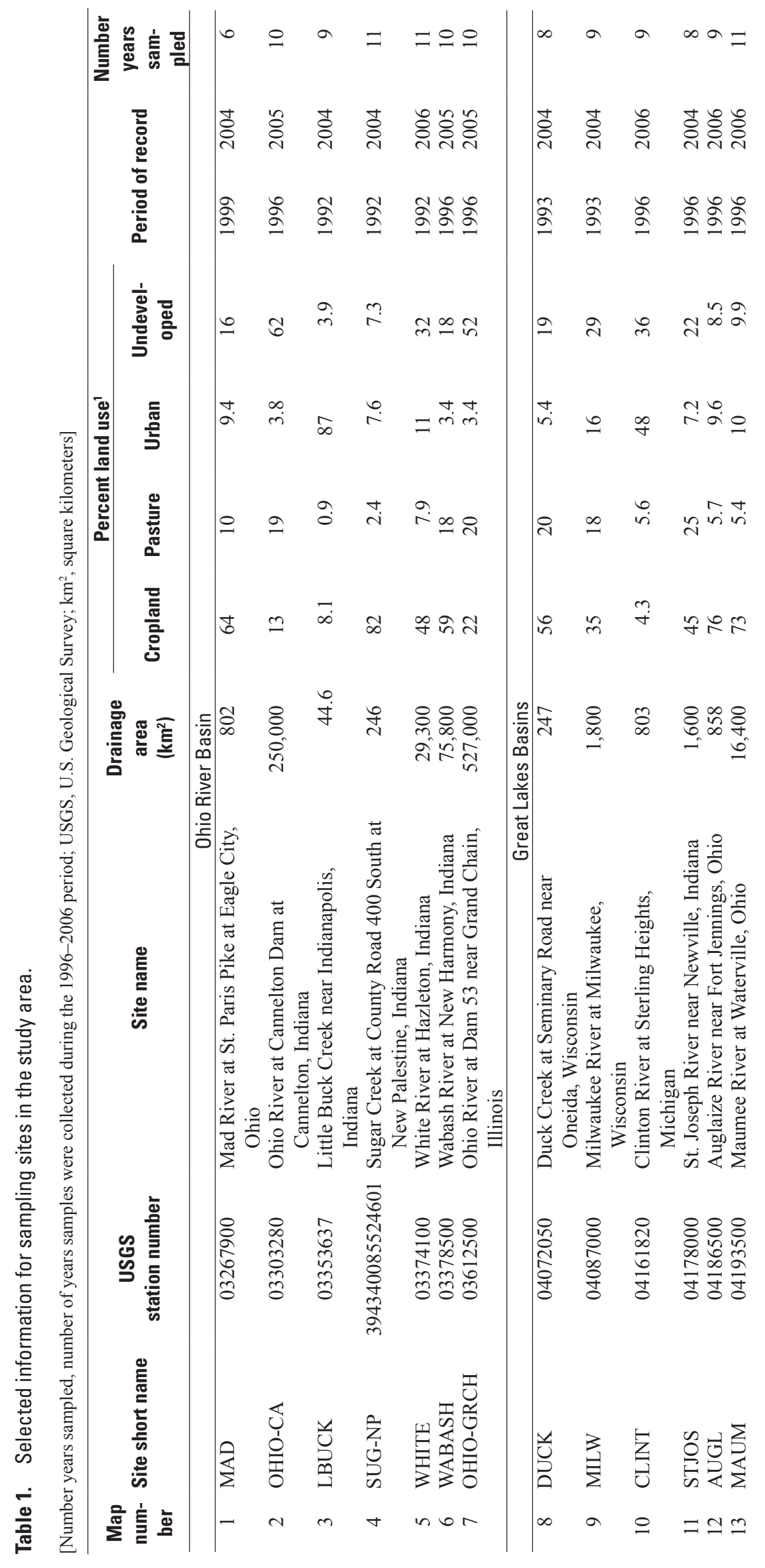




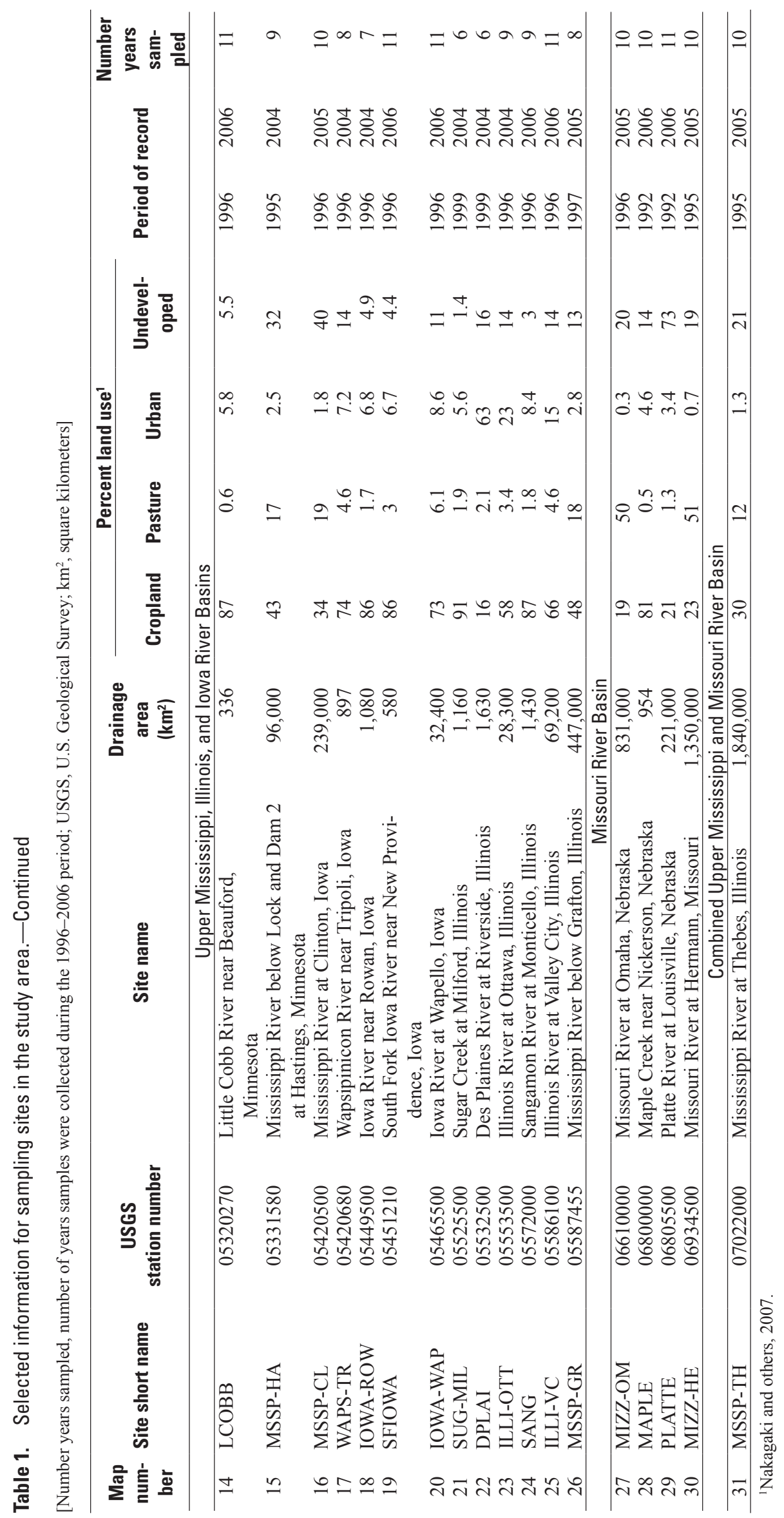


Flow-weighted, depth- and width-integrated water samples for the analysis of pesticides were collected using Teflon-coated isokinetic samplers and processed following standard USGS methods (Shelton, 1994; Edwards and Glysson, 1999). Most water samples were collected from bridges or by wading, but samples from large rivers were collected from boats or cableways. All sample collection and processing equipment that came in contact with sample water was constructed of Teflon, glass, aluminum, or stainless steel. Equipment was cleaned with a dilute solution of phosphate-free detergent and rinsed with deionized water and pesticide-grade methanol. Water samples were filtered using pre-combusted glass-fiber filters with a nominal 0.7-micrometer $(\mu \mathrm{m})$ pore diameter to remove suspended particulate matter and collected in baked amber glass bottles. Filtered samples were placed on ice in coolers and shipped to the NWQL in Denver, Colorado, for pesticide analysis.

The quality of the stream-water pesticide data was evaluated using quality-control procedures presented in Mueller and others (1997). The field quality-control program included the collection of field blank water samples to asses potential contamination, replicate water samples to assess variability, and field matrix spikes to assess bias from the analytical method, potential pesticide degradation, or matrix effects.

\section{Sample Analysis}

Although various analytical techniques have been used to analyze samples for pesticide concentrations as part of the NAWQA Program, data for samples reported herein were analyzed solely at the NWQL by gas chromatography/ mass spectrometry (GCMS) with selected-ion monitoring (Zaugg and others, 1995; Lindley and others, 1996). In this method, solid-phase extraction is used to extract pesticides from filtered water samples. This method is available from the National Environmental Methods Index (http://www.nemi. gov/) as USGS-NWQL method O-1126-95.

The GCMS analytical method does not have specified "detection limits" for each pesticide analyte. All detections conclusively identified by retention time and spectral characteristics are quantified (Zaugg and others, 1995, p. 19-21). Nondetections of pesticides (analyses that do not meet identification criteria based on retention time or spectral characteristics) are reported as less than a "reporting level" (for example: $<0.005$ micrograms per liter $[\mu \mathrm{g} / \mathrm{L}]$ ). The types and numerical values of reporting levels used to report nondetections of pesticides analyzed by GCMS have changed through time. See Martin (2009) for additional information on reporting procedures for GCMS analytical data.

\section{Preparation of Concentration Data for Trend Analysis}

Pesticide concentration data were prepared for trend analysis using the approach presented in Martin (2009). The principal data-preparation steps were to (1) identify routine reporting levels used to report nondetections for each sample; (2) reassign the concentration value for routine nondetections to the maximum value of the long-term method detection level; (3) round concentrations to a consistent level of precision for the concentration range; (4) adjust concentrations to compensate for temporal changes in bias of recovery of the GCMS analytical method; and (5) identify and remove samples collected too frequently in time for trend analysis. These steps are described briefly below. In addition to procedures applied by Martin (2009), low-level pesticide detections below the maximum long-term method detection level (maxLTMDL) were treated as nondetections at the maxLT-MDL.

\section{Identification of Reporting Levels}

Two types of reporting levels were identified for the purposes of trend analysis: routine and raised. Nondetections of pesticides (analyses that do not meet identification criteria based on retention time and spectral characteristics) are reported as less than the "routine" reporting level (for example: $<0.005 \mu \mathrm{g} / \mathrm{L}$ ). A small number of samples have "matrix effects" or other analytical difficulties that interfere with the measurement of pesticide retention time or spectral characteristics. Under conditions of interference, pesticides (1) cannot be identified/detected if they are present at concentrations less than the level of interference, and (2) are reported as nondetections less than a "raised" reporting level (for example: $<0.03 \mu \mathrm{g} / \mathrm{L}$; six times greater than the routine reporting level). Nondetections at raised reporting levels indicate the maximum possible concentration of the pesticide on the basis of the magnitude of the interference. Raised reporting levels always are greater than routine reporting levels (for a given time period). Raised reporting levels are sample-specific and determined by the magnitude of the interference. Routine reporting levels are the same for all samples (for a given time period) that are not affected by interference.

The types and numerical values of routine reporting levels used to report nondetections analyzed by GCMS have changed over time. The value of the routine reporting level in effect for a given time period was determined from NWQL records and from review of the data set (Martin, 2009). 


\section{Reassignment of the Concentration Value for Routine Nondetections}

Temporal changes in the magnitude of reporting levels used to report routine nondetections have the potential to adversely affect trend analysis because they introduce a temporal "structure" to the timeseries of routine nondetections. The temporal structure of routine nondetections was removed for trend analysis by "reassigning" the temporally inconsistent concentration value to a uniform, temporally consistent concentration value. The concentration value of all pesticide nondetections at routine reporting levels was assumed to be less than the maximum value of the long-term method detection level for water years 1994-2006 (maxLT-MDL). As noted earlier, the detections at concentrations below maxLT-MDL were also treated as censored values at the maxLT-MDL. Pesticide nondetections at raised reporting levels were not reassigned to maxLT-MDL. The maxLT-MDL is used in this report as a temporally consistent, conservatively high, estimate of the detection limit.

\section{Rounding of Concentrations to a Consistent Level of Precision}

The precision of pesticide data compiled for trend analysis changed through time. Concentration data were rounded consistently for trend analysis (Martin, 2009).

\section{Adjustment of Concentrations for Temporal Changes in Recovery}

Recovery of a pesticide compound in the analytical process is measured by analysis of "spiked" quality-control samples. "Spikes" are water samples to which a known amount of pesticide is added. Recovery is the measured concentration of the pesticide, divided by the expected concentration, then expressed as a percentage. Recovery measures bias in the analytical method. Bias is the systematic error in the measurement process and results in measurements that differ from the true (or expected) value in the same direction. Procedures used to adjust pesticide concentrations for temporal changes in recovery are presented by Martin and others (2009). Lowess smooths (Cleveland and McGill, 1985, p. 833; Helsel and Hirsch, 2002, p. 45-47) were used to model recovery as a function of time. Temporal changes in lowessmodeled recovery of more than 50 percent were observed for some pesticides during 1992-2006 (Martin and others, 2009). Measured concentrations of pesticides were adjusted to 100 -percent recovery to compensate for changes in recovery through time. Concentrations were adjusted by dividing the measured concentration by the modeled recovery; where recovery was expressed as a fraction (Martin, 2009, p. 17).

\section{Reduction of Samples Collected Too Frequently in Time}

Samples collected too frequently in time typically have highly correlated, redundant information that is inappropriate for use in trend analyses. A weekly sampling frequency was considered to be the maximum frequency for trend analysis. All samples at a site were assigned to calendar weeks (Sunday through Saturday) and if two or more samples were collected during the same week, only the sample collected closest in time to noon Wednesday was retained for trend analysis.

\section{Selection of Pesticides for Trend Analysis}

Pesticides considered for trend analysis were all of the 52 compounds included in the USGS GCMS method described above. For a pesticide to be selected for trend analysis (table 2), data were required to be available for at least 10 of the 31 sites, with 10 or more uncensored values (detections at or above maxLT-MDL) at each site during either of the trend assessment time periods (table 3). In addition, waterquality samples without streamflow data were not used in trend analysis by SEAWAVE or SEAWAVE-Q. The two trend assessment periods, which are explained in the section of this report, "Trend Analysis Intervals and Model Comparisons," were partially overlapping 7-year periods: 1996-2002 and 2000-2006.

\section{Statistical Methods for Analyzing Trends in Pesticide Concentrations}

The statistical methods applied and compared for the selected sites and pesticides were (1) a modified version of the nonparametric seasonal Kendall test described by Hirsch and Slack (1984), herein referred to as SEAKEN; (2) a modified version of the Regional Kendall test (Helsel and Frans, 2006); (3) a parametric regression model designed for analyzing seasonal variability and trends in pesticide concentrations (Vecchia and others, 2008), herein referred to as SEAWAVE; and (4) a version of SEAWAVE with adjustment for streamflow (SEAWAVE-Q). 
Table 2. Pesticides selected for trend analysis.

[Pesticides are listed in order of average use over the study period, from most to least. Other pesticides and pesticide degradation products for which results were available, but were not included in trend analyses due to insufficient uncensored data, include azinphos-methyl, benfluralin, butylate, carbaryl, carbofuran, dacthal, $p, p^{\prime}$-DDE, deethylatrazine, desulfinylfipronil, desulfinylfipronil amide, dieldrin, 2,6-diethylaniline, disulfoton, ethalfluralin, ethoprophos, fipronil, fipronil sulfide, fipronil sulfone, fonofos, alpha- $\mathrm{HCH}$, gamma-HCH, linuron, malathion, molinate, napropamide, parathion, parathion-methyl, pebulate, pendimethalin, cis-permethrin, phorate, propachlor, propanil, propargite, propyzamide, tebuthiuron, terbacil, terbufos, thiobencarb, triallate, and trifluralin. CAS, Chemical Abstracts Service; LT-MDL, long-term method detection level; $\mu \mathrm{g} / \mathrm{L}$, micrograms per liter]

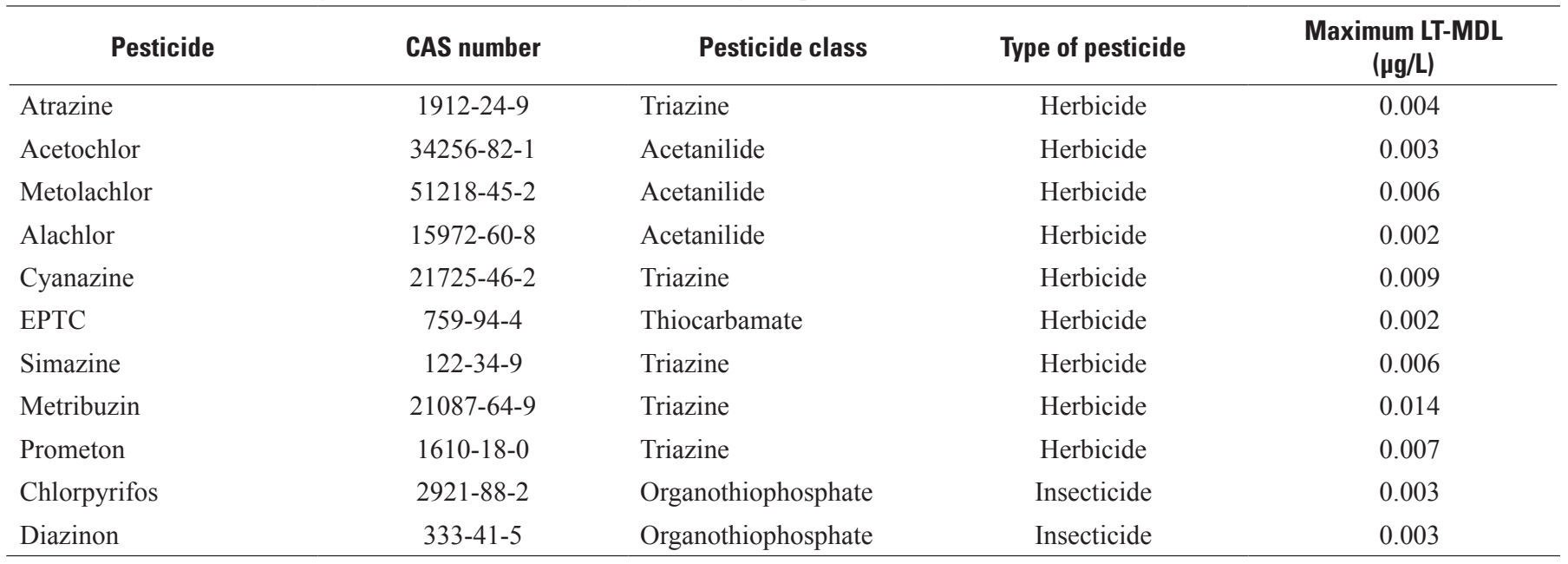

Two related concepts - statistical significance and $p$-values - will be used to discuss and compare the trends results from the various methods. The less likely the obtained value of a particular trend statistic (such as the SEAKEN test statistic or the estimated trend slope from the SEAWAVE model) could have occurred by chance (that is, even if there was no trend), the more confidence we have that the trend is real and not an artifact of random variation. The $p$-value is the probability the trend statistic could have been as extreme, or more extreme, than the value obtained simply by chance. All $p$-values in this report are two-sided $p$-values, which means they do not distinguish between negative values (downtrends) or positive values (uptrends). Thus, the $p$-value is the probability that the absolute value of the trend statistic could have been as large, or larger than, the obtained value simply by chance. A significance level often is specified, which is the $p$-value below which a trend is deemed to be "statistically significant." For this report, two significance levels-1 percent and 10 percent - are used. A trend is significant at the 1-percent level if the $p$-value is less than or equal to 0.01 and significant at the 10-percent level if the $p$-value is less than or equal to 0.10 . The $p$-value sometimes is referred to as the "attained significance level," because it is the smallest significance level for which the trend can be deemed significant.

\section{Seasonal Kendall (SEAKEN) Test for Site Trends}

The SEAKEN test is a statistical hypothesis test for detecting monotonic trends in seasonal time-series data, such as unadjusted pesticide concentrations at a particular site. The data requirements and assumptions of the test are described briefly in this section, and more detail is provided in Appendix 1 of this report.

The data requirements for applying the SEAKEN test in this report are similar to those described by Schertz and others (1991), with some modifications to accommodate high censoring rates that are typical of pesticides. The first consideration is to fix the number and length of the seasons that can be analyzed, on the basis of the sampling frequencies of the available data. Approximately monthly or higher sampling frequencies were maintained for most pesticide/site combinations during 1996-2002. However, sampling frequencies generally decreased to 6-12 samples per year after 2002 . To facilitate comparisons between pesticides and sites as well as to maintain a balance between the power of the trend test and the number of stations that could be analyzed; a monthly sampling frequency was used for all the SEAKEN results. Data for some sites were thinned if necessary, particularly during 1996-2002, to at most one sample per month and some sites were not analyzed, particularly for the 2000-2006 analysis period, because too many monthly values were missing to apply the SEAKEN test. For months with multiple samples, the sample closest to the middle of the month was used for analysis. 


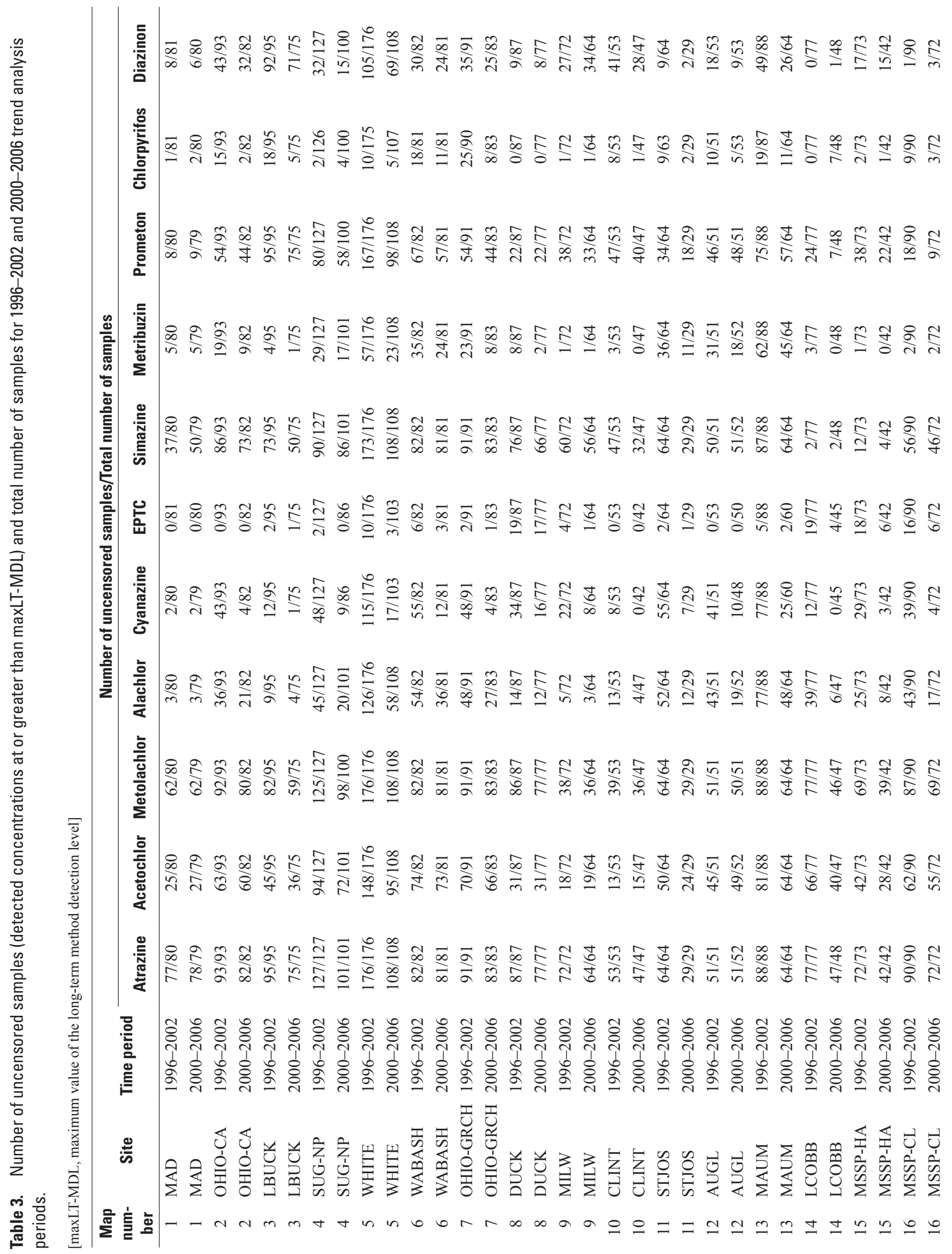




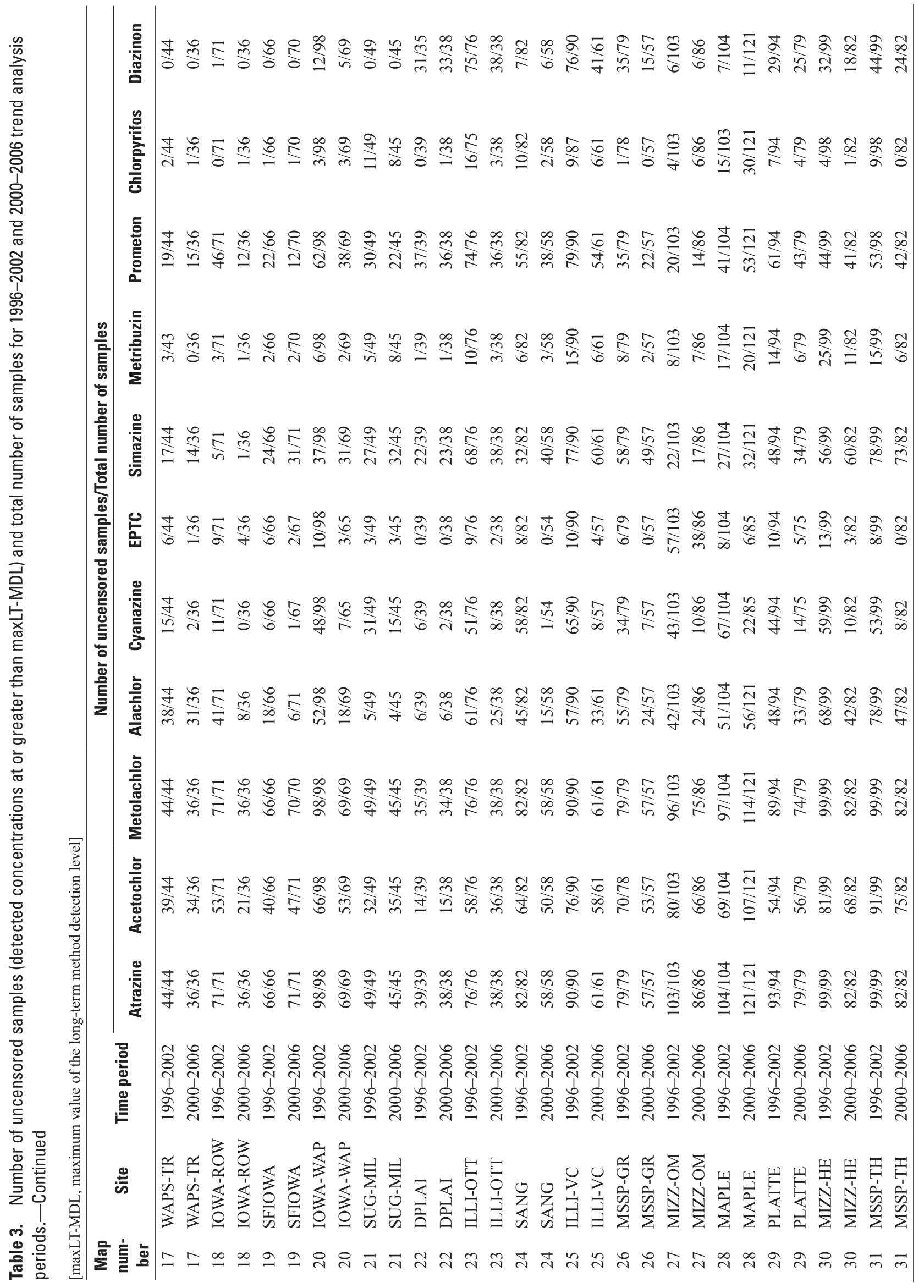


The second consideration for applying the SEAKEN test is the amount of censored data. Although censored data easily can be accommodated in the SEAKEN test by assuming data below the maxLT-MDL are all equal to the maxLT-MDL, Schertz and others (1991) recommend that a maximum of 50 percent of the data be censored for applying the SEAKEN test. However, given that data for many of the site-pesticide combinations considered here were highly censored, a more lenient requirement was applied to the data for this report. Specifically, the SEAKEN test was applied if at least 10 detections were at or above above the maxLT-MDL, regardless of the percentage of censored values. This requirement was selected to conform to the SEAWAVE trend analysis, described later in this report, in order to increase the number of comparisons that could be made between the two methods.

To define the assumptions of the SEAKEN test, let $X_{M}=\left\{C_{M}(1), C_{M}(2), \ldots\right\}$ be the set of all pesticide concentration values for a designated pesticide/site combination and a designated month $M$ (Jan, Feb, ... Dec). The null hypothesis of the SEAKEN test is that $X_{M}$ constitutes a random sample from a fixed distribution - that is, the probability distribution of all values within a given month is the same year after year. The SEAKEN test is called a nonparametric procedure because the form of the distribution (as determined by its parameters) does not need to be specified. The test statistic is computed by examining all pairwise-differences between values within the same month $\left(C_{M}(j)\right.$ and $C_{M}(k)$ with $\left.j<k\right)$, subtracting the total number of negative differences from the total number of positive differences, and combining the resulting values for all months,

$$
S^{*}=\sum\left\{P P D_{M}-N P D_{M} ; M=1,2, \ldots, 12\right\}
$$

where
$S^{*}$ is the SEAKEN test statistic;
$P P D_{M} \quad$ is the number of positive pairwise-differences for month $\mathrm{M}$; and
$N P D_{M} \quad$ is the number of negative pairwise-differences
for month $\mathrm{M}$.

If there is no trend in any of the months, then the number of positive differences will balance the number of negative differences and the test statistic is close to zero. The null distribution of the test statistic (its probability distribution under the assumption that no trend occurs in any of the months) is given by Hirsch and Slack (1984), along with provisions for dealing with ties, censored values, missing values, and potential serial correlation between values from different months. An unusually large positive value of the test statistic (as determined by comparing it to the null distribution) indicates an uptrend in one or more months, and an unusually large negative value indicates a downtrend.

Although the SEAKEN test can determine if a significant trend exists, it cannot be used to estimate the magnitude of the trend. For site-pesticide combinations with few censored values (less than 5 percent, according to Schertz and others [1991]), the slope of the trend can be estimated using the techniques of Hirsch and others (1982). A new approach for estimating the slope of the trend that can be used with censored data was developed for this report (Appendix 1).

\section{Seasonal Kendall (SEAKEN) Test for Regional Trends}

Consistent trends in pesticide concentrations may be present across a region represented by multiple sites. The regions evaluated in this study were the major drainages described earlier. Regional unadjusted trends in concentration were examined using the regional seasonal Kendall test - the Regional Kendall test (Helsel and Frans, 2006) modified to account for seasonality. The data requirements and assumptions of the test are described briefly in this section, and more detail is provided in Sprague and Lorenz (2009).

The regional seasonal Kendall test computes a test for an overall trend for all sites within a region by computing a score for each season at each site and adding the scores to compute the total for the region. To define the assumptions of the regional seasonal Kendall test, let $X_{M i}=\left\{C_{M i}(1), C_{M i}(2), \ldots\right\}$ be the set all pesticide concentration values for the designated pesticide at site $i$ and a designated month $M$ (Jan, Feb, ...

Dec). The null hypothesis of the SEAKEN test is that $X_{M i}$ constitutes a random sample from a fixed distribution - that is, the probability distribution of all values within a given month and site is the same year after year. The test statistic is computed by examining all pairwise-differences between values within the same month and site $\left[C_{M i}(j)\right.$ and $C_{M i}(k)$ with $\left.j<k\right]$, subtracting the total number of negative differences from the total number of positive differences, and combining the resulting values for all months and sites,

$$
\begin{gathered}
S_{R}^{*}=\sum\left(\sum_{\mathrm{i}=1,2, \ldots, \text { total number of sites })}\left\{P P D_{M i}-N P D_{M i} ; M=1,2, \ldots, 12\right\} ;\right.
\end{gathered}
$$

where

$S_{R}^{*}$ is the regional seasonal Kendall test statistic; $P P D_{M i}$ is the number of positive pairwise-differences for month $\mathrm{M}$ and site $\mathrm{i}$; and

$N P D_{M i}$ is the number of negative pairwise-differences for month $\mathrm{M}$ and site $\mathrm{i}$. 
If there is no regional trend in any of the months, then the number of positive differences should balance the number of negative differences and the test statistic should be close to zero. The null distribution of the test statistic (its probability distribution under the assumption that no trend occurs in any of the months) is given by Sprague and Lorenz (2009). An unusually large positive value of the test statistic (as determined by comparing it to the null distribution) indicates a regional uptrend in one or more months, and an unusually large negative value indicates a regional downtrend.

For the purposes of this report, an arbitrary value of one-half the maxLT-MDL (or for results with elevated censoring levels, one-half the reported value) was substituted for censored data for the Regional seasonal Kendall test. For singly-censored data, there is no bias in the computation of $S_{R}$ (Hirsch and Slack, 1984). There were very few elevated censoring limits in the pesticide data interpreted in this report and it was assumed that any bias in the computation of $S_{R}$ was very small and could be ignored. The pesticide data with the most elevated censoring levels was chlorpyrifos (3.1 percent of samples). The data requirements for the regional seasonal Kendall test basically are the same as for SEAKEN, except that because all censored data are recoded, there are no system limits on the number of censored data. However, there is a practical limit to the number of tied values caused by recoding censored data that affect the ability to detect a trend. The regional seasonal Kendall trend test does not compute an estimate of the magnitude of the trend, but only an indication of whether the trend is upward or downward and an attained level of significance. A key characteristic of the regional seasonal Kendall test is that effects from highly cross-correlated sites are down weighted. For example, strong trends at a subset of sites, such as small agricultural streams in a limited area, do not have a substantial effect on the test results. When closely spaced sites repeatedly sample a limited geographic area, the sites may not be independent and the regional seasonal Kendall test accounts for that lack of independence by reducing the effect of the sites on the overall test statistic.

\section{Seasonal Wave (SEAWAVE) Model}

The SEAWAVE model is a parametric regression model specifically designed for analyzing seasonal variability and trends in pesticide concentrations (Vecchia and others, 2008). In its simplest form, the model can be expressed as

$$
\log C(t)=\beta_{0}+\beta_{1} W(t)+\beta_{2} t+\varepsilon(t)
$$

where

Log denotes the base-10 logarithm;

$t$ is decimal time, in years, with respect to an arbitrary time origin;

$C(t)$ is pesticide concentration, in micrograms per liter;

$W(t)$ is a seasonal wave representing intra- annual variability in concentration

(Appendix 2);

$\beta_{0}, \beta_{1}$, and $\beta_{2}$ are regression coefficients; and

$\varepsilon(t)$ is the model error.

The seasonal wave is a periodic function of time with a period of 1 year, similar to mixtures of sine and cosine functions often used to model seasonality in concentration data. However, the seasonal wave differs from a trigonometric function in that it is specifically designed to mimic the behavior of pesticide concentrations in response to seasonal application rates, basin accumulation, and removal from processes such as degradation and runoff (Vecchia and others, 2008). The methodology used to estimate the seasonal wave and the regression coefficients, given a sample of censored pesticide concentration data, is given in Appendix 2.

Data requirements for the SEAWAVE model are less restrictive than those given previously for the SEAKEN test. Unlike SEAKEN, there was no need to assume a fixed monthly sampling frequency for the SEAWAVE model. The model could be applied with as few as six samples per year during a period of at least 3 years and as few as a total of ten uncensored values. Also, unlike SEAKEN, in which the magnitude of the trend is estimated using a separate method, the magnitude of the trend for SEAWAVE (the regression coefficient $\beta_{2}$ ) is obtained directly from the SEAWAVE model.

The SEAWAVE model for each site-pesticide combination is fitted by maximizing the likelihood function of the log-transformed data, assuming the model errors are independent, normally distributed random variables with a mean of zero and a constant variance. Intra-annual changes in the mean and variance of the pesticide data are modeled by a combination of the logarithmic transformation, which helps stabilize seasonal differences in the variance, and the seasonal wave, which models seasonality in the mean of the log-transformed concentration data. In contrast, the SEAKEN test does not assume a distribution for the pesticide concentration data, and seasonality in the mean is handled by comparing values only within like seasons. The null distribution of the SEAKEN test 
statistic ( $S^{*}$, eq. 1), however, depends on cross-products of the pairwise-differences both within and between seasons, and needs to be approximated using a relatively complex formula that may not be accurate for small sample sizes, especially when there is a high percentage of censored data (Hirsch and Slack, 1984). The SEAKEN test, which has few assumptions, and the SEAWAVE model, which has more assumptions but can be applied to more limited data (provided the assumptions hold), are compared in a later section to help evaluate their applicability for analyzing trends in pesticide concentrations.

\section{Seasonal Wave with Flow Adjustment (SEAWAVE-0) Model}

When analyzing trends in concentration data, the effect of changing flow conditions on those trends needs to be considered if it is desired to separate changes caused by hydrologic trends from changes caused by other factors, such as pesticide use. This often is done by regressing concentration (or logtransformed concentration) on concurrent flow (or log-transformed flow), subtracting the fitted concentration values from the observed values to obtain residuals (flow-adjusted concentrations), and analyzing trends in flow-adjusted concentrations using an established technique such as SEAKEN (Hirsch and others, 1982). However, flow-adjusted concentrations cannot be computed for censored data without substituting arbitrary fixed values for the censored concentrations. Therefore, a different approach was used for this study in which flow-related variables were added to the SEAWAVE model. This section describes adjustments that were made to the SEAWAVE model to account for flow-related variability in pesticide concentrations and to separate flow-related trends from trends due to other factors such as changes in pesticide use.

Changing flow conditions can affect pesticide concentrations in subtle ways that may not be removed easily by simply regressing concentration on concurrent flow (Vecchia and others, 2008). The seasonal hydrologic cycle, though often a large component of the variability in flow, may not be correlated in any meaningful way with pesticide concentrations because the timing and length of the pesticide application season is the dominant factor controlling seasonality of concentrations. However, short-term flow anomalies resulting from rainfallrunoff events during or after the application season can have a substantial effect on pesticide concentrations. Long-term flow anomalies resulting from changes in climate or stream regulation also would be expected to affect pesticide concentrations by changing the amount of dilution of pesticide runoff by ground water or ambient streamflow.

Three dimensionless flow variables were added to the SEAWAVE model to help account for flow-related variability in pesticide concentrations. The variables are computed by using log-transformed flow aggregated over various time scales, including daily, monthly and yearly time scales. The first variable represents short-term (day-to-day) flow variability, and is defined as

$$
\operatorname{STFA}(t)=X(t)-X_{M}(t)
$$

where

$S T F A$ is the short- term flow anomaly (dimensionless);

$X(t)=\log Q(t)$ is log-transformed daily flow; and

$X_{M}(t)=\operatorname{Ave}\{X(u), t-(1 / 12)<u \leq t\}$ is the average of

$\log$ - transformed daily flow for $1 / 12$ of a year

(about 1 month) up to and including time $t$.

Reasons for using STFA as a predictor of pesticide concentration are given by Vecchia and others (2008). Large positive values of STFA and associated increases in pesticide concentrations tend to occur near the beginning of a substantial rainfall-runoff event, whereas negative values of STFA and associated decreases in pesticide concentrations tend to occur after the event passes. The second flow variable added to the SEAWAVE model represents mid-term (month-to-month) flow variability and is defined as

$$
\operatorname{MTFA}(t)=X_{M}(t)-X_{A}(t)
$$

where

$M T F A$ is the mid- term flow anomaly

(dimensionless); and

$$
X_{A}(t)=A v e\{X(u), t-1<u \leq t\} \text { is the average of }
$$

$\log$ - transformed daily flow for 1 year up to and including time $t$.

The third flow variable added to the SEAWAVE model represents long-term (year-to-year) flow variability, and is defined as

$$
\operatorname{LTFA}(t)=X_{A}(t)-X_{*}
$$

where

LTFA is the long-term flow anomaly (dimensionless); and $\mathrm{X} *$ is the average of log-transformed daily flow for a specified trend analysis period (either $1996-2002$ or $2000-2006$ ). 
Unlike STFA, which tends to affect pesticide concentrations in a relatively consistent manner among different sites and pesticides, MTFA and LTFA can affect pesticide concentrations in different ways and to different degrees, depending on the type of pesticide, the size of the basin being analyzed, the climatic and hydrologic properties of the basin, and the degree of streamflow regulation. For example, for a large basin with substantial non-agricultural runoff, higher-than-normal annual flow conditions (as indicated by a positive value for LTFA) may lead to decreased pesticide concentrations because of more dilution from non-agricultural runoff.

Adding the flow anomalies to eq. 3 and changing the notation for the regression coefficients and error term yields

$$
\begin{aligned}
& \log C(t)=\gamma_{0}+\gamma_{1} W(t)+\gamma_{2} \operatorname{LTFA}(t)+ \\
& \gamma_{3} \operatorname{MTFA}(t)+\gamma_{4} \operatorname{STFA}(t)+\gamma_{5} t+\eta(t) .
\end{aligned}
$$

The regression model without the flow terms (eq. 3) will be referred to as SEAWAVE and the model with the flow terms (eq. 7) as SEAWAVE-Q. The estimated value of $\beta_{2}$ from SEAWAVE will be referred to as a trend in concentration and the estimated value of $\gamma_{5}$ from SEAWAVE-Q will be referred to as a flow-adjusted trend in concentration.

\section{Trend Analysis Intervals and Model Comparisons}

One of the primary objectives of this report is to interpret trends in pesticide concentrations in relation to spatially and temporally varying flow conditions and pesticide-use patterns. When making these interpretations, it is important to have comparable sampling intervals among the sites. Most sites had either no samples or few samples collected before 1996. Therefore, the trend analysis for this report is based on data collected from 1996-2006. Initially, trends were evaluated for this entire interval. However, examination of the residuals from the SEAWAVE model indicated that trends for most pesticide-site combinations were not uniform in magnitude during 1996-2006. Rather, most trends tended to either occur from the mid 1990s to the early 2000s, or, in some cases, during 2000-2006. In still other cases, there appeared to be substantial changes in the seasonal concentration patterns from the mid- to late 1990s to the early to mid-2000s (presumably from changes in seasonal-use patterns), making difficult the selection of a single seasonal wave for 1996-2006.

Because of the potential problems with assessing monotonic trends over the entire 1996-2006 period, trends in this report are analyzed for both an early (1996-2002) and late (2000-2006) time period, as stated earlier. This approach also facilitated comparison of trend-analysis results from the SEAKEN and SEAWAVE models, because the 1996-2002 analysis period resulted in the most complete set of sites that could be analyzed using SEAKEN. Trends from SEAKEN and SEAWAVE (both for unadjusted concentrations) are comparatively evaluated in a later section for both time periods. Subsequently, trends from SEAWAVE and SEAWAVE-Q are compared and contrasted for both time intervals to help separate flow-related trends from trends due to other causes. Finally, flow-adjusted trends from SEAWAVE-Q are evaluated in relation to changing use patterns or other potential causes of the trends. In these evaluations of flow-adjusted trends, rough estimates of average annual pesticide fluxes for the 1996-2002 and 2000-2006 periods are used to help interpret the fitted trends. The flux estimates were obtained using the fitted daily concentrations from the SEAWAVE-Q model along with observed daily flows. The fitted daily log-transformed concentrations were untransformed, multiplied by a bias correction factor based on a normal distribution for the model errors (Appendix 2), multiplied by the daily flows (with the appropriate conversion factor), and aggregated to obtain annual flux estimates. The flux estimates are approximations intended primarily for relative comparisons, and should not be relied upon as final quantitative estimates of actual fluxes.

\section{Use and Properties of Pesticides}

Trends in the use of a pesticide (fig. 2) and its physical and chemical properties (table 4) are important influences on changes in stream concentrations over time and how they may change as water passes through stream drainage systems. In particular, pesticide use generally is the single most important influence on pesticide concentrations in streams (Gilliom and others, 2006).

Annual estimates of agricultural use of each pesticide during 1996-2006 were developed for all counties in the conterminous U.S. using proprietary data (DMRKynetec, Inc.) on the mass of pesticides applied to agricultural crops each year and data on county-harvested crop acreage. Pesticide use estimates, which were based on surveys of major row crops and specialty crops, were reported for multi-county areas referred to as "Crop Reporting Districts" (CRDs). The estimates were combined with annual harvested acres available from the 1992, 1997, 2002, and 2007 Census of Agriculture and NASS annual crop acreage to calculate pesticide application rates for individual crops. The CRD-level use estimates were disaggregated to county-level application rates by dividing the mass of pesticides applied to a crop by the acres of that crop in the CRD to yield a rate per harvested acre. Pesticide estimates were not available for all of the 304 CRDs in the conterminous U.S., nor for every crop or year; in such cases a crop application rate was estimated from median surveyed rates for surrounding CRDs. Pesticide-crop application rates were then applied to crop acreages for each county. Annual pesticide-use intensities for individual watersheds were calculated on the basis of county-level pesticide use estimates and information on the proportion of agricultural land use in each of the watersheds. Using a geographic information system, mapped land cover was combined with the digital maps of drainage basins and county boundaries to compute the basin's areal weights of agricultural land in each intersecting county. 

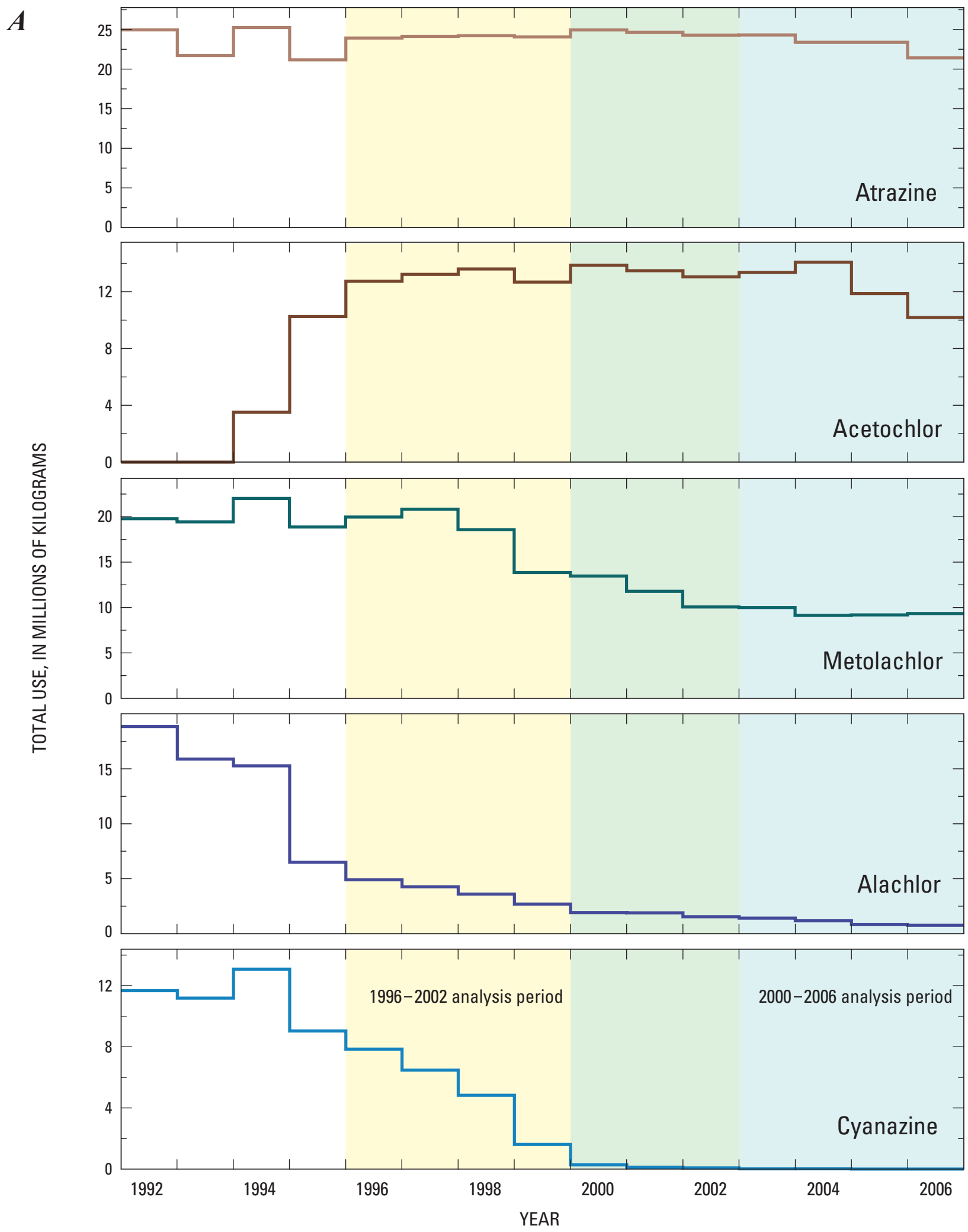

Figure 2. Trends in total annual pesticide use in major river basins of the Corn Belt, 1992-2006. A. Atrazine, acetochlor, metolachlor, alachlor, and cyanazine. B. EPTC, simazine, metribuzin, chlorpyrifos, and diazinon. 

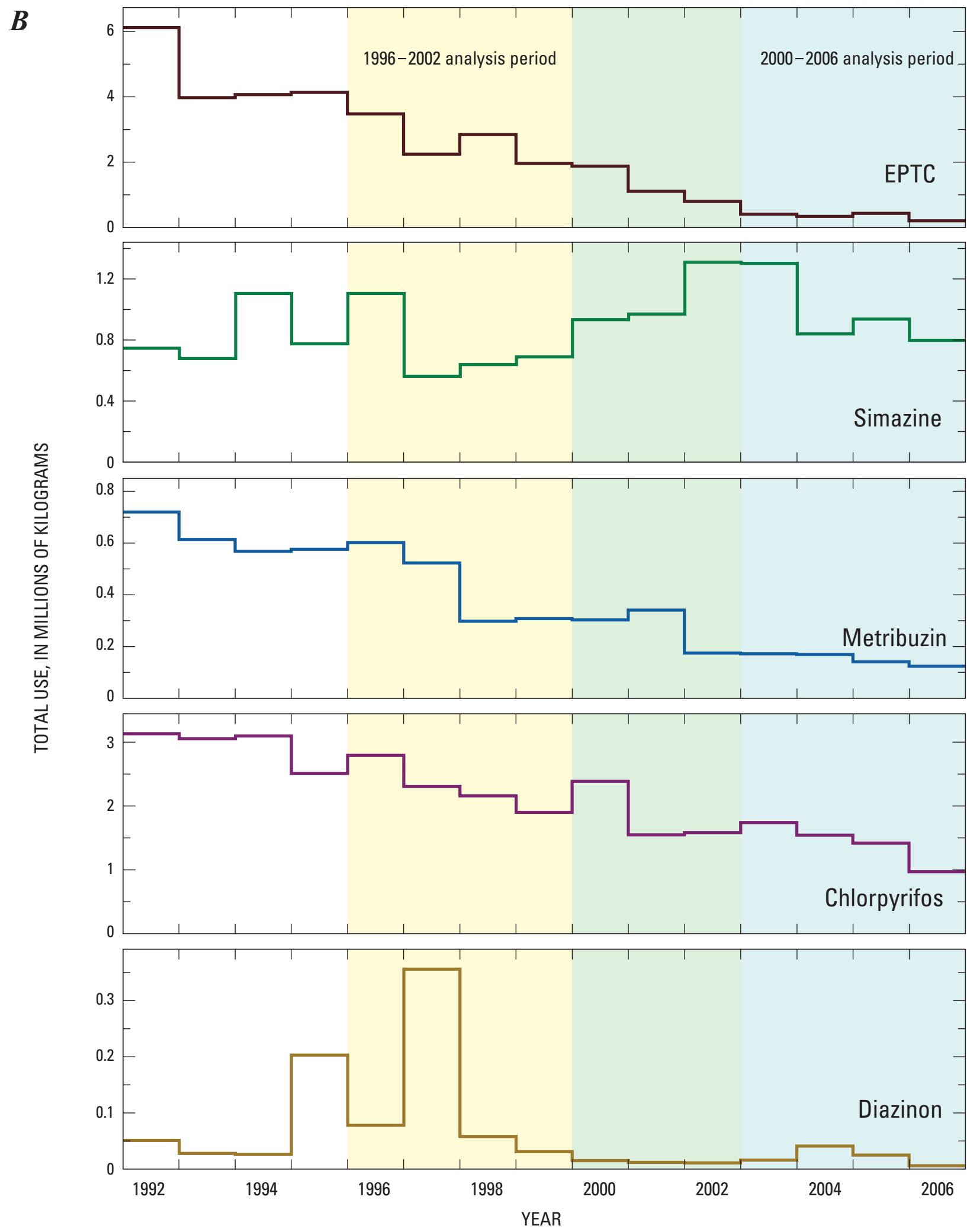

Figure 2. Continued. 
The basin's areal weights, or "weighting factors" of agricultural land, were computed such that a county entirely within the basin had a weighting factor of 1.0; a county entirely consisting of agricultural land and intersected half-way into the basin had a value of 0.5 ; and so forth. The estimated pesticide use for a basin was computed by multiplying the basin's county weighting factors by the total county pesticide use and summing the results. The source for mapped agricultural land for 1996 and 1997 pesticide estimates was U.S. Geological Survey's National Land Cover Dataset 1992 (Vogelmann and others, 2001), as enhanced by Nakagaki and others (2007); for 1998 through 2006 pesticide estimates, the source was U.S. Geological Survey's National Land Cover Database 2001 (Homer and others, 2004).

\section{Use Trends}

Regional trends in annual use for agricultural purposes during 1992-2006 are shown in figure 2 for the pesticides assessed in this study (prometon is registered only for noncrop uses and is not included). Corn Belt agricultural use during 1996-2006 generally decreased for metolachlor, alachlor, cyanazine, metribuzin, EPTC, chlorpyrifos, and diazinon, increased somewhat for simazine, and stayed relatively constant for atrazine and acetochlor. The use within individual drainage basins may not follow these regional trends, however, and estimates of use for some of the study sites are different in direction or degree. It also is important to note that, while the use data in this report are believed to be the best estimates available, they are based on user surveys and, as such, are subject to error.

Most of the agricultural pesticides assessed in this study primarily were used on corn during the study period, with the exceptions of metribuzin and alachlor, which were used on both corn and soybeans. Nonagricultural uses were most important for the herbicides simazine (used for both agricultural and industrial weed control in roughly equivalent total amounts, although it generally is applied at a higher rate for nonagricultural uses [EXTOXNET, accessed June 16, 2008]) and prometon (right-of-ways and construction sites), and for the insecticides diazinon and chlorpyrifos.

\section{Physical and Chemical Properties}

The occurrence and transport of pesticides in the environment are influenced strongly by the chemical and physical properties that affect their persistence and partitioning (Gilliom and others, 2006). Of the 11 pesticides assessed in this study, five are triazine herbicides (atrazine, cyanazine, metribuzin, prometon, and simazine), three are chloroacetanilide herbicides (acetochlor, alachlor, and metolachlor), two are organophosphorus insecticides (chlorpyrifos and diazinon), and one is a thiocarbamate herbicide (EPTC).

Pesticides with high persistence remain in their original chemical form in the environment for long periods, whereas those with low persistence more rapidly transform following their application. The tendency of a pesticide to partition into water, sediment, or other media determines where it most likely is to be detected in the environment, and how it is transported through the hydrologic system. Pesticides with relatively low soil adsorption coefficients (Koc) and high water solubility are more mobile than those with high soil adsorption and low solubility.

With the exception of chlorpyrifos, the pesticides in this report have moderate to high water solubility and relatively low soil-adsorption coefficients (table 4), resulting in relatively similar and high mobility in water and moderate-tostrong potential for transport from fields by surface runoff, primarily in the dissolved phase. Chlorpyrifos has the highest soil adsorption coefficient and the lowest water solubility and, thus, is the least mobile when dissolved in water and has the greatest tendency to adsorb to soil. None of the 11 pesticides is highly volatile. Seven of the pesticides have half-lives in the range of 1-6 weeks, three are in the range of 3-6 months, and prometon has a half-life of more than 2 years. Overall, the relatively high mobilities (except for chlorpyrifos) and half-lives of less than a year (except for prometon) indicate that stream concentrations of most of the pesticides assessed should respond to year-to-year changes in use and not be much affected by use in past years. Some of the pesticides with the shortest half-lives, such as EPTC, may not show consistent trends among upstream to downstream locations if sites are far apart.

\section{Trends in Pesticide Concentrations}

Results of trend analysis are presented and evaluated in three main parts:

1. The first analysis focuses on a regional overview that comparatively evaluates results from SEAKEN (both site and regional applications) and SEAWAVE for both 1996-2002 and, to the extent possible, 2000-2006 (data constraints limited SEAKEN applications during this period).

2. The second analysis compares and evaluates results from SEAWAVE and SEAWAVE-Q for all sitepesticide combinations, for both 1996-2002 and 2000-2006, in order to assess the overall influence and potential importance of flow adjustment.

3. The third analysis is comprised of more detailed assessments of individual pesticides (using SEAWAVE-Q), with an emphasis on interpreting the inter-relations among sites in a hydrologic framework and more detailed interpretation of concentration trends in relation to changes in use. 
Table 4. Properties affecting the transport and fate of selected pesticides.

[All values measured at (or estimated for) $25^{\circ} \mathrm{C}$. Unless noted otherwise, (1) values for soil organic carbon-water partition coefficient $\left(\mathrm{K}_{o c}\right)$, water solubility $\left(\mathrm{S}_{\mathrm{w}}\right.$ ) and Henry's law constant $\left(\mathrm{K}_{\mathrm{H}}\right)$ are from Mackay and others (1997); (2) transformation half-lives in soil and water were measured in the laboratory (rather than in the field) at neutral pH in the dark, and obtained from the U.S. Department of Agriculture (2005); and (3) all are recommended values selected by the compilation authors when more than one value was available from the literature. Numbers of significant figures are identical to those given in original sources. $\mathrm{mL} / \mathrm{g}$, milliliter per gram; mg/L, milligram per liter; $\mathrm{Pa} \bullet \mathrm{m}^{3} / \mathrm{mol}$, pascal-cubic meter per mole]

\begin{tabular}{|c|c|c|c|c|}
\hline Pesticide name & $\left(K_{o c}^{\log K_{o c}}\right.$ in $\left./ g\right)$ & $\underset{(\mathrm{mg} / \mathrm{L})}{\mathrm{S}_{\mathrm{w}}}$ & $\begin{array}{c}\log \mathrm{K}_{\mathrm{H}} \\
\left(\mathrm{K}_{\mathrm{H}} \text { in } \mathrm{Pa} \mathrm{m}^{3} / \mathrm{mol}\right)\end{array}$ & $\begin{array}{c}\text { Half-life for } \\
\text { transformation } \\
\text { in aerobic soil } \\
\text { (days) }\end{array}$ \\
\hline Atrazine & 2 & 30 & -3.54 & 146 \\
\hline Acetochlor & ${ }^{1} 2.38$ & ${ }^{2} 223$ & $3-5.26$ & ${ }^{4} 11$ \\
\hline Metolachlor & 2.26 & 430 & -2.63 & 26 \\
\hline Cyanazine & 2.3 & 171 & -6.52 & ${ }^{6} 17$ \\
\hline EPTC & 2.3 & 370 & 0.00988 & ${ }^{7} 7$ \\
\hline Simazine & 2.11 & 5 & -3.46 & ${ }^{6} 91$ \\
\hline Metribuzin & ${ }^{8} 1.72$ & ${ }^{8,9} 1,000$ & ${ }^{8,10}-5.31$ & 172 \\
\hline
\end{tabular}

${ }^{1}$ Median among five values reported by U.S. Environmental Protection Agency (1994).

${ }^{2}$ Source: Shiu and others (1990).

${ }^{3} \mathrm{~K}_{\mathrm{H}}$ value computed by dividing vapor pressure reported by Ma and others (2004a) by $\mathrm{S}_{\mathrm{w}}$ value reported by Shiu and others (1990).

${ }^{4} \mathrm{Computed}$ for $25^{\circ} \mathrm{C}$ by interpolation using data reported by Ma and others (2004b).

${ }^{5} \mathrm{Half}-$ life interpolated to $25^{\circ} \mathrm{C}$ from rates of alachlor disappearance from a sandy loam soil $\left(0.7\right.$ percent organic carbon) at 10,20 and $30^{\circ} \mathrm{C}$ reported by Zimdahl and Clark (1982).

${ }^{6}$ Sole value reported by the U.S. Department of Agriculture (2005) database authors, but not "selected."

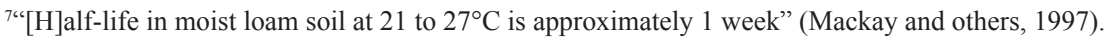

${ }^{8}$ Source: U.S. Department of Agriculture (2005).

${ }^{9}$ Measured at $20^{\circ} \mathrm{C}$.

${ }^{10}$ Adjusted from value measured at $20^{\circ} \mathrm{C}$ to $25^{\circ} \mathrm{C}$ using equation 13 from Mackay and others (2000), and an enthalpy of vaporization $\left(\Delta \mathrm{H}_{v}\right)$ of $46.8 \mathrm{~kJ} / \mathrm{mol}$, based on $\mathrm{K}_{\mathrm{H}}$ data from 197 compounds (Staudinger and Roberts, 2001).

\section{Comparison of SEAKEN and SEAWAVE}

Comparison of SEAKEN (both site and regional applications) with SEAWAVE results serves to evaluate the similarity of results for nonparametric and parametric methods, computed with no adjustments for flow. Most of these comparisons focus on the 1996-2002 analysis period because of more complete data during those years.

\section{Overview of Trend Results for 1996-2002}

There is broad, general agreement between trends identified by the SEAKEN and SEAWAVE methods during 19962002 (table 5). Less than 10 percent of the paired comparisons (15 of 175 site-pesticide combinations) between the methods indicated a difference in the direction of the trend, and only one of the 15 site-pesticide combinations with differences had trends significant at the 10-percent level $(p<0.10)$. For some pesticide/site combinations with many censored values, the SEAKEN method was unable to produce a reliable estimate of the trend (Appendix 1), but the direction of the trend could be determined from Kendall's tau. These cases are indicated by " " - " for a downtrend and "++" for an uptrend. The broad, general agreement between trends indicates that the methods produce similar results when adequate data are available for both, and that they reinforce each other for interpretation of results.

Most of the trends identified during 1996-2002 were downtrends, including all of the trends that could be quantified for alachlor, cyanazine, metribuzin, and chlorpyrifos. All trends for metolachlor and EPTC were downward except at MILW, CLINT, SUG-MIL, and DPLAI (metolachlor) and DUCK (EPTC). Most trends for atrazine were downward, and only LCOBB had a significant uptrend at the 10-percent significance level. Trends for acetochlor, simazine, prometon, and diazinon were mixed. Many sites had downtrends identified 


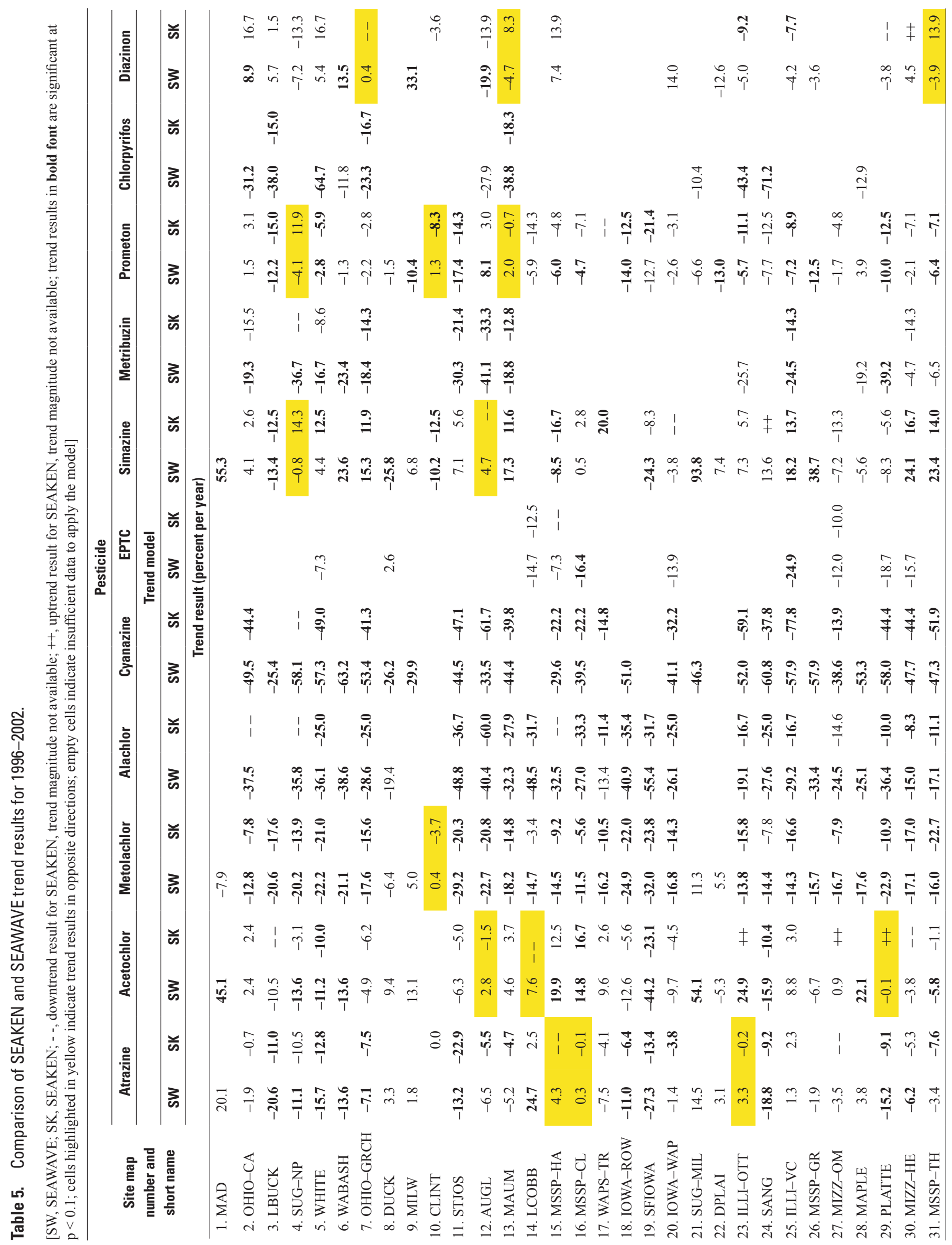


from both methods for all of the agricultural herbicides (atrazine, acetochlor, metolachlor, alachlor, cyanazine, EPTC, and metribuzin). No site had only uptrends, but MILW had downtrends only in cyanazine.

A regional seasonal Kendall analysis of trends was done for the four major river basins shown in figure 1 (table 6). A consistent set of sites were used in the analysis for each basin: the Ohio River Basin included OHIO-CA, LBUCK, SUG-NP, WHITE, and the OHIO-GRCH sites; the Great Lakes River Basins included CLINT, STJOS, AUGL, and the MAUM sites; the Upper Mississippi, Illinois, and Iowa River Basins included the LCOBB, MSSP-HA, MSSP-CL, WAPS-TR, IOWA-ROW, SFIOWA, ILLI-OTT, and the ILLI-VC sites; the Missouri River Basin included the MIZZ-OM, PLATTE, and the MIZZ-HE sites. A regional seasonal Kendall analysis also was done for the entire Corn Belt using all of the previously mentioned sites plus MSSP-TH. Downtrends in atrazine, metolachlor, alachlor, cyanazine, EPTC, metribuzin, prometon, and chlorpyrifos concentrations were indicated for streams in all basins as well as the Corn Belt as a whole and, except for EPTC, all of these constituents have at least one basin that had significant downtrends at the 10-percent significance level. The downtrends in metolachlor, alachlor, and cyanazine concentrations were significant at the 10-percent confidence level for all basins and for the Corn Belt as a whole.

Regional trends for acetochlor, simazine, and diazinon were mixed - some basins had downtrends and some had uptrends. The most widespread regional uptrends were observed for simazine, although none of the regional trends for acetochlor, simazine, and diazinon were significant at the 10-percent significance level (table 6).

\section{Overview of Trend Results for 2000-2006}

There also is good agreement between trends identified by the SEAKEN and SEAWAVE methods for the four sites that could be analyzed by the SEAKEN method for the period from 2000 to 2006 (table 7). Only 3 of 27 of the paired comparisons between the methods indicated a difference in the direction of the trend, and in no case were either of the trends significant at the 10-percent level. The good agreement between trends confirms the similar results for the period 1996-2002, but there are not enough analyses by the SEAKEN method for a regional analysis. Results for SEAWAVE for 2000-2006 will be discussed in more detail in the following sections.

\section{Influence of Flow Adjustment: Comparison of SEAWAVE and SEAWAVE-0}

Results presented in the previous section show that numerous statistically significant trends in pesticide concentrations occurred during both the 1996-2002 and 2000-2006 analysis periods, and that the trends generally were in agreement using either SEAKEN or SEAWAVE. Neither of these methods incorporates the influence of streamflow conditions on trends, however, and it is important to determine if some of the trends (or lack of trends) may be influenced by variable or trending streamflow conditions. Either sampling biases in relation to short-term streamflow conditions, or sustained trends in streamflow conditions, can contribute to, or obscure, trends in a concentration time series. A primary goal of this study is to evaluate trends due to changes in such factors as use and management practices, which requires adjustment for streamflow influences. For this purpose, SEAWAVE-Q, which accounts for influences of flow conditions, was the primary method used in this study for detailed interpretation.

Before focusing on the analysis of flow-adjusted trend results from SEAWAVE-Q, in relation to changes in use and other management factors, the overall effect of flow-related variability and trends on pesticide concentration trends is evaluated by comparing the trends using SEAWAVE, which does not include flow-related variables, and SEAWAVE-Q, which includes flow-related variables. Detailed trend results for both SEAWAVE and SEAWAVE-Q are given in tables 8 and 9 . This section gives a general overview of comparative results for SEAWAVE and SEAWAVE-Q, and several specific examples to illustrate the types of situations that arise. The purpose of these comparisons is not to systematically distinguish flow contributions to trends from use-or-management contributions to trends, which would require detailed site-specific analysis, but to provide a perspective on the degree of potential influence on results and interpretation if the influences of flow conditions (short, medium, and long term) are not included in the model.

\section{Overview of Trend Results for 1996-2002}

The trends in pesticide concentrations for the 1996-2002 analysis period are shown in table 8 . Of the 341 possible sitepesticide combinations, 251 had adequate data for application of both SEAWAVE and SEAWAVE-Q. Of the 251 pairs of results, almost half (122 pairs) had significant trends by both methods, and the direction of the trends were in agreement between the methods in every one of those 122 cases. Of the remaining 129 pairs, 52 were different in terms of statistical significance, with about equal numbers of cases in which significant unadjusted trends changed to nonsignificant flowadjusted trends (27 cases) or nonsignificant unadjusted trends changed to significant flow-adjusted trends ( 25 cases). There only were 26 pairs of results, or about 10 percent of cases, for which the direction of the unadjusted and flow-adjusted trends differed, and in 21 of those 26 pairs neither of the trends was significant. 


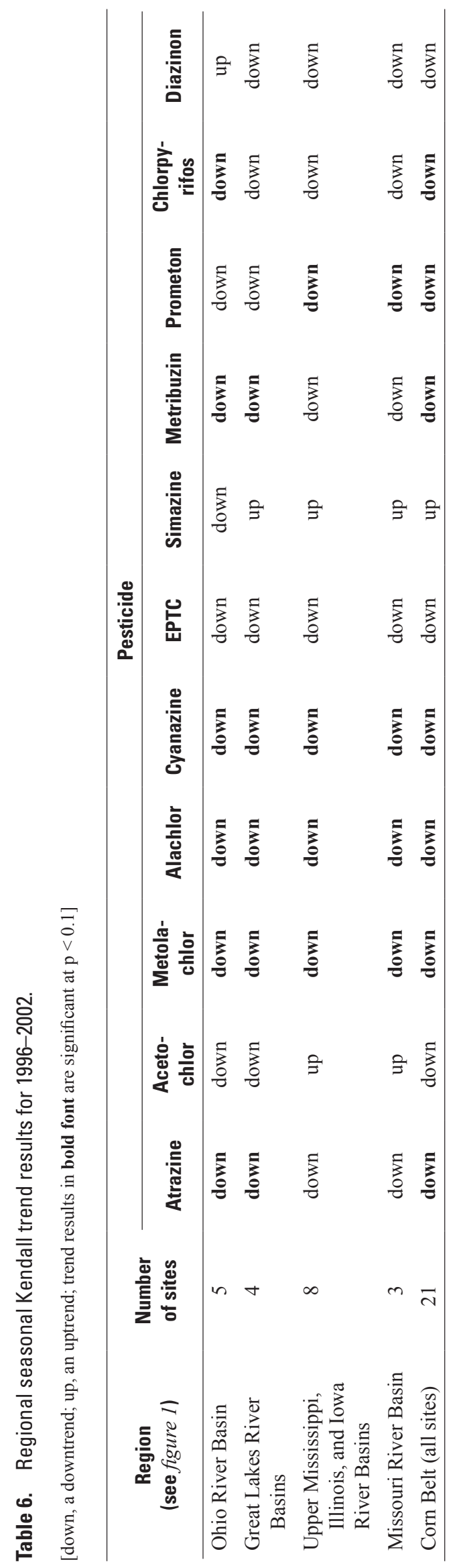




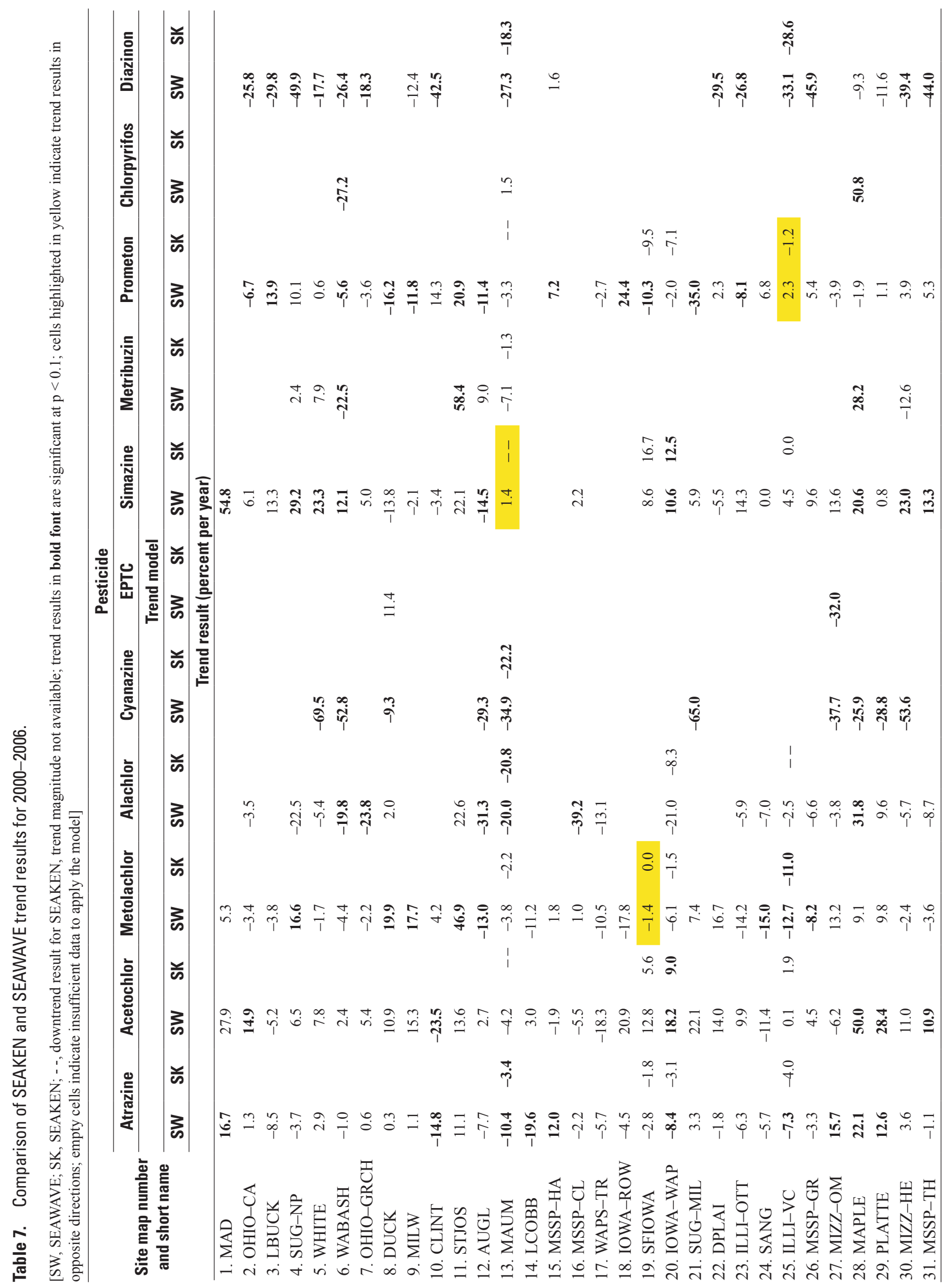




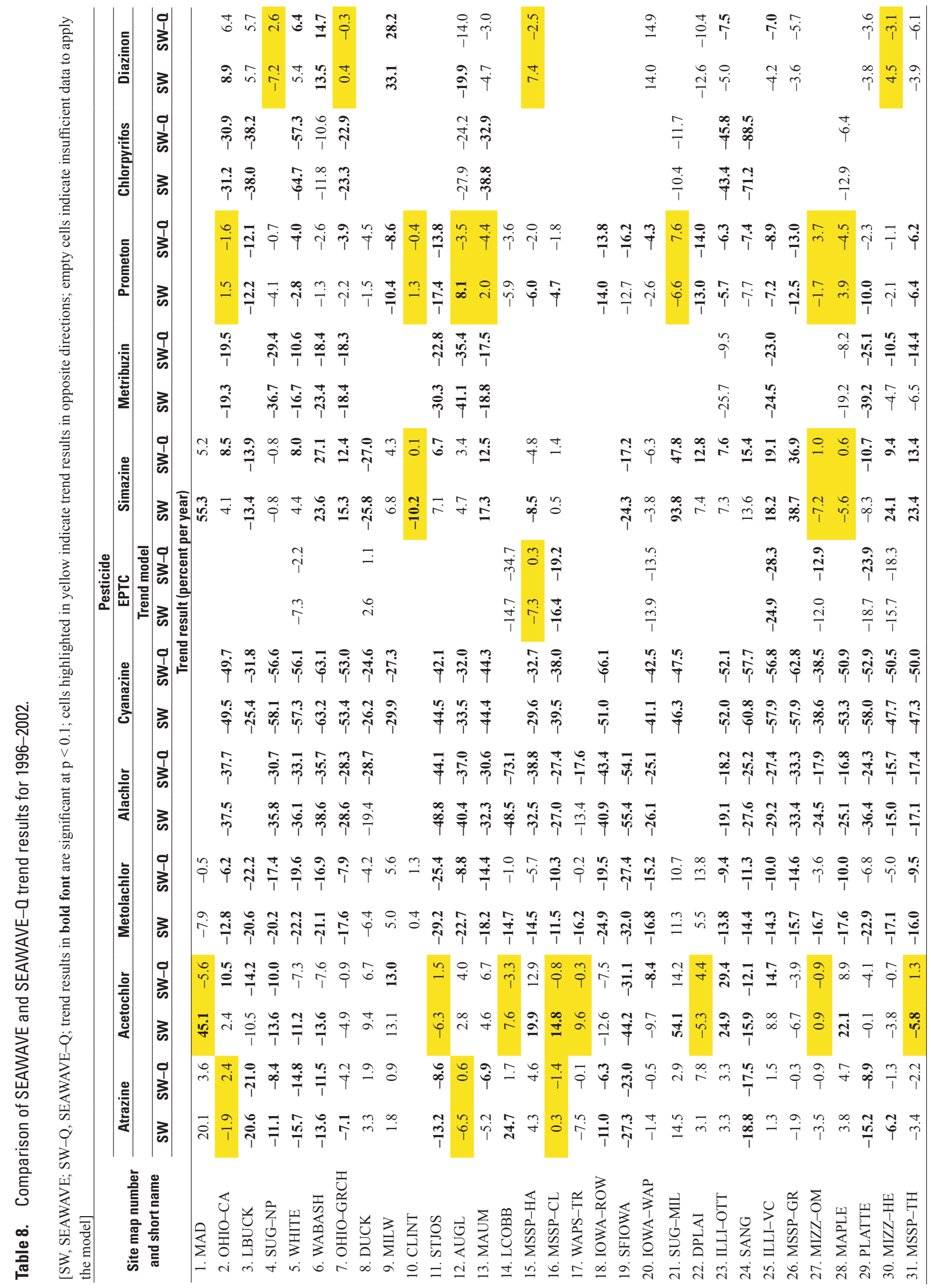




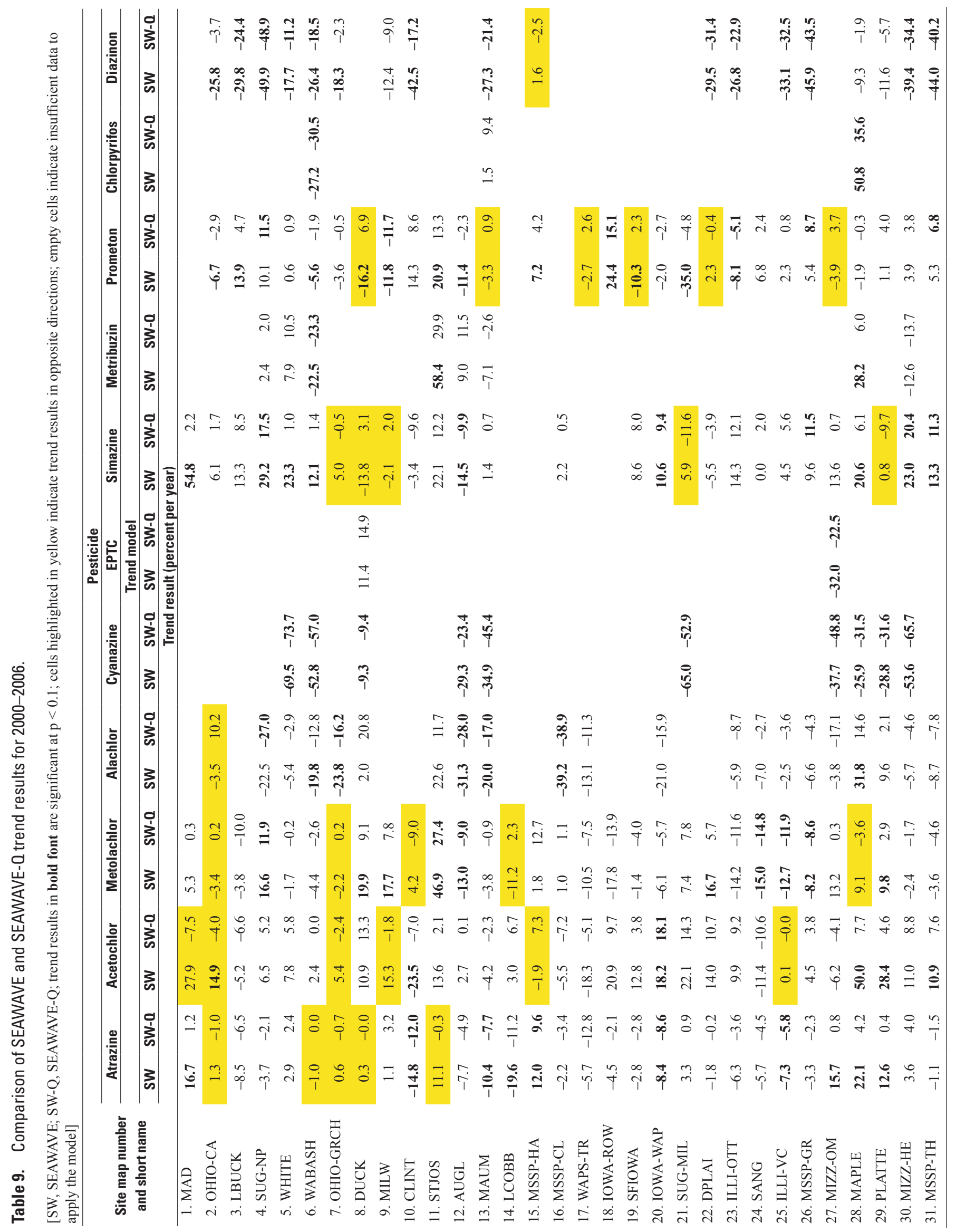


Flow adjustment affected the fitted trends for atrazine, acetochlor, and metolachlor to varying degrees (table 8). Considering atrazine, for example, both the unadjusted and flow-adjusted trends indicated generally stable or decreasing concentrations. Of the 30 sites analyzed, both approaches indicated no significant trend in atrazine concentration for 17 sites and both approaches indicated a significant decrease for 9 sites. Of the remaining four sites, there was a difference in the significance but not the direction of the trends between the two methods. Of the 30 sites analyzed for acetochlor trends for 1996-2002, both unadjusted and flow-adjusted trends indicated no significant change for 13 sites, both approaches indicated a significant decrease for 3 sites, and both approaches indicated a significant increase for 1 site. However, there were 13 sites for which the significance of the trends changed. Both the unadjusted and flow-adjusted trends for metolachlor concentration indicated significant downtrends for 19 of the 31 sites analyzed. Of the remaining 12 sites, the directions of the unadjusted and flow-adjusted trends were in agreement, but the significance of the trends differed for 6 of those sites.

Closer examination of the model results for atrazine, acetochlor, and metolachlor indicated that substantial flowrelated variability existed in the pesticide concentrations for most sites and, despite qualitative differences in the way that variability affected the significance of the fitted trends, there was a consistent pattern in the way the flow-related variables affected the trend magnitudes among the three pesticides. One or more of the flow variables in eq. (7) were strongly related to atrazine, acetochlor, and metolachlor concentration for most sites and the coefficients for the flow anomalies (LTFA, MTFA, and STFA) were similar among the three pesticides. Summary statistics of the fitted trends in atrazine, acetochlor, and metolachlor concentrations for the sites analyzed for those pesticides (table 10) indicate the effect of the flow adjustment on the trend magnitudes. The flow-adjusted downtrends generally were smaller in magnitude than the unadjusted downtrends by an average of about 2 percent per year (pct/ $\mathrm{yr})$ for atrazine $(-7.7 \mathrm{pct} / \mathrm{yr}$ compared to $-10.1 \mathrm{pct} / \mathrm{yr})$, about $4 \mathrm{pct} / \mathrm{yr}$ for acetochlor, and about $6 \mathrm{pct} / \mathrm{yr}$ for metolachlor.
Similarly, with the exception of metolachlor (for which there were only four uptrends), the flow-adjusted uptrends generally were smaller in magnitude than the unadjusted uptrends by an average of about 4 pct/yr for atrazine and about 6 pct/yr for acetochlor. The large unadjusted uptrends for atrazine and acetochlor were particularly sensitive to flow adjustment. For example, the largest, unadjusted uptrend for acetochlor was $54.1 \mathrm{pct} / \mathrm{yr}$, compared to the largest flow-adjusted uptrend of $29.4 \mathrm{pct} / \mathrm{yr}$.

There was near unanimous agreement among the direction and significance of the unadjusted and flow-adjusted trends for 1996-2002 for alachlor and cyanazine (table 8). All of the trends for these herbicides were downtrends and almost all were significant. Although there was significant flow-related variability in the pesticide concentrations for most sites, the variability was small, in relation to the overall pattern of decreasing concentrations. Similarly, most of the EPTC, metribuzin, and chlorpyrifos concentration trends that could be analyzed were downtrends as well, and most were significant. However, the high number of censored values for those pesticides (table 3) made it difficult to detect trends for most sites either with or without flow adjustment.

The fitted trends for simazine and prometon concentration for 1996-2002 were the most sensitive to flow adjustment of the 11 pesticides evaluated (table 8 ). Of the 28 sites analyzed for simazine trends, both unadjusted and flow-adjusted trends indicated significant uptrends for 8 sites and significant downtrends for 3 sites. However, either the direction or significance of the unadjusted and flow-adjusted trends differed for 13 of the remaining 17 sites. Most of the significant trends were uptrends, with 9 significant unadjusted uptrends and 14 significant flow-adjusted uptrends. For prometon, either the direction or significance of the unadjusted and flow-adjusted uptrends differed for 14 sites. However, unlike simazine, most of the significant trends for prometon were downtrends. Of the 29 sites analyzed, both unadjusted and flow-adjusted trends for prometon indicated significant downtrends for 10 sites. There was only one significant unadjusted uptrend and no significant flow-adjusted uptrends.

Table 10. Statistical comparison of unadjusted and flow-adjusted trend magnitudes for atrazine, acetochlor, and metolachlor for the 1996-2002 analysis period.

[pct/yr, percent per year]

\begin{tabular}{|c|c|c|c|c|c|c|c|}
\hline \multirow[b]{2}{*}{ Pesticide } & \multirow[b]{2}{*}{ Trend type } & \multicolumn{3}{|c|}{ Downward trends } & \multicolumn{3}{|c|}{ Upward trends } \\
\hline & & Count & $\begin{array}{c}\text { Average } \\
\text { (pct/yr) }\end{array}$ & $\begin{array}{l}\text { Largest } \\
\text { (pct/yr) }\end{array}$ & Count & $\begin{array}{c}\text { Average } \\
\text { (pct/yr) }\end{array}$ & $\begin{array}{l}\text { Largest } \\
\text { (pct/yr) }\end{array}$ \\
\hline Atrazine & Unadjusted & 19 & -10.1 & -27.3 & 11 & 7.3 & 24.7 \\
\hline Acetochlor & Unadjusted & 15 & -10.9 & -44.2 & 15 & 16.0 & 54.1 \\
\hline \multirow[t]{2}{*}{ Metolachlor } & Unadjusted & 27 & -17.7 & -32.0 & 4 & 5.6 & 11.3 \\
\hline & Flow-adjusted & 27 & -11.2 & -27.4 & 4 & 7.8 & 13.8 \\
\hline
\end{tabular}


The trends for diazinon concentration for 1996-2002 also were affected by flow adjustment (table 8). Either the direction or significance of the unadjusted and flow-adjusted trends differed for 9 of the 18 sites analyzed. However, most of the trends were not significant. There were three significant unadjusted uptrends and one significant unadjusted downtrend, compared to three significant flow-adjusted uptrends and two significant flow-adjusted downtrends.

A detailed examination of selected results for acetochlor shows the influence of flow adjustment on the significance and degree of trend. Model results for four sites (OHIOCA, WABASH, MSSP-CL, and IOWA-WAP) are shown in figure 3. The measured acetochlor concentrations are shown along with the fitted concentrations and trends from the SEAWAVE model (left-hand plots) and SEAWAVE-Q model (right-hand plots). For OHIO-CA, there was a small and nonsignificant uptrend (2.4 pct/yr, $p=0.65)$ without flowadjustment, compared to a significant flow-adjusted uptrend (10.5 pct/yr, $p=0.03)$. Of the three flow coefficients in the model (eq. 7), the coefficient for LTFA was positive and highly significant $(0.91, p=0.01)$, MTFA was negative and not significant $(-0.26, p=0.11)$, and STFA was negative and not significant $(-0.15, p=0.40)$. LTFA for this site was high during 1997 and low during 2000, which is reflected in the fitted concentrations from SEAWAVE-Q for those years. Without LTFA in the model, the slope of the unadjusted trend line was reduced as a result of the anomalous concentrations during those years. For WABASH, there was a highly significant unadjusted downtrend $(-13.6 \mathrm{pct} / \mathrm{yr}, p=0.01)$ compared to a smaller and not significant flow-adjusted downtrend $(-7.6 \mathrm{pct} / \mathrm{yr}, p=0.12)$. Neither LTFA nor MTFA were significant predictors of acetochlor concentration for this site. However, the coefficient for STFA was positive and highly significant $(0.99, p<0.001)$. The significant unadjusted downtrend for this site may have been caused, at least in part, by failure to account for short-term flow-related variability (because STFA is not included in SEAWAVE). For MSSP-CL, there was a highly significant unadjusted uptrend (14.8 pct/yr, $p=0.01)$ compared to a slight and nonsignificant flowadjusted downtrend $(-0.8 \mathrm{pct} / \mathrm{yr}, p=0.86)$. The coefficients for LTFA $(-2.04, p=0.03)$, MTFA $(0.63, p=0.02)$, and STFA $(0.77, p=0.004)$ all were significant for this site. The large negative coefficient for LTFA was particularly noteworthy. The unadjusted uptrend probably was caused by generally decreasing annual flows for this site during 1996-2000. For IOWA-WAP, there was a fairly large but nonsignificant unadjusted downtrend $(-9.7 \mathrm{pct} / \mathrm{yr}, p=0.16)$ compared to a similar but more significant flow-adjusted downtrend ( $-8.4 \mathrm{pct} / \mathrm{yr}$, $p=0.08)$. The coefficients for LTFA $(1.07, p=0.003)$, MTFA (1.04, $\mathrm{p}<0.001)$, and STFA $(1.68, p<0.001)$ all were positive and highly significant for this site. In this case, the flow variables were effective in explaining variability in the acetochlor concentration data but had little effect on the fitted trend, other than to increase its significance.

\section{Overview of Trend Results for 2000-2006}

The unadjusted and flow-adjusted trends for the 2000 2006 analysis period are shown in table 9. Compared to the 1996-2002 analysis period (table 8), there were fewer significant trends during 2000-2006. Of the 210 pairs of results for 2000-2006, only about 25 percent (49 pairs) had significant trends by both methods. However, the directions of the trends were in agreement for all of the pairs that had significant trends by both methods. There were 38 pairs of results for 2000-2006 for which the statistical significance of the trends differed, and in most of those (33 pairs), significant unadjusted trends changed to nonsignificant flow-adjusted trends. This is in contrast to the results for 1996-2002, in which there were a substantial number of pairs (26) in which nonsignificant unadjusted trends changed to significant flow-adjusted trends. However, the number of pairs in which the direction of the unadjusted and flow-adjusted trends changed for 2000-2006 was similar to the earlier period-29 pairs for 2000-2006 compared to 26 pairs for 1996-2002.

With the exception of cyanazine and diazinon, for which both unadjusted and flow-adjusted trends for 2000-2006 were predominately downtrends and significant, and EPTC, metribuzin, and chlorpyrifos, for which there were too few uncensored concentrations to draw any definitive conclusions, flow-adjustment was an important consideration for interpreting trends in the remaining pesticides. Careful consideration of flow-related variability is important for interpreting and analyzing trends for this latter period, especially because of the generally lower sampling frequencies compared to 1996-2002.

Flow adjustment had a similar effect on the fitted trends for atrazine, acetochlor, and metolachlor for 2000-2006 (table 9). There were more unadjusted uptrends than flowadjusted uptrends for those pesticides. A total of 49 of the 93 site-pesticide combinations had unadjusted uptrends, 16 of which were significant, compared to 43 site-pesticide combinations with flow-adjusted uptrends, only 4 of which were significant. This situation is illustrated in figure 4 for acetochlor concentration for several of the sites (MAD, STJOS, IOWA-ROW, and PLATTE). There were substantial unadjusted uptrends for all four of the sites, although only one of the trends (PLATTE) was significant. However, all of the flow-adjusted trends were small and nonsignificant and one (MAD) was downward. There was strong and highly significant flow-related variability in acetochlor concentrations for all four sites and that variability may have resulted in upward bias in the unadjusted trends. Such bias would be expected to be especially evident for small sample sizes, especially if the sampling frequencies change from year to year, as was the case for each of these sites. 


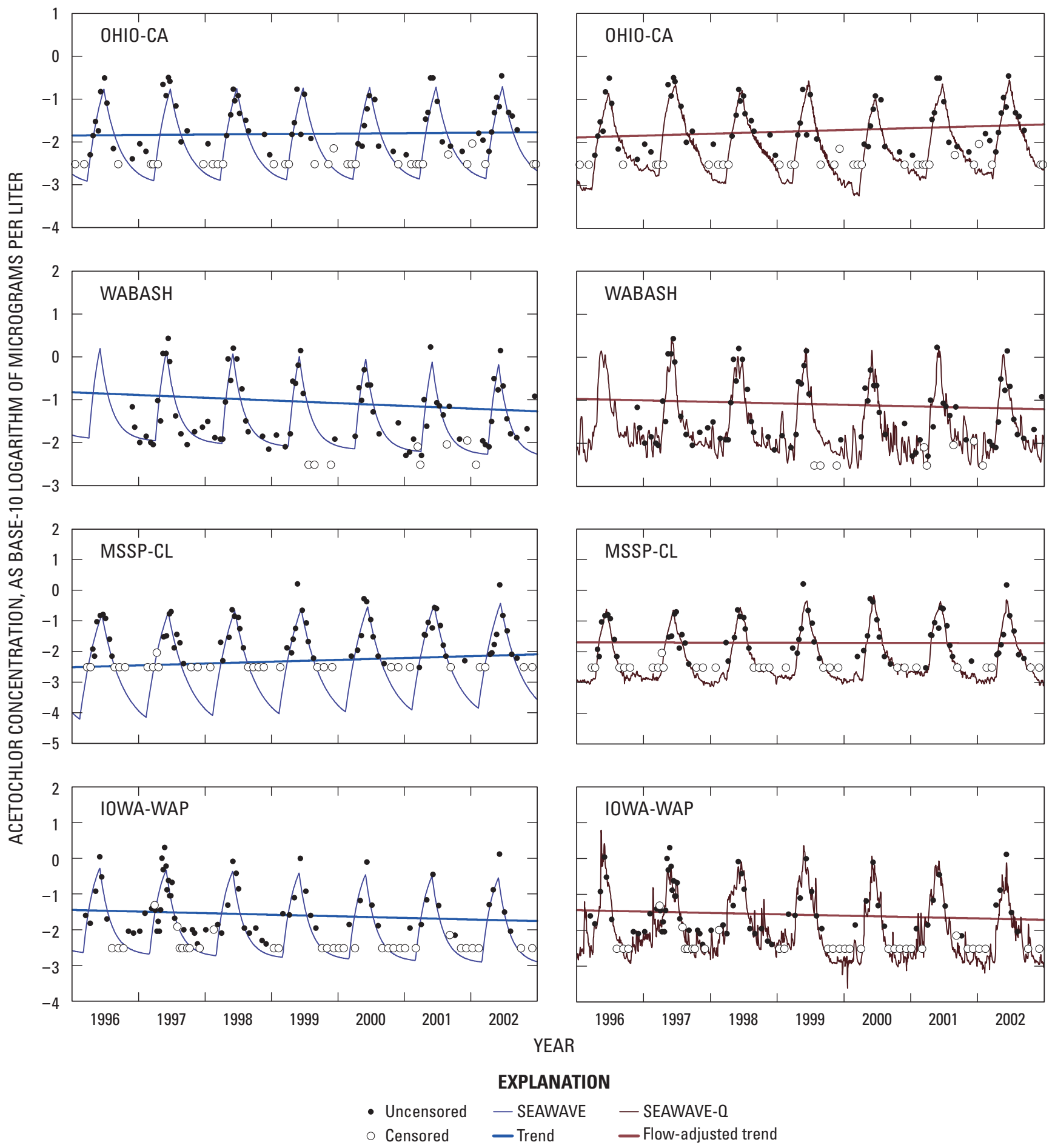

Figure 3. Observed and fitted acetochlor concentrations for selected sites for the 1996-2002 analysis period using SEAWAVE (left) and SEAWAVE-Q (right). 


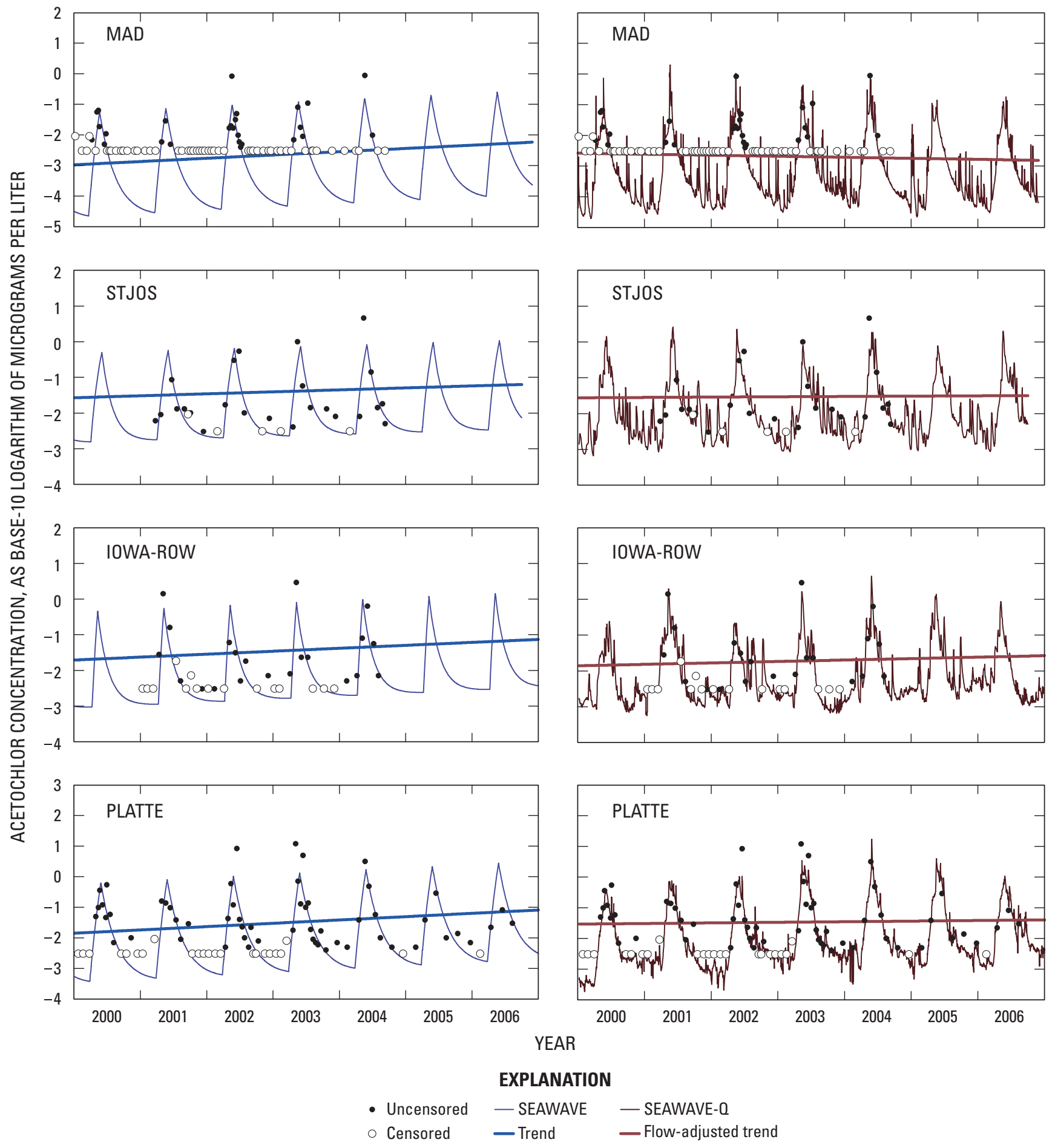

Figure 4. Observed and fitted acetochlor concentrations for selected sites for the 2000-2006 analysis period using SEAWAVE (left) and SEAWAVE-0 (right). 
Flow adjustment also affected the trends for simazine concentrations for the 2000-2006 analysis period (table 9). Either the direction or significance of the unadjusted and flowadjusted trends for simazine differed for 10 of the 27 sites analyzed. Examples of the trends for four of the sites (OHIOCA, WABASH, ILLI-VC, and MSSP-GR) are shown in figure 5. For OHIO-CA, both the unadjusted and flow-adjusted trends were small and nonsignificant. For WABASH, there was a strong and significant unadjusted uptrend but a slight and nonsignificant flow-adjusted uptrend. For ILLI-VC and MSSP-GR, the unadjusted and flow-adjusted uptrends were similar in magnitude. However, the significance of the trends increased as a result of the flow adjustment.

Flow adjustment had the most pronounced effect on prometon concentration trends for 2000-2006 (table 9). There were significant unadjusted trends in prometon concentration for 12 of the 28 sites analyzed, including 8 significant downtrends and 4 significant uptrends. However, there were only 2 significant flow-adjusted downtrends and 4 significant flowadjusted uptrends. The results are shown in figure 6 for four of the sites (OHIO-CA, WABASH, AUGL, and SUG-MIL). In each case, significant unadjusted downtrends were reduced in both size and significance with flow adjustment. The effect of the flow-related variability is particularly evident for the AUGL and SUG-MIL sites.

\section{Detailed Analysis of Flow-Adjusted Trends}

Analysis of flow-adjusted trends, which is the focus of this section, is preferable to analysis of non-adjusted trends for evaluating potential effects of changes in pesticide use or management practices because flow-adjusted trends account for the influence of flow-related variability. If ignored, these influences of flow conditions may alter or disguise trends caused by changes in pesticide use or management practices. In addition, the hydrologic connectivity between watersheds and the relative contributions of streamflow and pesticide flux from specific sites are important considerations for interpreting trend directions and magnitudes.

For each pesticide, trend results are summarized with two figures and a table that follow a consistent format to facilitate comparisons. The first figure illustrates the significance level, magnitude, and direction of flow-adjusted trends in relation to: (1) site locations within the drainage network, and (2) relative contributions of streamflow and pesticide transport. Figure 7, which summarizes results for atrazine, is an example of this first figure. Figure 8 is an example of the second figure, a time-series plot of concentration and use intensity for seven study sites that were selected as indicators of major subareas of the Corn Belt, and that have large enough drainage areas such that reasonable use estimates are possible. Changes in pesticide use intensity over time were estimated for the watersheds of these sites, plus the four major river sites that are at the outlets of major drainages and that have the greatest flows (OHIO-GRCH, MSSP-GR, MIZZ-HE, and MSSP$\mathrm{TH}$ ) by fitting a straight line to log-transformed annual use intensity for the specified analysis period using ordinary least-squares regression. Results for the 11 sites, referred to as "use-trend" sites, are summarized in a table for each pesticide, such as in table 11 for atrazine.

\section{Atrazine}

Atrazine concentrations generally were stable or decreasing during 1996-2002 (fig. 7). Of the 30 sites analyzed for this period, 20 had small and nonsignificant trends and the remaining 10 sites had significant or highly significant downtrends.

Atrazine concentrations also were generally stable or decreasing during 2000-2006, but the downtrends were smaller and less significant than during 1996-2002. Of the 31 sites analyzed during the latter period, 26 had nonsignificant trends, 4 had significant but relatively small (less than $13 \mathrm{pct} / \mathrm{yr}$ ) downtrends, and one site had a significant uptrend. Although the downtrends were smaller and less significant than the earlier analysis period, generally there was a similar frequency of downtrends during 2000-2006 (21 of 31 sites) compared to 1996-2002 (18 of 30 sites).

\section{Ohio River and Great Lakes Basins (sites 1-13)}

There was a small (about $5 \mathrm{pct} / \mathrm{yr}$ ) and nonsignificant downtrend in atrazine concentration for the most downstream Ohio River Basin site, OHIO-GRCH (site 7) during 1996-2002, but the four sites in the tributary Wabash River Basin (sites 3-6) had highly significant downtrends. The small downtrend for OHIO-GRCH during 1996-2002 is consistent with the combined influence of the downtrend for WABASH, which is a major source of atrazine to the Ohio River, and a small and nonsignificant uptrend for OHIO-CA (site 2). Although OHIO-CA contributed much more streamflow than WABASH, the Wabash River drains some of the most intensively farmed area of the Ohio River Basin and provided a substantially larger atrazine flux than $\mathrm{OHIO}-\mathrm{CA}$. There also were significant downtrends during 1996-2002 for MAUM (site 13), the Great Lakes Basins site with the largest drainage area, and for a small tributary to that site, STJOS (site 11).

During 2000-2006, trends were notably different in the Ohio River Basin, with only small and nonsignificant trends for all seven sites. In the Great Lakes Basin, however, MAUM still had a significant downtrend, as did CLINT (site 10), a site with a small watershed and substantial urban influence. 

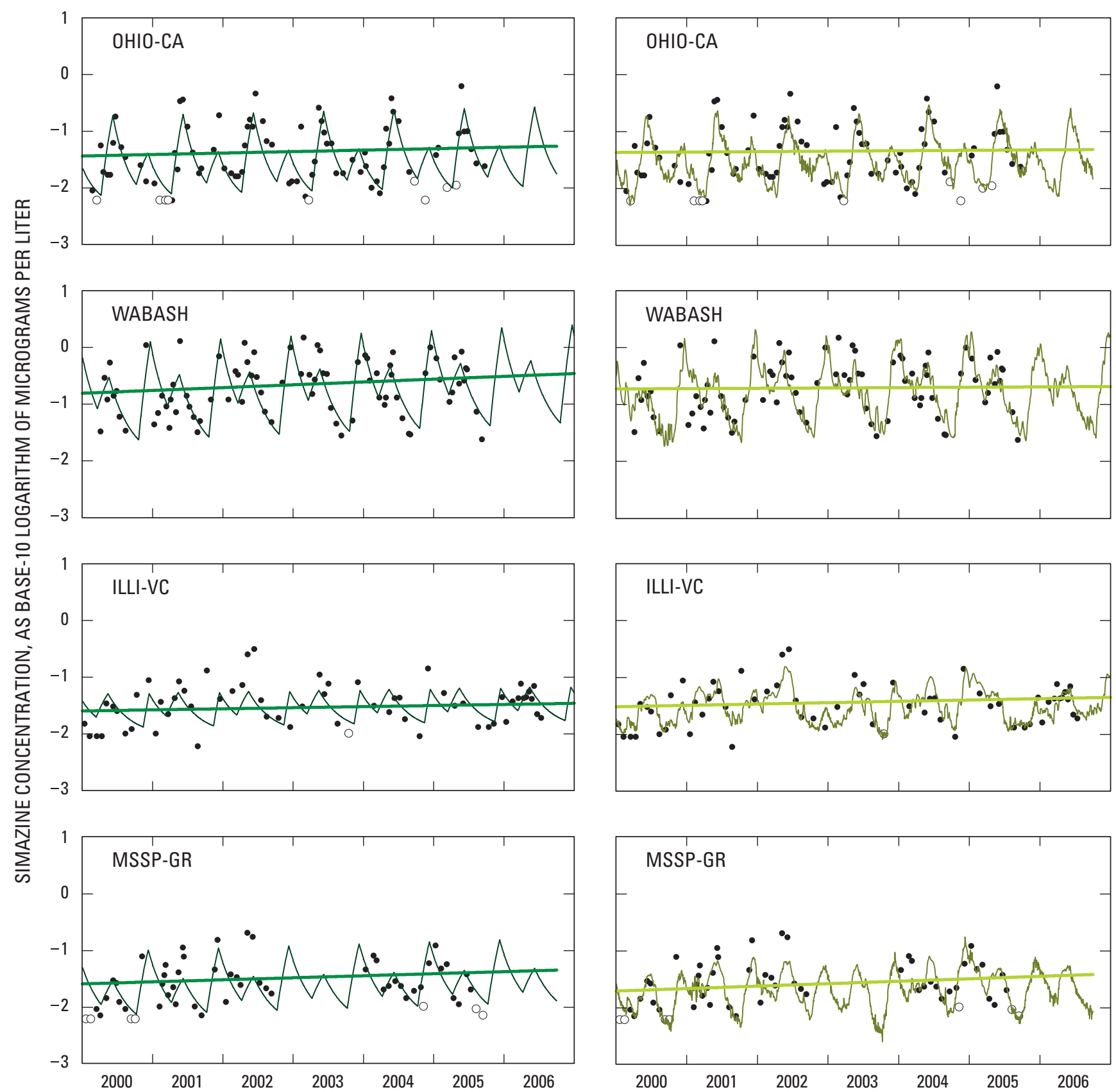

$$
\text { YEAR }
$$

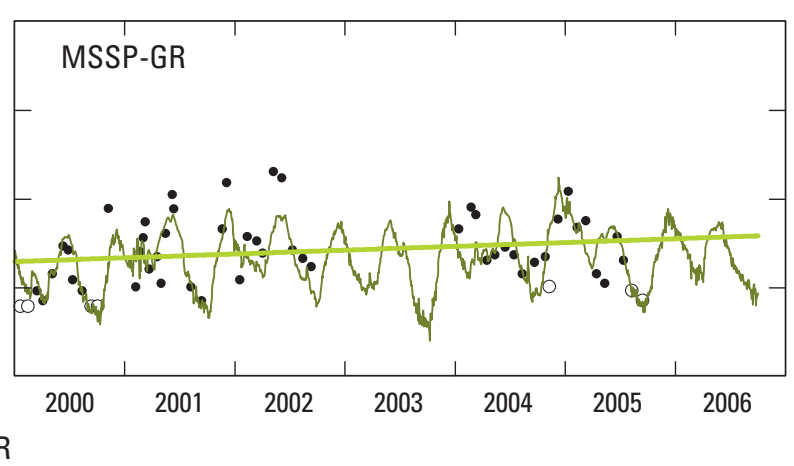

\section{EXPLANATION}

$$
\begin{array}{lll}
\text { - Uncensored } & \text { - SEAWAVE } & \text { - SEAWAVE-0 } \\
\text { - Censored } & \text { - Trend } & \text { - Flow-adjusted trend }
\end{array}
$$

Figure 5. Observed and fitted simazine concentrations for selected sites for the 2000-2006 analysis period using SEAWAVE (left) and SEAWAVE-0 (right). 


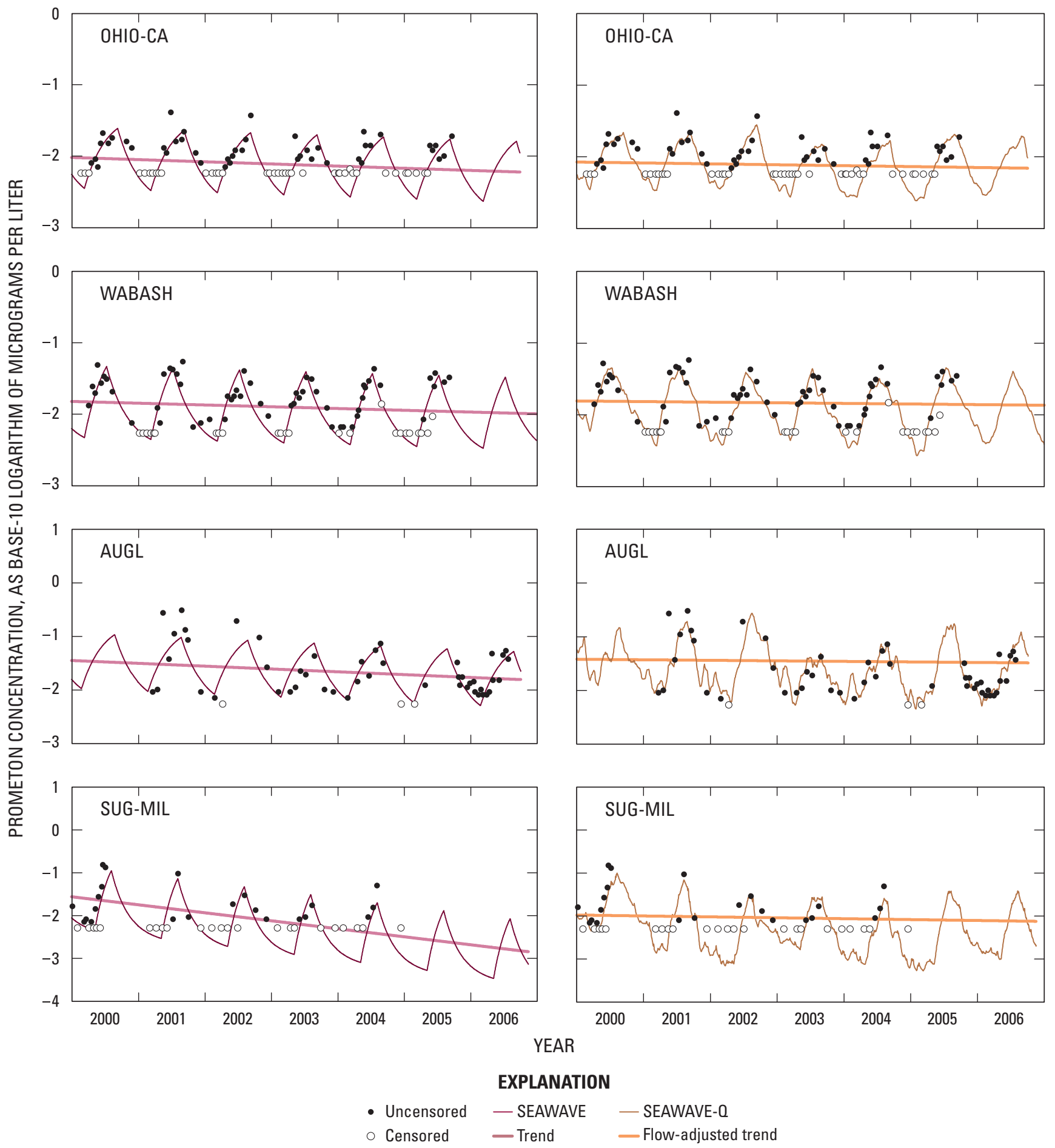

Figure 6. Observed and fitted prometon concentrations for selected sites for the 2000-2006 analysis period using SEAWAVE (left) and SEAWAVE-Q (right). 


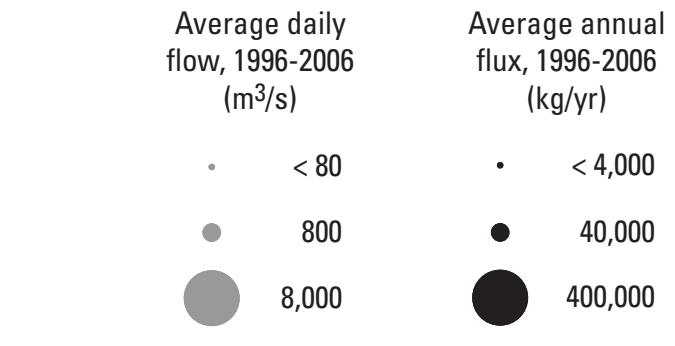

NA is not analyzed; $>$ is greater than;
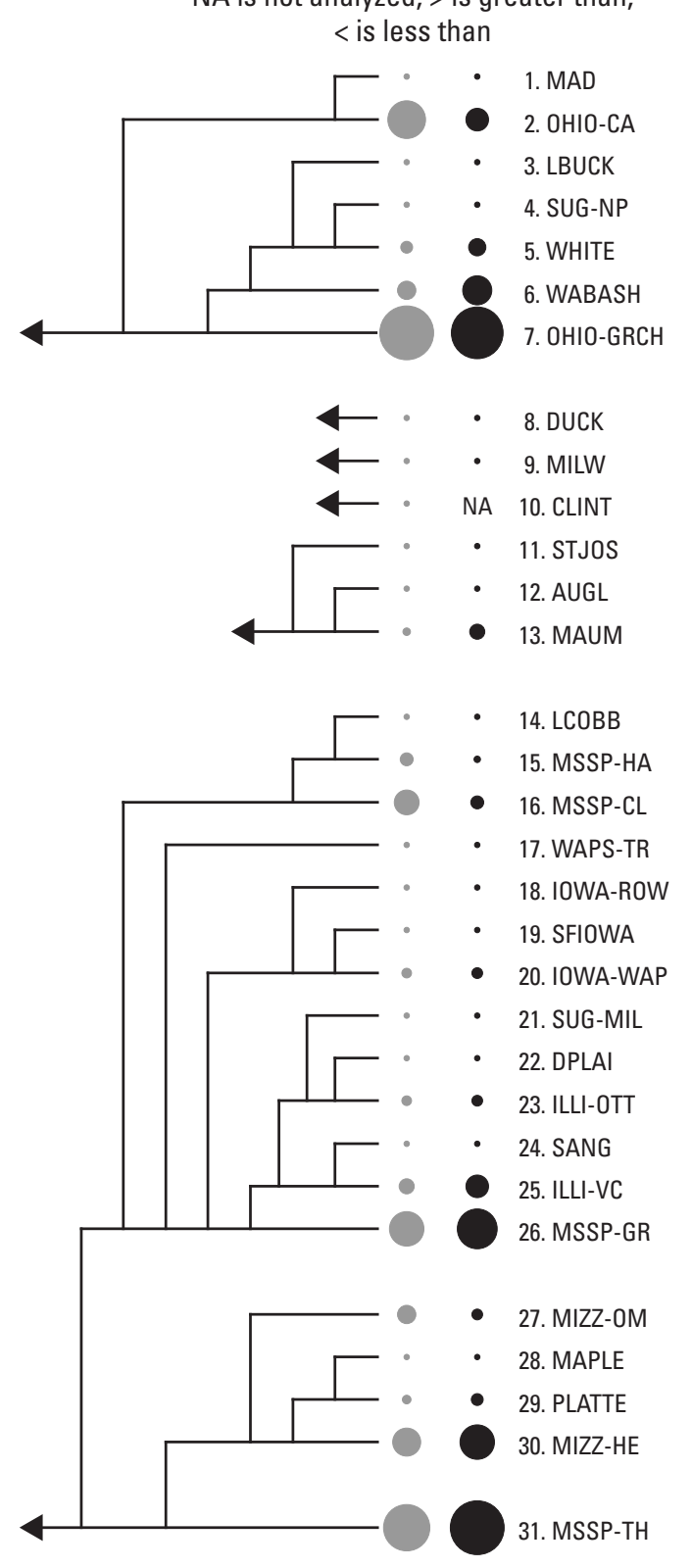

\section{Atrazine}

Flow-adjusted trends in concentration

Estimated value

I

90-percent confidence limits

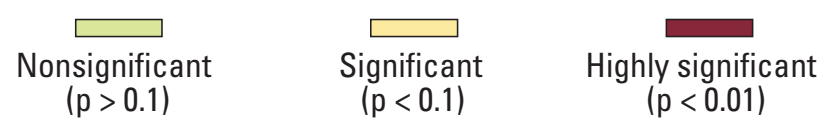

1996-2002
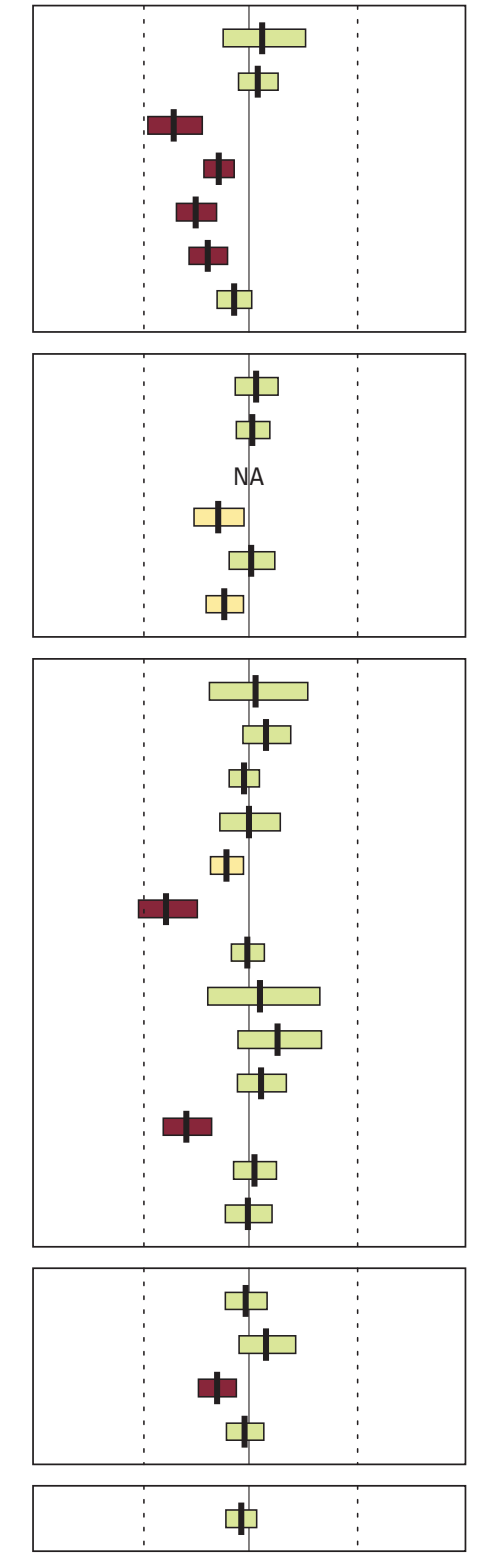

$+60-60$
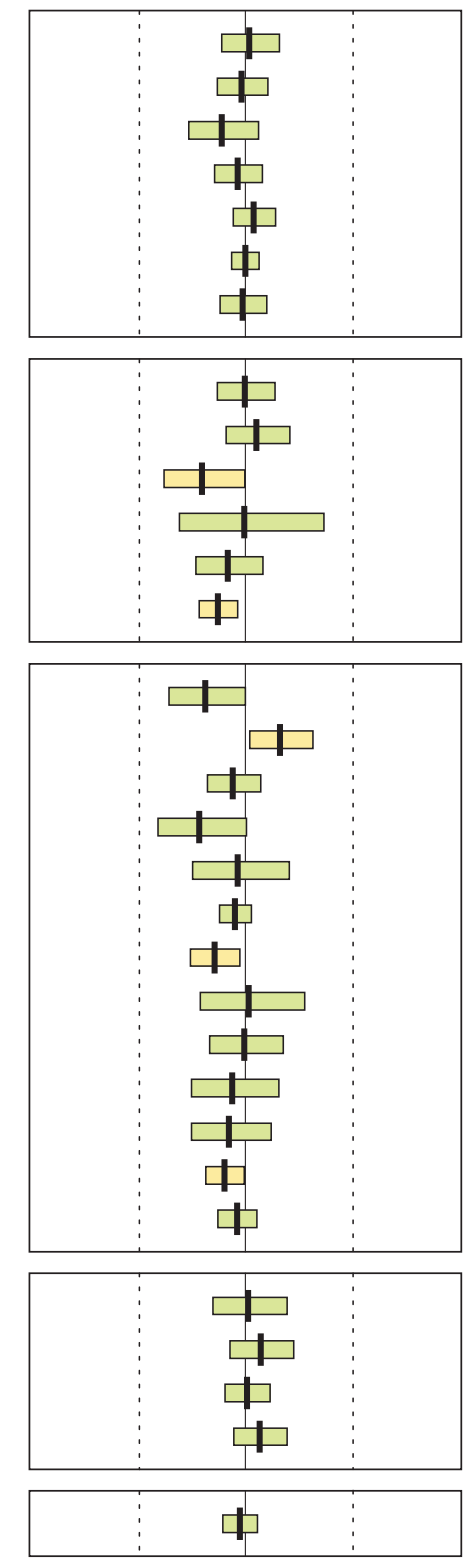

0

$+60$

TREND, IN PERCENT PER YEAR

Figure 7. Flow-adjusted trends in atrazine concentration for 1996-2002 and 2000-2006 analysis periods. 


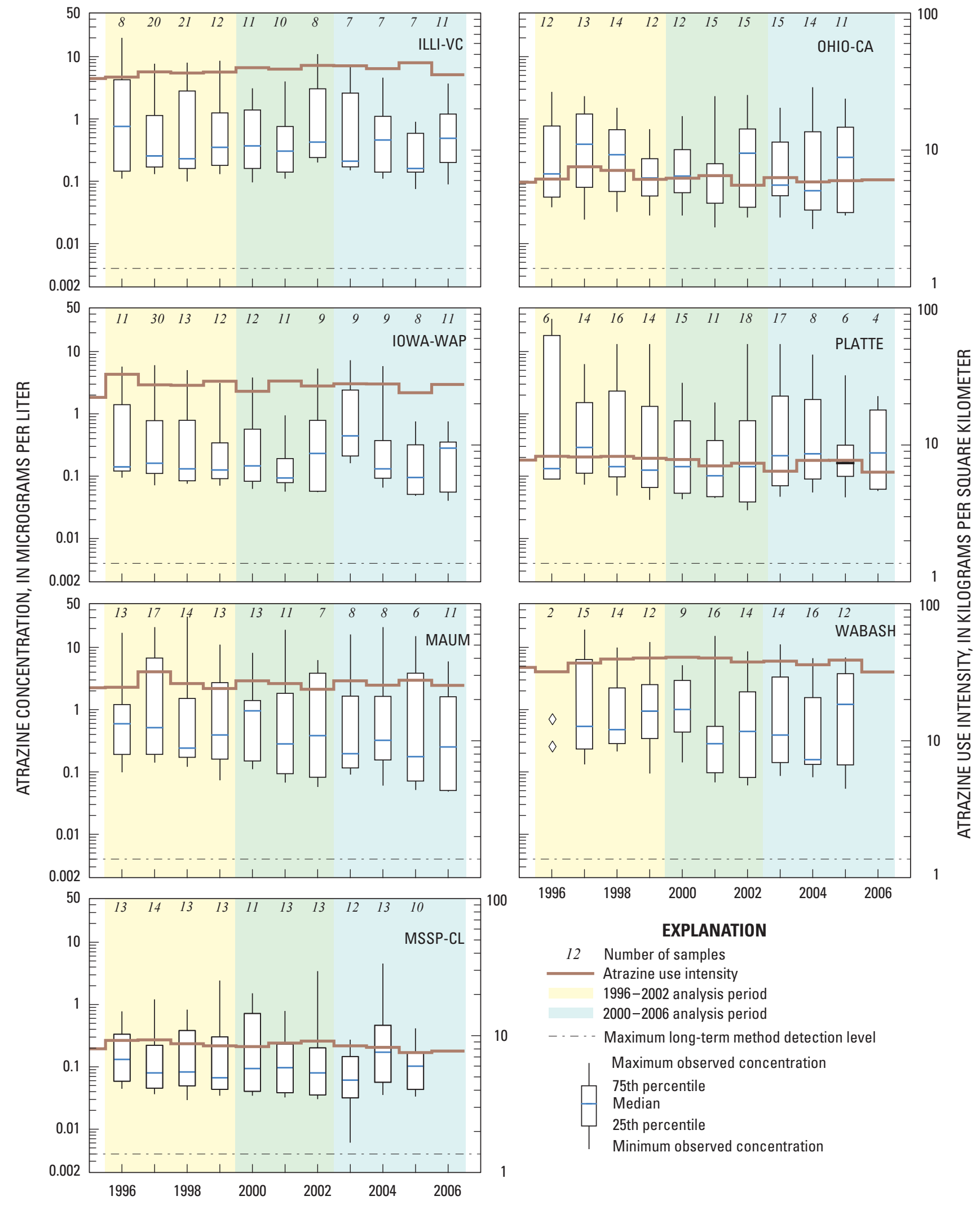

Figure 8. Atrazine use intensity and stream-water concentrations for selected trend sites in the Corn Belt, 1996-2006. 
Table 11. Flow-adjusted trends in atrazine concentration and changes in atrazine use intensity for selected sites for the 1996-2002 and 2000-2006 trend analysis periods.

[Bold type indicates significant $(\mathrm{p} \leq 0.10)$ trends or changes in use intensity]

\begin{tabular}{|c|c|c|c|c|}
\hline \multirow{2}{*}{$\begin{array}{l}\text { Site map number } \\
\text { and short name } \\
\text { (see table 1) }\end{array}$} & \multicolumn{2}{|c|}{ 1996-2002 } & \multicolumn{2}{|c|}{ 2000-2006 } \\
\hline & $\begin{array}{l}\text { Flow-adjusted trend } \\
\text { (percent per year) }\end{array}$ & $\begin{array}{l}\text { Change in use } \\
\text { (percent per year) }\end{array}$ & $\begin{array}{l}\text { Flow-adjusted trend } \\
\text { (percent per year) }\end{array}$ & $\begin{array}{c}\text { Change in use } \\
\text { (percent per year) }\end{array}$ \\
\hline 2. OHIO-CA & 2.4 & -2.6 & -1.0 & -0.7 \\
\hline 6. WABASH & -11.5 & 2.5 & 0.0 & -3.0 \\
\hline 7. OHIO-GRCH & -4.2 & 0.9 & -0.7 & -2.7 \\
\hline 13. MAUM & -6.9 & -1.6 & -7.7 & -0.2 \\
\hline 16. MSSP-CL & -1.4 & -0.8 & -3.4 & -2.3 \\
\hline 20. IOWA-WAP & -0.5 & -1.9 & -8.6 & -0.1 \\
\hline 25. ILLI-VC & 1.5 & 2.8 & -5.8 & -0.7 \\
\hline 26. MSSP-GR & -0.3 & -0.4 & -2.3 & -0.5 \\
\hline 29. PLATTE & -8.9 & -2.5 & 0.4 & -1.4 \\
\hline 30. MIZZ-HE & -1.3 & 0.6 & 4.0 & -3.6 \\
\hline 31. MSSP-TH & -2.2 & 0.3 & -1.5 & -1.9 \\
\hline
\end{tabular}

\section{Mississippi and Missouri River Basins (sites 14-31)}

For the 1996-2002 time period, there were small (less than $5 \mathrm{pct} / \mathrm{yr}$ ) and nonsignificant flow-adjusted trends in atrazine concentration for the downstream Mississippi River site, MSSP-TH (site 31); both large tributaries to that site, MSSP-GR (site 26) and MIZZ-HE (site 30); and all three major tributaries to MSSP-GR, which are MSSP-CL, IOWAWAP, and ILLI-VC (sites 16, 20, and 25). There were highly significant downtrends for smaller tributaries in the Iowa River Basin (SFIOWA, site 19), the Illinois River Basin (SANG, site 24), and the Missouri River Basin (PLATTE, site 29), and a significant downtrend for another small Iowa tributary (IOWA-ROW, site 18). The average annual atrazine fluxes for the small basins were negligible compared to the larger downstream basins, however, and the large downtrends in the small basins did not substantially impact the overall stable concentrations at downstream sites. The trends for the remaining smaller basins, like the large downstream basins, were small and nonsignificant during 1996-2002.

For 2000-2006, as during 1996-2002, there were small and nonsignificant trends for the three largest basins, MSSPGR, MIZZ-HE, and MSSP-TH (sites 26, 30, and 31, respectively). However, unlike 1996-2002, there were significant downtrends for two of the major tributaries to MSSP-GR, specifically IOWA-WAP and ILLI-VC (sites 20 and 25), and a significant uptrend for MSSP-HA (site 15).

\section{Trends in Relation to Changes in Use Intensity}

Atrazine use for all 11 use-trend sites was relatively stable during both analysis periods (table 11 and fig. 8). Estimated use trends range from a decrease of $3.6 \mathrm{pct} / \mathrm{yr}$ for MIZZ-HE during 2000-2006 to an increase of 2.8 pct/yr for ILLI-VC during 1996-2002. Consistent with stable use, 16 of the 22 cases analyzed for both time periods had flow-adjusted trends in atrazine concentration that were nonsignificant. However, there were two sites during 1996-2002: WABASH and MAUM, and three sites during 2000-2006: MAUM, IOWA-WAP, and ILLI-VC at which significant downtrends occurred despite no significant trend in use intensity. These downtrends may be the result of reduced transport of atrazine to streams due to agricultural management changes, such as increases in conservation tillage and application buffer strips along streams during the trend-assessment periods. The proportion of crop acreage with conservation tillage practices has increased steadily since 1990 (Fawcett, 2008) and, beginning in 1992, label instructions on most atrazine products called for 20-m no-application buffers along streams, including seeded buffers for highly erodible land (Paul Hendley, Syngenta, written commun., 2008). The degree and timing of implementation of these changes in the basins of the four sites requires further investigation, however, in order to further evaluate this potential influence. Another possible explanation is inaccurate estimates of use trends for these sites, which have among the smaller watershed areas of the 11 use-trend sites. Both the concentration and use trends are relatively low and a more quantitative uncertainty analysis of differences in concentration and use trends is needed. 


\section{Acetochlor}

Trends in acetochlor concentrations for 1996-2002 were highly variable among sites (fig. 9). Of the 30 sites analyzed, 20 had nonsignificant trends, 6 had significant downtrends, and 4 had significant uptrends. For the Ohio River Basin sites (sites 1-7), the upper Mississippi and Iowa River Basin sites (sites 14-20), and the Missouri and lower Mississippi River Basin sites (sites 26-31), trends in acetochlor concentration during 1996-2002 were qualitatively similar to atrazine (fig. 7). However, for the Great Lakes Basins sites (sites 8-13) and the Illinois River Basin sites (sites 21-25), there were more uptrends and fewer downtrends in acetochlor compared to atrazine. During 2000-2006, there were no significant downtrends and only one significant uptrend in acetochlor concentration. Although not individually significant, acetochlor concentrations at 19 of 31 sites showed uptrends during 2000-2006, in contrast to atrazine, in which most (21 of 31 sites) trends were downward.

\section{Ohio River and Great Lakes Basins (sites 1-13)}

In the highly agricultural Wabash River Basin, there were moderate (5-15 pct/yr) downtrends for all four sites (3-6) during 1996-2002, and three of the trends were significant. Conversely, there was a significant uptrend (about $10 \mathrm{pct} / \mathrm{yr}$ ) for OHIO-CA (site 2) during that time. The OHIO-CA site is only 55 percent agricultural land use and is less intensively row-cropped than sites in the Wabash River Basin. During 1996-2002 the small (about 2 pct/yr) and nonsignificant downtrend in acetochlor concentration for OHIO-GRCH (site 7), the downstream-most Ohio River Basin site, reflects influences from both WABASH (site 6), which provided a large part of the flux for OHIO-GRCH, and OHIO-CA, which provided a smaller but still substantial part of the flux for OHIO-GRCH. All five Great Lakes Basins sites analyzed had uptrends during 1996-2002, and the uptrend at MILW (site 9) was significant. During 2000-2006, there were no significant trends in acetochlor concentration for any of the Ohio River Basin and Great Lakes Basins sites.

\section{Mississippi and Missouri River Basins (sites 14-31)}

During 1996-2002, there were small (less than $5 \mathrm{pct} / \mathrm{yr}$ ) and nonsignificant trends in acetochlor concentration for MSSP-TH (site 31, the downstream-most Mississippi River site), as well as for both major tributaries to that site, MSSP-GR and MIZZ-HE (sites 26 and 30). However, trends for the 3 main tributary sites to MSSP-GR were mixed: MSSP-CL (site 16) had a nonsignificant downtrend; IOWAWAP (site 20) had a significant downtrend; and ILLI-VC (site 25) had a significant uptrend during 1996-2002. There also was a large and highly significant downtrend for SFIOWA (site 19), a small Iowa tributary, a large and highly significant uptrend at the upstream Illinois River site ILLI-OTT (site 23), and a significant downtrend for an Illinois River tributary, SANG (site 24) during that time. During 2000-2006, most (13 of 18) of the trends in acetochlor concentration for sites 14-31 were upward, although only one, IOWA-WAP (site 20) was significant.

\section{Trends in Relation to Changes in Use Intensity}

Acetochlor was registered in 1994, the same year it was first used for weed control in corn fields, and use of this herbicide increased rapidly during the following 2 years. During 1996-2006, total acetochlor use for the overall Corn Belt was relatively constant (fig. 2). However, within the watersheds of the 11 use-trend sites, acetochlor use was variable (table 12, fig. 10) and ranged from a decrease of $6.7 \mathrm{pct} / \mathrm{yr}$ at WABASH during 2000-2006 to an increase of $6.9 \mathrm{pct} / \mathrm{yr}$ at ILLI-VC during 1996-2002. The trends in acetochlor concentration also were variable and, moreover, the trends were not significant for 18 of the 22 cases analyzed for both trend analysis periods for the 11 use-trend sites. A significant downtrend occurred at one site, IOWA-WAP, during 1996-2002, despite nonsignificantly declining use. In contrast, concentrations trended upward at OHIO-CA, despite nonsignificantly declining use (table 12). During 2000-2006, the IOWA-WAP concentration trend reversed to a significant uptrend even though use was significantly downward. This difference in results for the two periods for IOWA-WAP, which is one of the smaller of the use-trend watersheds, may result from inaccurate usetrend estimates. Results do not provide a consistent pattern, compared to atrazine, for the potential influence of non-use management practices. While atrazine results indicated steeper concentration downtrends during 1996-2002 at WABASH and MAUM, acetochlor, which would have been affected by many of the same practices, had no significant trend in either concentration or use. During 2000-2006, atrazine results indicated steeper concentration downtrends at MAUM, IOWA-WAP, and ILLI-VC, whereas acetochlor concentration trends were nonsignificant, upward, and nonsignificant, respectively. 


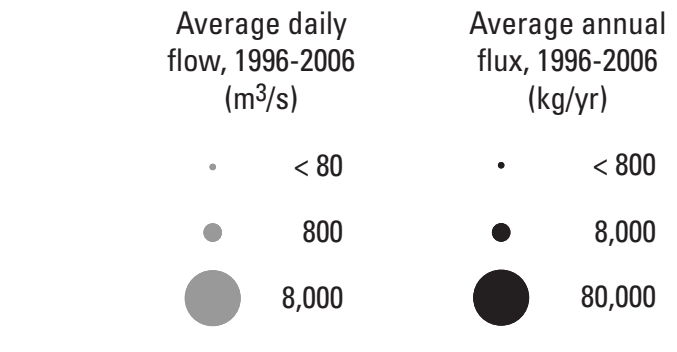

NA is not analyzed; > is greater than;
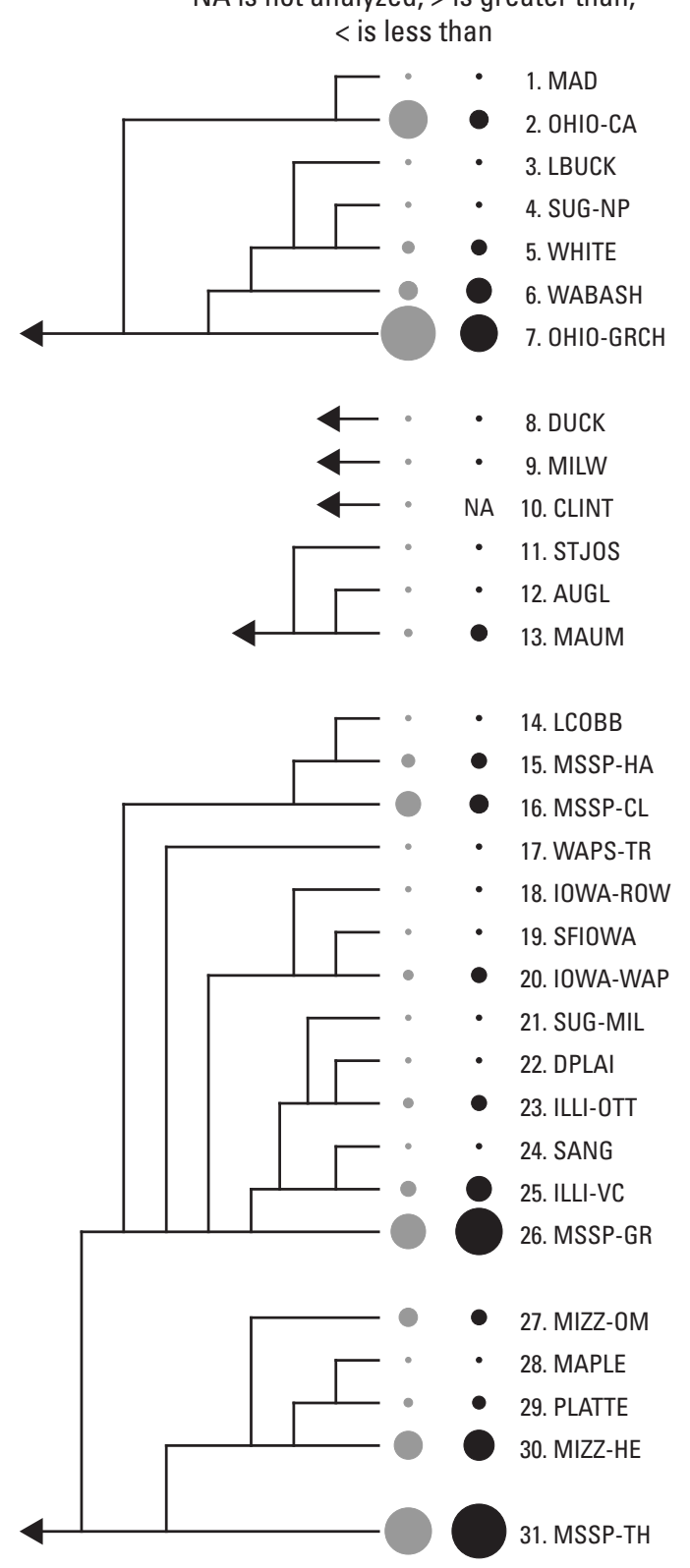

\section{Acetochlor}

Flow-adjusted trends in concentration

Estimated value

I

90-percent confidence limits

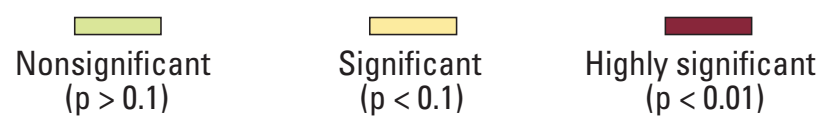

1996-2002
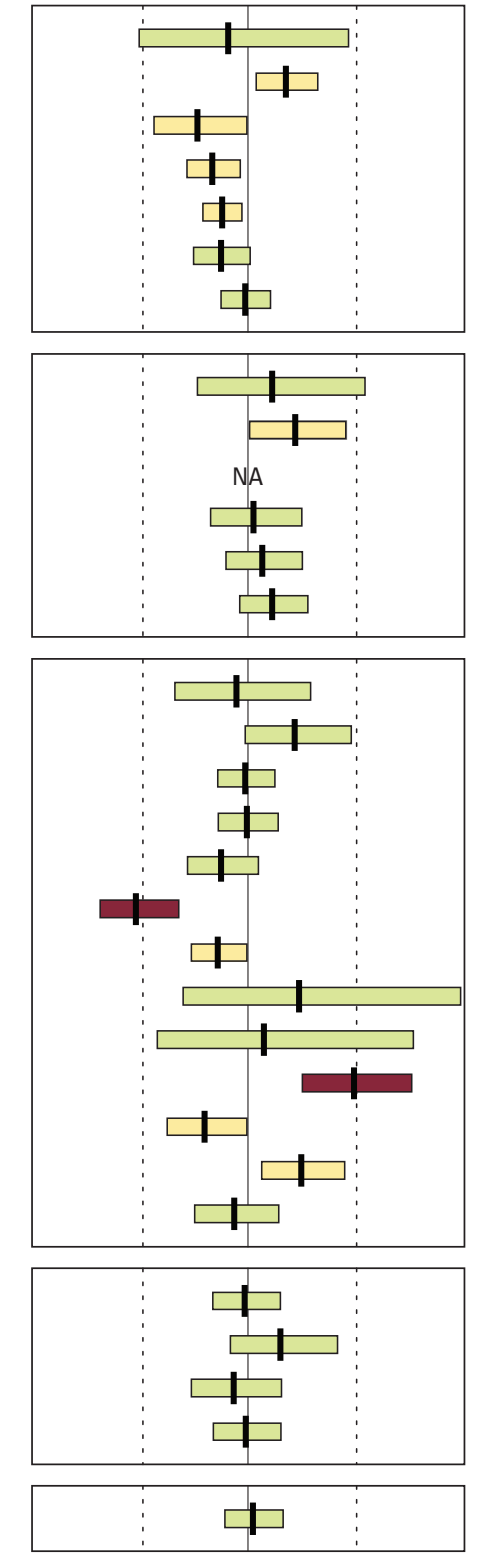

$+60-60$
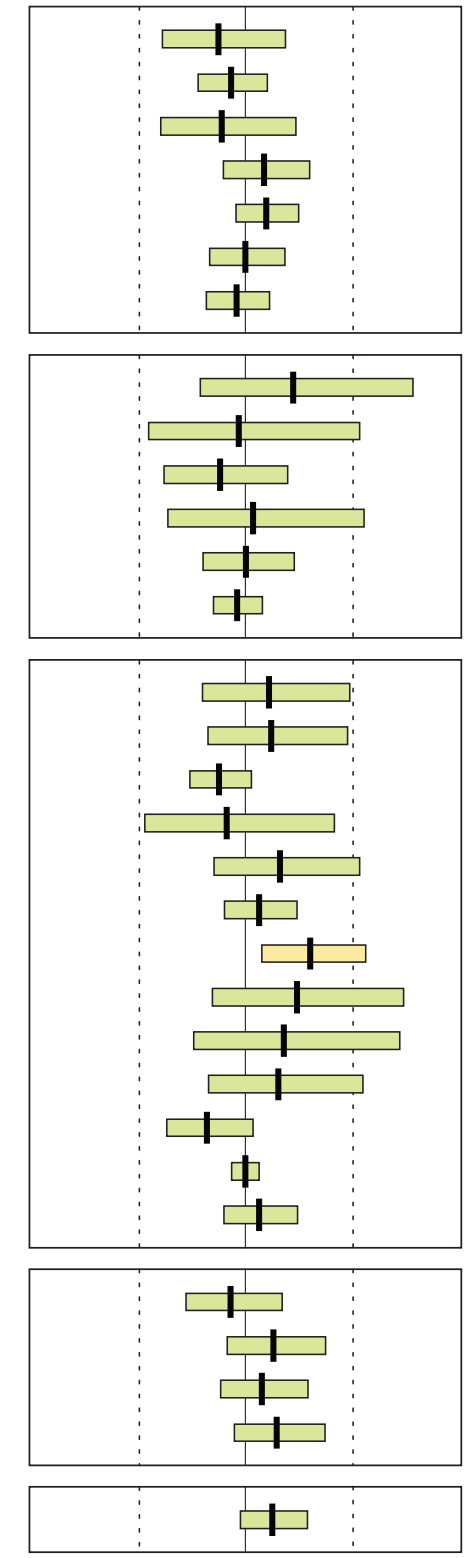

0

TREND, IN PERCENT PER YEAR

Figure 9. Flow-adjusted trends in acetochlor concentrations for 1996-2002 and 2000-2006 analysis periods. 


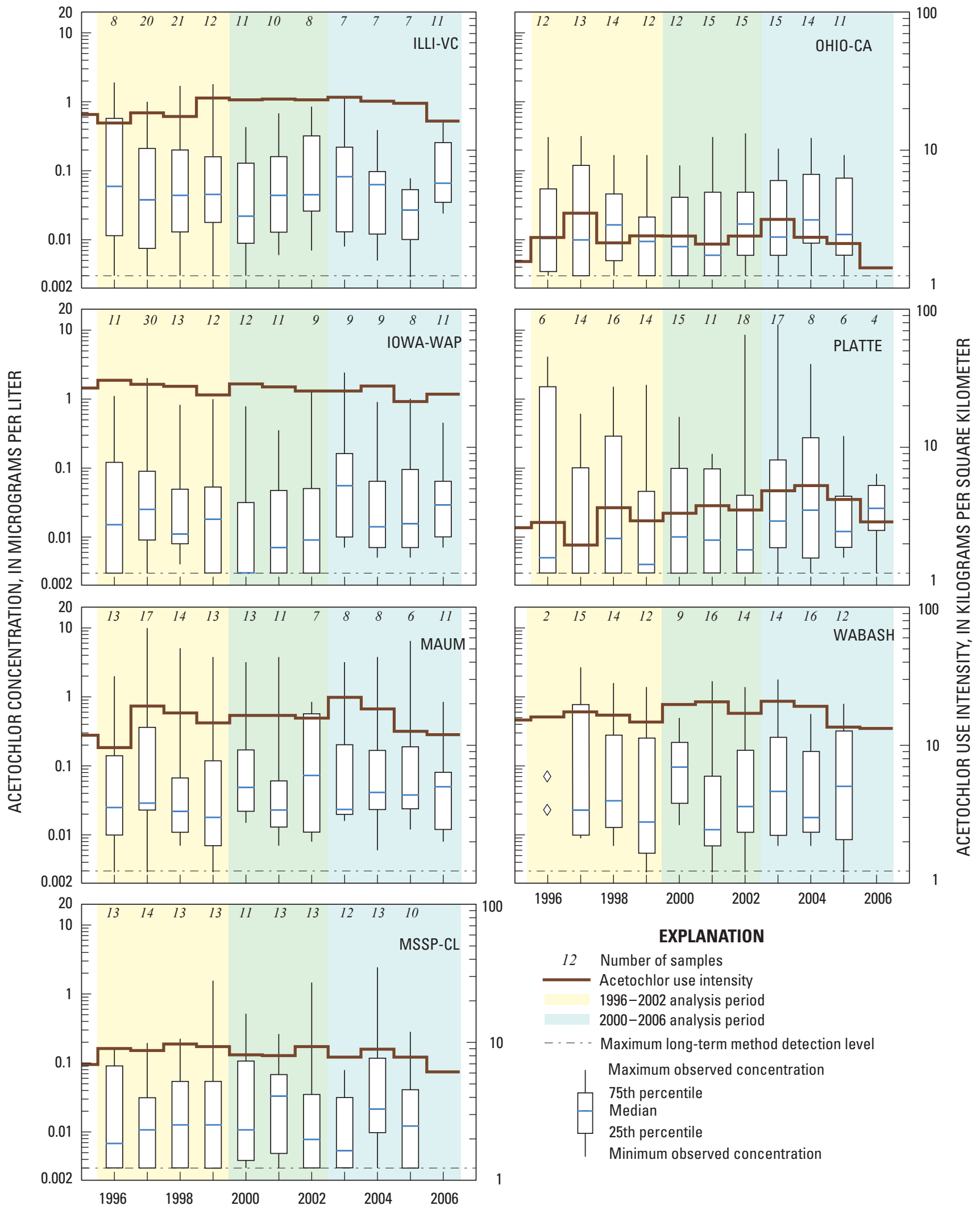

Figure 10. Acetochlor use intensity and stream-water concentrations for selected trend sites in the Corn Belt, 1996-2006. 
Table 12. Flow-adjusted trends in acetochlor concentration and changes in acetochlor use intensity for selected sites for the 1996-2002 and 2000-2006 trend analysis periods.

[Bold type indicates significant $(p \leq 0.10)$ trends or changes in use intensity]

\begin{tabular}{|c|c|c|c|c|}
\hline \multirow{2}{*}{$\begin{array}{l}\text { Site map number } \\
\text { and short name } \\
\text { (see table 1) }\end{array}$} & \multicolumn{2}{|c|}{ 1996-2002 } & \multicolumn{2}{|c|}{ 2000-2006 } \\
\hline & $\begin{array}{l}\text { Flow-adjusted trend } \\
\text { (percent per year) }\end{array}$ & $\begin{array}{l}\text { Change in use } \\
\text { (percent per year) }\end{array}$ & $\begin{array}{l}\text { Flow-adjusted trend } \\
\text { (percent per year) }\end{array}$ & $\begin{array}{c}\text { Change in use } \\
\text { (percent per year) }\end{array}$ \\
\hline 2. OHIO-CA & 10.5 & -3.0 & -4.0 & -5.5 \\
\hline 6. WABASH & -7.6 & 2.6 & 0.0 & -6.7 \\
\hline 7. OHIO-GRCH & -0.9 & 0.6 & -2.4 & -6.1 \\
\hline 13. MAUM & 6.6 & 4.1 & -2.3 & -4.7 \\
\hline 16. MSSP-CL & -0.8 & -0.9 & -7.2 & -3.2 \\
\hline 20. IOWA-WAP & -8.4 & -2.0 & 18.1 & -3.2 \\
\hline 25. ILLI-VC & 14.7 & 6.9 & -0.0 & -4.3 \\
\hline 26. MSSP-GR & -3.8 & -0.2 & 3.8 & -2.8 \\
\hline 29. PLATTE & -4.1 & 6.8 & 4.6 & 0.6 \\
\hline 30. MIZZ-HE & -0.7 & 0.7 & 8.8 & -4.4 \\
\hline 31. MSSP-TH & 1.3 & 0.4 & 7.6 & -3.4 \\
\hline
\end{tabular}

\section{Metolachlor}

Metolachlor concentrations were broadly decreasing during 1996-2002 (fig. 11). Of the 31 sites analyzed, 27 had downtrends; of these, 14 were highly significant and 5 were significant. Although four sites had uptrends indicated, none were significant. When compared to atrazine (fig. 7) and especially acetochlor (fig. 9), there were many more and larger significant downtrends in metolachlor concentrations during 1996-2002. Trends in metolachlor during 2000-2006 were somewhat mixed, although there were still more downtrends than uptrends. Trends were significant at only six sites during 2000-2006; of these, four were downtrends. The significant downtrends for 2000-2006 were similar to trends for 19962002 for the same sites, but the two significant uptrends for the latter period were in contrast to highly significant downtrends for 1996-2002 at the same sites.

\section{Ohio River and Great Lakes Basins (sites 1-13)}

Highly significant downtrends in metolachlor concentration occurred for sites in the Wabash River Basin (sites 3-6) and the downstream Ohio River Basin site OHIO-GRCH (site 7) during 1996-2002. However, since the upstream Ohio River site OHIO-CA (site 2) had a smaller though still significant downtrend, it effectively diluted the downtrend at OHIO-GRCH, which was substantially smaller in magnitude (8 pct/yr) than the downtrend of about $17 \mathrm{pct} / \mathrm{yr}$ at WABASH (site 6). Significant downtrends also occurred during 19962002 for the three Maumee River Basin sites (sites 11-13), and those trends were similar in magnitude to the downtrends for the Wabash River Basin sites. There were no significant uptrends during 1996-2002 at any of the Ohio River or Great
Lakes Basins sites. There were fewer significant trends in metolachlor concentrations during 2000-2006 in the Ohio River and Great Lakes Basins. A significant downtrend occurred at small tributary site AUGL (site 12), and significant uptrends occurred at SUG-NP and STJOS (sites 4 and 11, respectively), which also are small tributary sites.

\section{Mississippi and Missouri River Basins (sites 14-31)}

There were substantial (about 10-15 pct/yr) and highly significant downtrends in metolachlor concentration at MSSP-GR and MSSP-TH (sites 26 and 31), and at all 3 major tributaries to MSSP-GR (MSSP-CL, IOWA-WAP, and ILLI-VC; sites 16, 20, and 25) during 1996-2002 (fig. 11). There also were highly significant downtrends at IOWA-ROW and SFIOWA (sites 18 and 19) and significant downtrends at Illinois River Basin sites ILLI-OTT and SANG (sites 23 and 24). There were uptrends at SUG-MIL and DPLAI (sites 21 and 22), but they were not significant and both sites are small tributaries to the Illinois Rver without much influence on total flows and fluxes. Although there were downtrends for the Missouri River Basin sites, all were nonsignificant with the exception of MAPLE (site 28), and the trend for downstream MIZZ-HE (site 30) was small and nonsignificant, contributing to a reduction in the magnitude of the trend at MSSP-TH compared to MSSP-GR. During 2000-2006, there again were significant downtrends at MSSP-GR of about $9 \mathrm{pct} / \mathrm{yr}$ and at several tributary sites, including ILLI-VC and SANG, as well as nonsignificant downtrends at numerous other tributary sites. There were no significant trends for the Missouri River Basin sites (sites 27-30) or the downstream Mississippi River site (site 31) during 2000-2006. 
Metolachlor

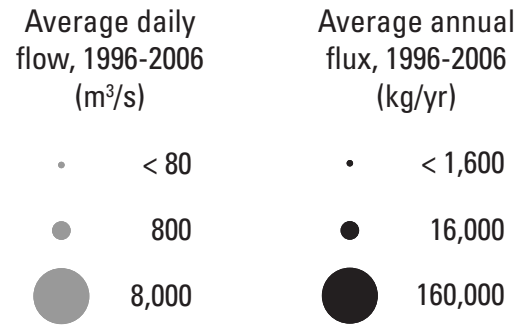

NA is not analyzed; > is greater than; $<$ is less than
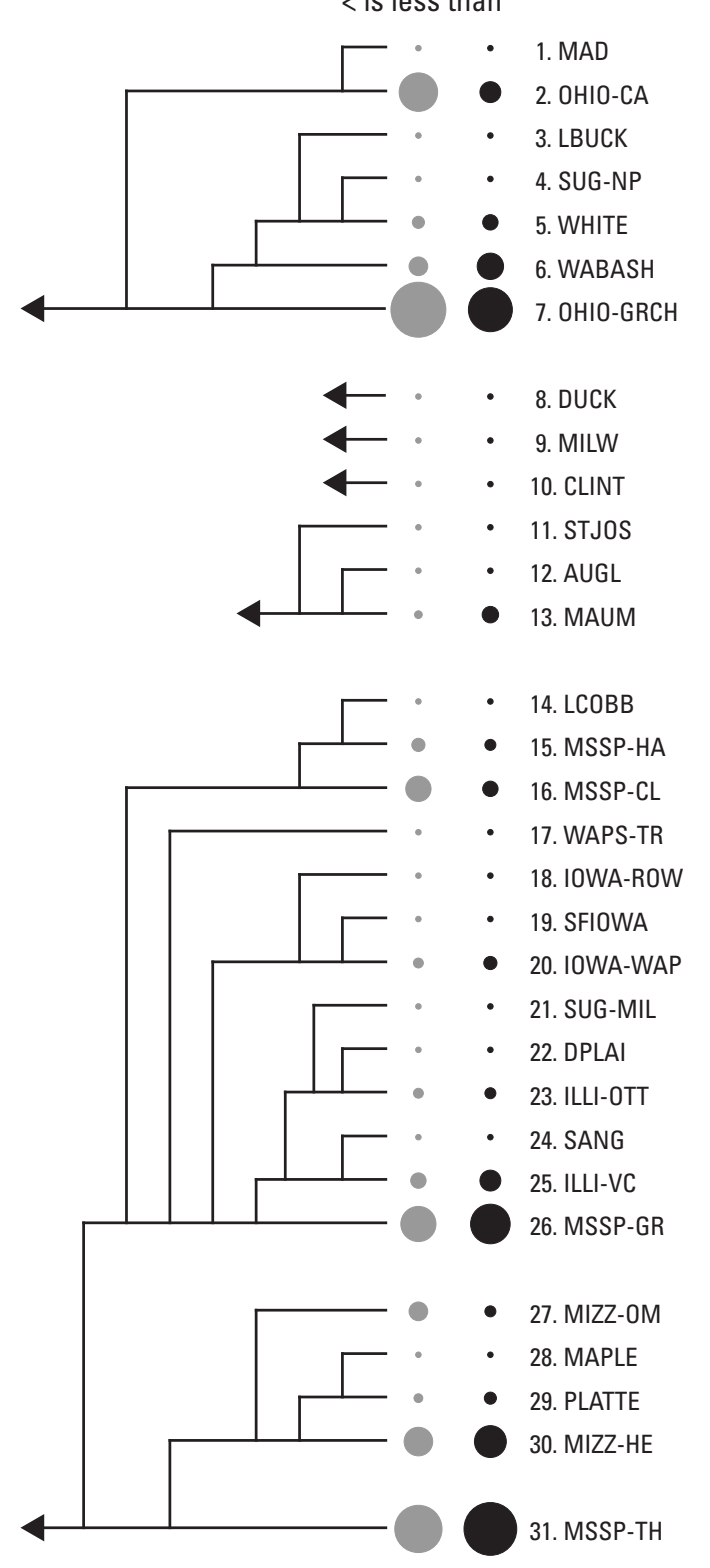

Flow-adjusted trends in concentration Estimated value I

90-percent confidence limits

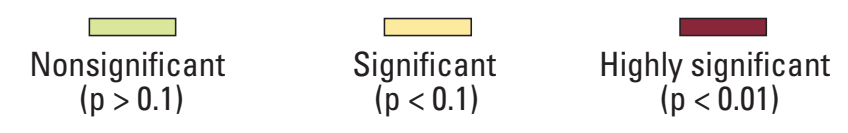

1996-2002
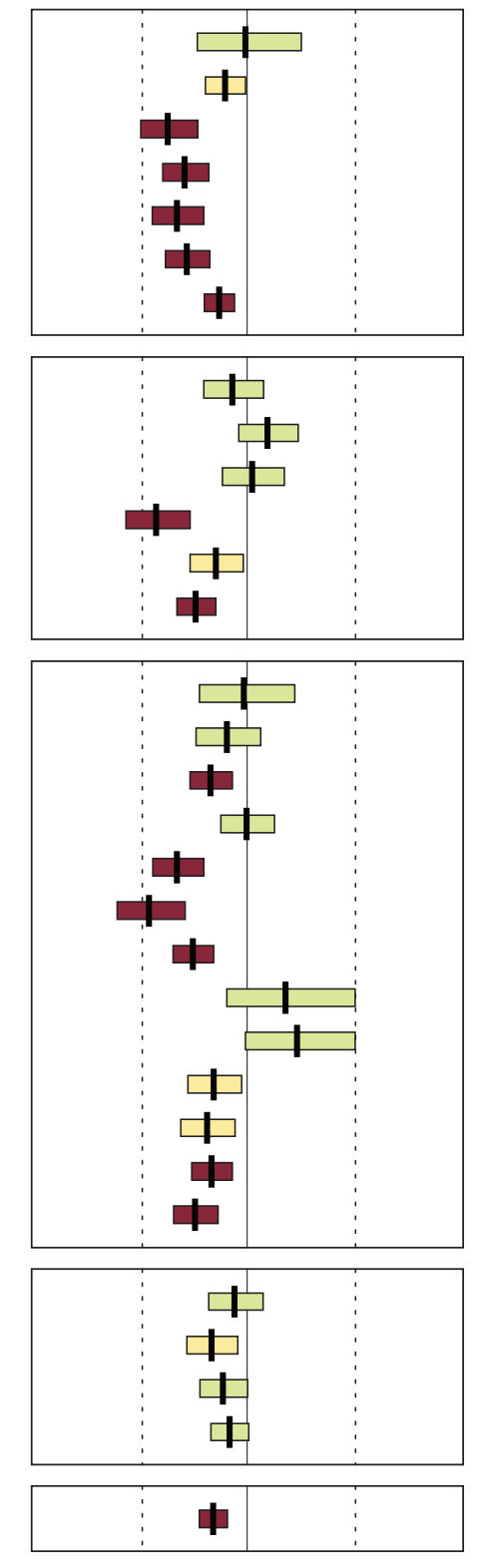

$+60-60$
2000-2006
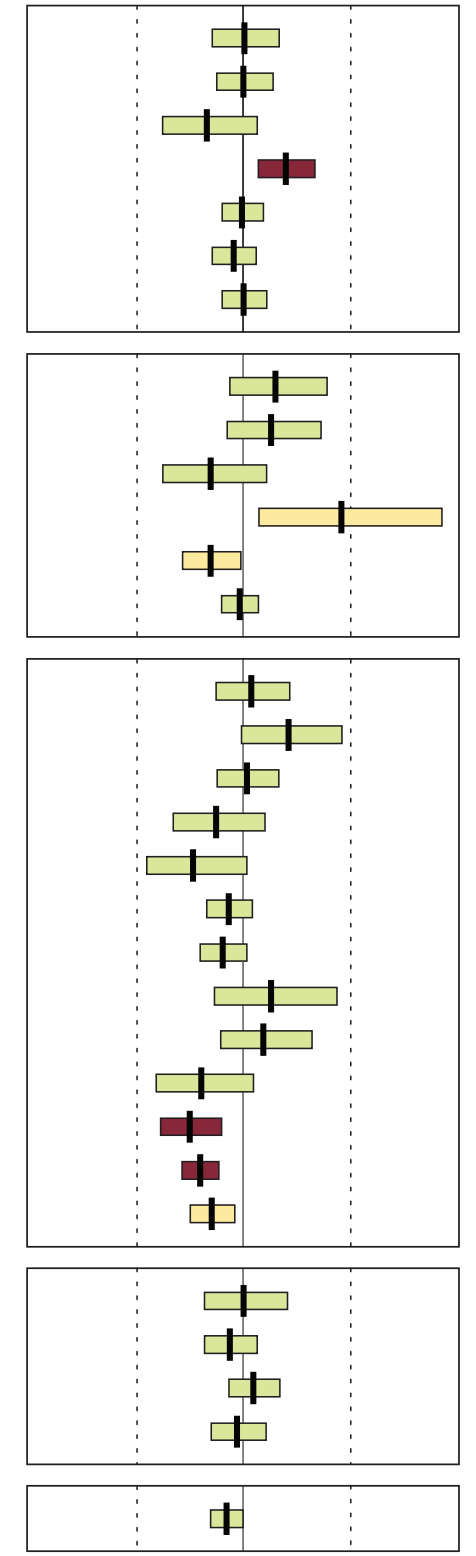

0

TREND, IN PERCENT PER YEAR

Figure 11. Flow-adjusted trends in metolachlor concentration for 1996-2002 and 2000-2006 analysis periods. 


\section{Trends in Relation to Changes in Use Intensity}

Metolachlor use decreased at all 11 use-trend sites during 1996-2002 (table 13, fig. 12). These decreases were due to the reductions in use of metolachlor mandated as part of the conditional registration for acetochlor. Part of this reduction was possible with the introduction of a reformulation of metolachlor ( $S$-metolachlor) that was introduced to the market in the late 1990s. $S$-metolachlor has a 30-percent lower application rate than previous formulations of metolachlor because of its greater potency.

Stream concentrations reflected the decrease in use as trends generally were downward and similar to changes in use during 1996-2002 (table 13). All but two sites had significant downtrends of similar magnitude in concentration and use. The PLATTE and MIZZ-HE also had downtrends in both use and concentration, but concentration downtrends were nonsignificant. During 2000-2006, use intensity also generally declined, but at less that half the rate at most sites, and the concentration trends were not significant at 9 of the 11 use-trend sites. The only major deviation from the pattern was at ILLI-VC, for which there was a significant downtrend of $11.9 \mathrm{pct} / \mathrm{yr}$ during 2000-2006, despite a nonsignificant decrease in use intensity for that site. There were nonsignificant concentration trends during 2000-2006 at MSSP-CL, IOWA-WAP, MIZZ-HE, and MSSP-TH despite significantly decreasing use, although all but one of the nonsignificant trends were downward. A possible explanation for the 2000-2006 results is that as use intensity decreases below a certain level, concentrations become lower and proportionally more variable (including more nondetections) and, as a result, do not provide clear indications of trend.

Table 13. Flow-adjusted trends in metolachlor concentration and changes in metolachlor use intensity for selected sites for the 1996-2002 and 2000-2006 trend analysis periods.

[Bold type indicates significant $(p \leq 0.10)$ trends or changes in use intensity]

\begin{tabular}{|c|c|c|c|c|}
\hline \multirow{2}{*}{$\begin{array}{l}\text { Site map number } \\
\text { and short name } \\
\text { (see table 1) }\end{array}$} & \multicolumn{2}{|c|}{ 1996-2002 } & \multicolumn{2}{|c|}{ 2000-2006 } \\
\hline & $\begin{array}{l}\text { Flow-adjusted trend } \\
\text { (percent per year) }\end{array}$ & $\begin{array}{c}\text { Change in use } \\
\text { (percent per year) }\end{array}$ & $\begin{array}{l}\text { Flow-adjusted trend } \\
\text { (percent per year) }\end{array}$ & $\begin{array}{c}\text { Change in use } \\
\text { (percent per year) }\end{array}$ \\
\hline 6. WABASH & -16.8 & -9.8 & -2.6 & -3.3 \\
\hline 7. OHIO-GRCH & -7.9 & -12.1 & 0.2 & -4.6 \\
\hline 20. IOWA-WAP & -15.2 & -10.1 & -5.7 & -12.2 \\
\hline 25. ILLI-VC & -10.0 & -11.7 & -11.9 & -2.0 \\
\hline 26. MSSP-GR & -14.6 & -11.9 & -8.6 & -5.3 \\
\hline 29. PLATTE & -6.8 & -13.0 & 2.9 & -2.6 \\
\hline
\end{tabular}




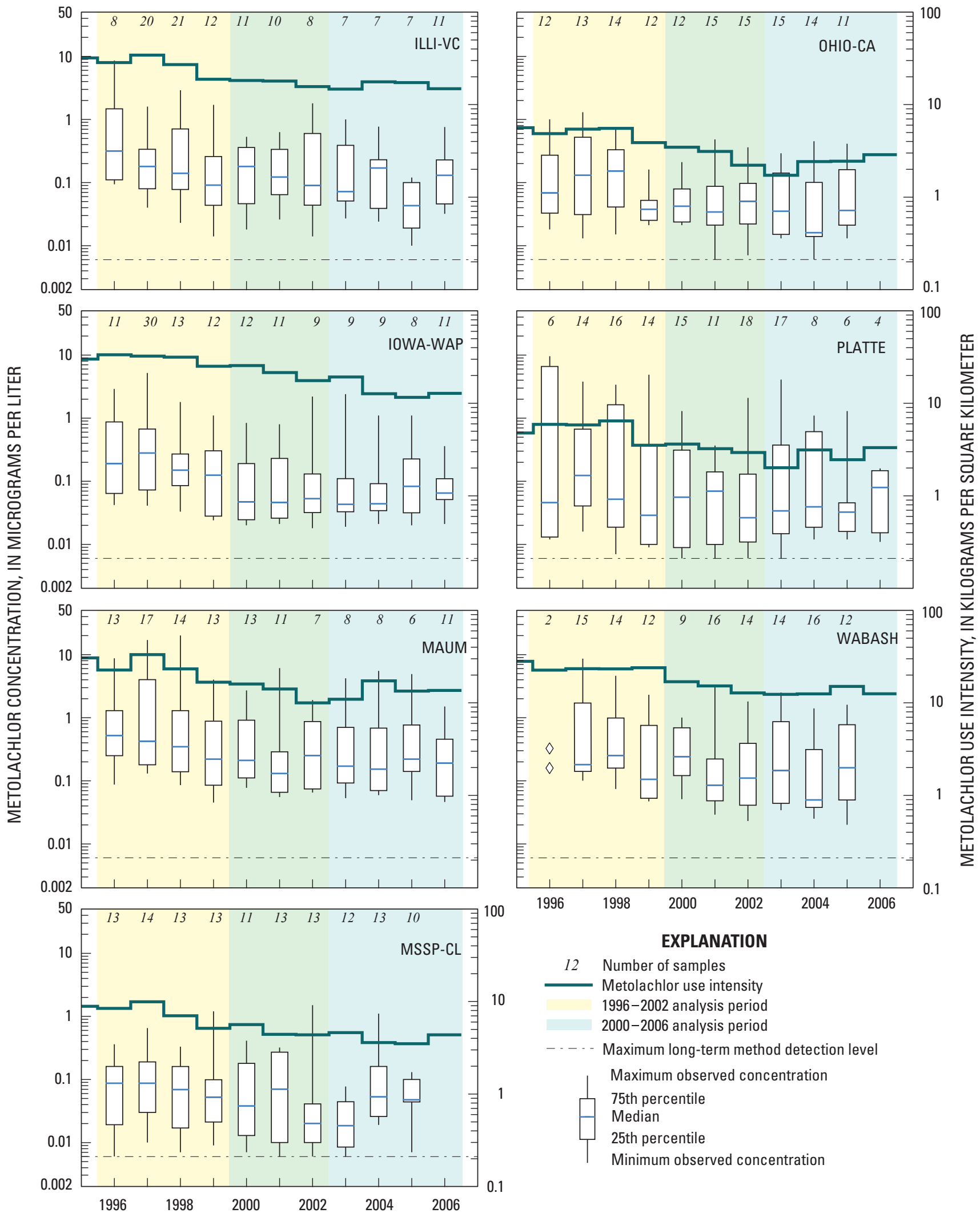

Figure 12. Metolachlor use intensity and stream-water concentrations for selected trend sites in the Corn Belt, 1996-2006. 


\section{Alachlor}

During 1996-2002, there were downtrends in alachlor concentrations at all 25 sites with sufficient data to compute trends. Of these, most (21 of 25 ) were highly significant, and most (19 of 25) were larger than $25 \mathrm{pct} / \mathrm{yr}$ (fig. 13). During 2000-2006, significant trends were found at only five sites and all were downtrends (two were significant, and three were highly significant). At many of the sites, the median concentration was below the LT-MDL in later years, thus further reductions in alachlor concentrations in streams may not have been detected at many sites.

\section{Ohio River and Great Lakes Basins (sites 1-13)}

During 1996-2002, all nine of the trends in alachlor concentration for sites 1-13 that could be analyzed were downward, all were substantial (greater than about $28 \mathrm{pct} / \mathrm{yr}$ in magnitude), and all were highly significant or significant. During 2000-2006, downtrends still prevailed, but five of nine trends were nonsignificant. There still were significant downtrends for the downstream Ohio River Basin site OHIOGRCH (site 7) as well as SUG-NP (site 4), a small tributary in the Wabash River Basin, and highly significant downtrends for two Maumee River Basin sites, AUGL and MAUM (sites 12 and 13).

\section{Mississippi and Missouri River Basins (sites 14-31)}

Downtrends in alachlor concentrations were found at all 16 sites with sufficient data for 1996-2002, most of which were highly significant (13) or significant (2) (fig. 13). The largest trend magnitudes (greater than $40 \mathrm{pct} / \mathrm{yr}$ ) were for small tributaries in the upper Mississippi and Iowa River Basins (LCOBB, IOWA-ROW, and SFIOWA; sites 14, 18, and 19). Downtrends at MSSP-GR (site 26) and all three main tributaries to that site (MSSP-CL, IOWA-WAP, and ILLI-VC; sites 16,20 , and 25) were somewhat smaller, ranging from about 25 to $35 \mathrm{pct} / \mathrm{yr}$ (fig. 13). The downtrend magnitudes for the Missouri River Basin sites (sites 27-30) and the downstream site MSSP-TH (site 31) tended to be smaller than the other trends, ranging from about 15 to $25 \mathrm{pct} / \mathrm{yr}$. During 2000-2006, trends at 11 of 12 sites that could be analyzed were nonsignificant, although there was a highly significant downtrend at MSSP-CL.

\section{Trends in Relation to Changes in Use Intensity}

In 1990, alachlor was the third most heavily used herbicide in the Corn Belt. However, because of the introduction of acetochlor for corn and the introduction of glyphosateresistant soybeans, the use of alachlor has steadily declined since 1994. Alachlor use at the 11 use-trend sites decreased substantially during both analysis periods at all sites, with significant downtrends for all but 3 of 22 cases (table 14, fig. 14). During 1996-2002, trends in stream concentrations also were all significant downtrends and generally similar in magnitude to the decreases in alachlor use during that time. During 2000-2006, downtrends at OHIO-GRCH, MAUM, and MSSP-CL also were similar in magnitude to decreases in alachlor use, but concentration trends for the remaining eight usetrend sites were not significant, despite substantial decreases in use intensity. As discussed previously for metolachlor, there may be a level below which further decreases in alachlor-use intensity do not result in a clearly discernable decrease in concentration. 


\section{Alachlor}

Average daily

flow, 1996-2006

$\left(\mathrm{m}^{3} / \mathrm{s}\right)$

$<80$

- 800

8,000
Average annual

flux, 1996-2006

$(\mathrm{kg} / \mathrm{yr})$

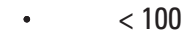

- 1,000

10,000

NA is not analyzed; > is greater than; $<$ is less than

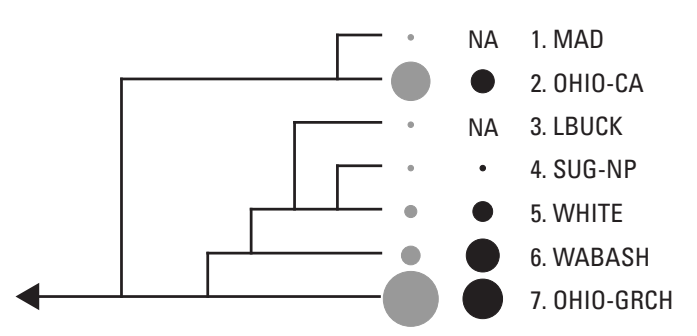

4 - 4 DUCK

$\longleftarrow$ NA 9. MILW

$\longleftarrow$ NA 10. CLINT
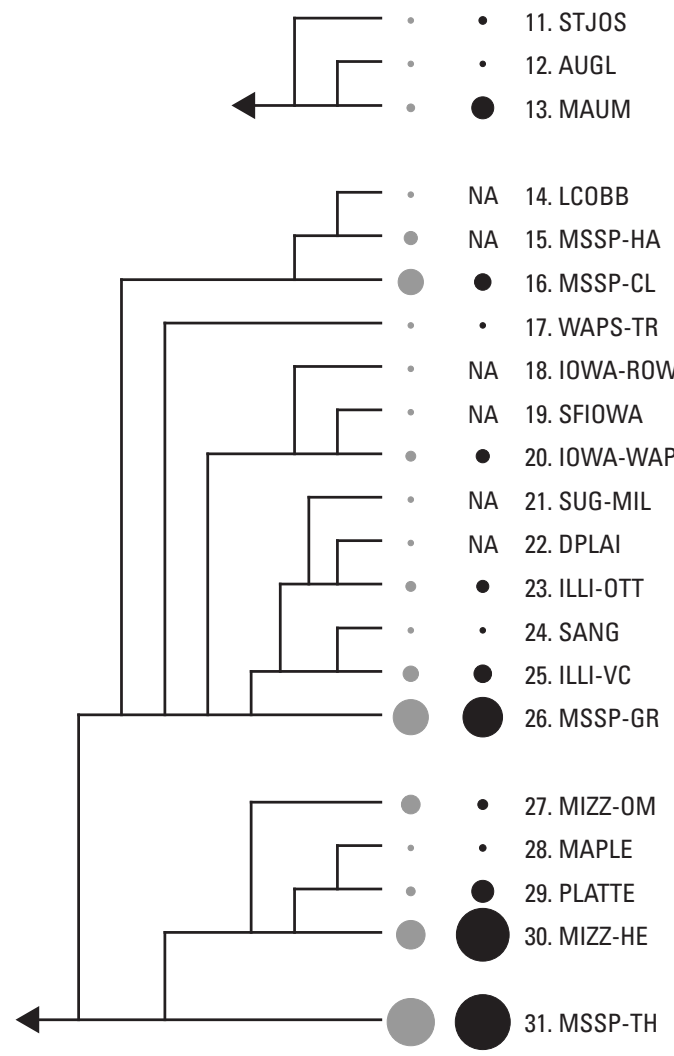

.

Flow-adjusted trends in concentration

Estimated value

I

90-percent confidence limits

$\begin{array}{ccc}\begin{array}{c}\text { Nonsignificant } \\ (p>0.1)\end{array} & \text { Significant } & \text { Highly significant } \\ & (p<0.1) & (p<0.01)\end{array}$

1996-2002
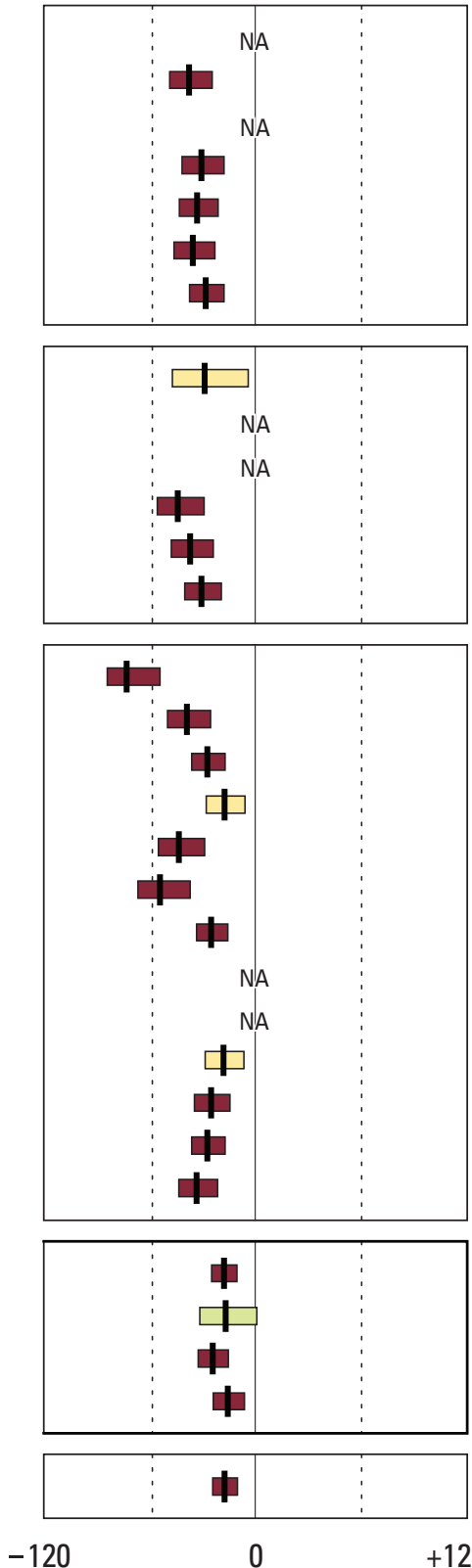

$+120-120$
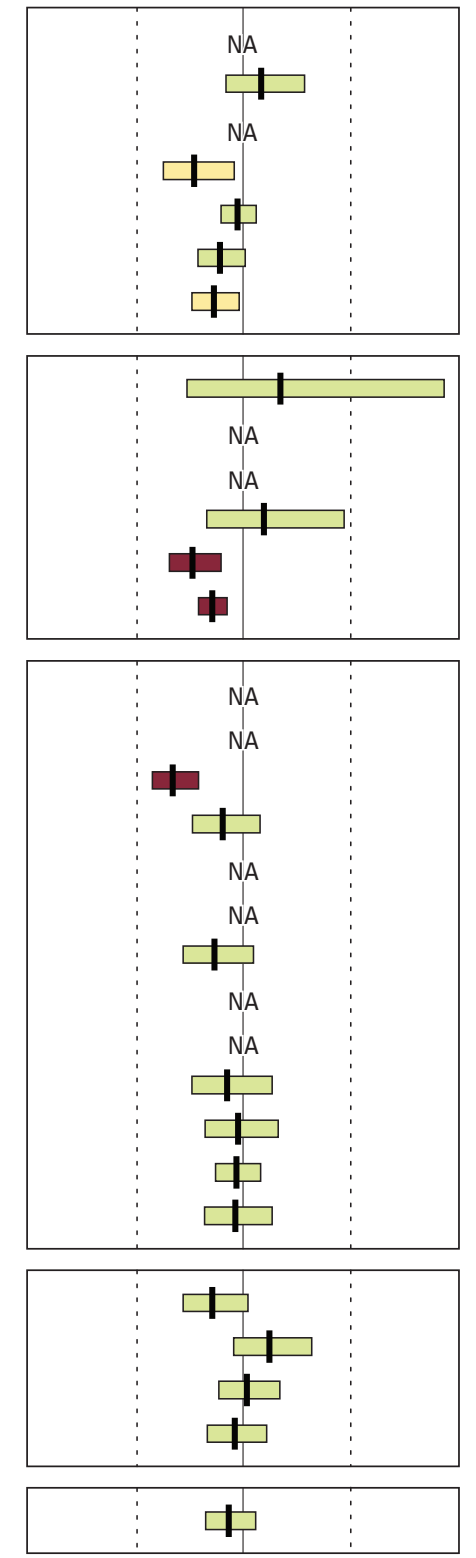

0

$+120$

TREND, IN PERCENT PER YEAR

Figure 13. Flow-adjusted trends in alachlor concentration for 1996-2002 and 2000-2006 analysis periods. 
Table 14. Flow-adjusted trends in alachlor concentration and changes in alachlor use intensity for selected sites for the 1996-2002 and 2000-2006 trend analysis periods.

[Bold type indicates significant $(\mathrm{p} \leq 0.10)$ trends or changes in use intensity]

\begin{tabular}{|c|c|c|c|c|}
\hline \multirow{2}{*}{$\begin{array}{l}\text { Site map number } \\
\text { and short name } \\
\text { (see table 1) }\end{array}$} & \multicolumn{2}{|c|}{ 1996-2002 } & \multicolumn{2}{|c|}{ 2000-2006 } \\
\hline & $\begin{array}{l}\text { Flow-adjusted trend } \\
\text { (percent per year) }\end{array}$ & $\begin{array}{c}\text { Change in use } \\
\text { (percent per year) }\end{array}$ & $\begin{array}{l}\text { Flow-adjusted trend } \\
\text { (percent per year) }\end{array}$ & $\begin{array}{l}\text { Change in use } \\
\text { (percent per year) }\end{array}$ \\
\hline 2. OHIO-CA & -37.7 & -26.9 & 10.2 & -16.0 \\
\hline 6. WABASH & -35.7 & -26.8 & -12.8 & -25.2 \\
\hline 7. OHIO-GRCH & -28.3 & -26.2 & -16.2 & -16.5 \\
\hline 13. MAUM & -30.6 & -34.9 & -17 & -21.1 \\
\hline 16. MSSP-CL & -27.4 & -20.8 & -38.9 & -27.9 \\
\hline 20. IOWA-WAP & -25.1 & -15.4 & -15.9 & -5.6 \\
\hline 25. ILLI-VC & -27.4 & -16.0 & -3.6 & -6.9 \\
\hline 26. MSSP-GR & -33.3 & -19.5 & -4.3 & -14.3 \\
\hline 29. PLATTE & -24.3 & -17.0 & 2.1 & -23.6 \\
\hline 30. MIZZ-HE & -15.7 & -15.3 & -4.6 & -15.5 \\
\hline 31. MSSP-TH & -17.4 & -16.8 & -7.8 & -15.2 \\
\hline
\end{tabular}




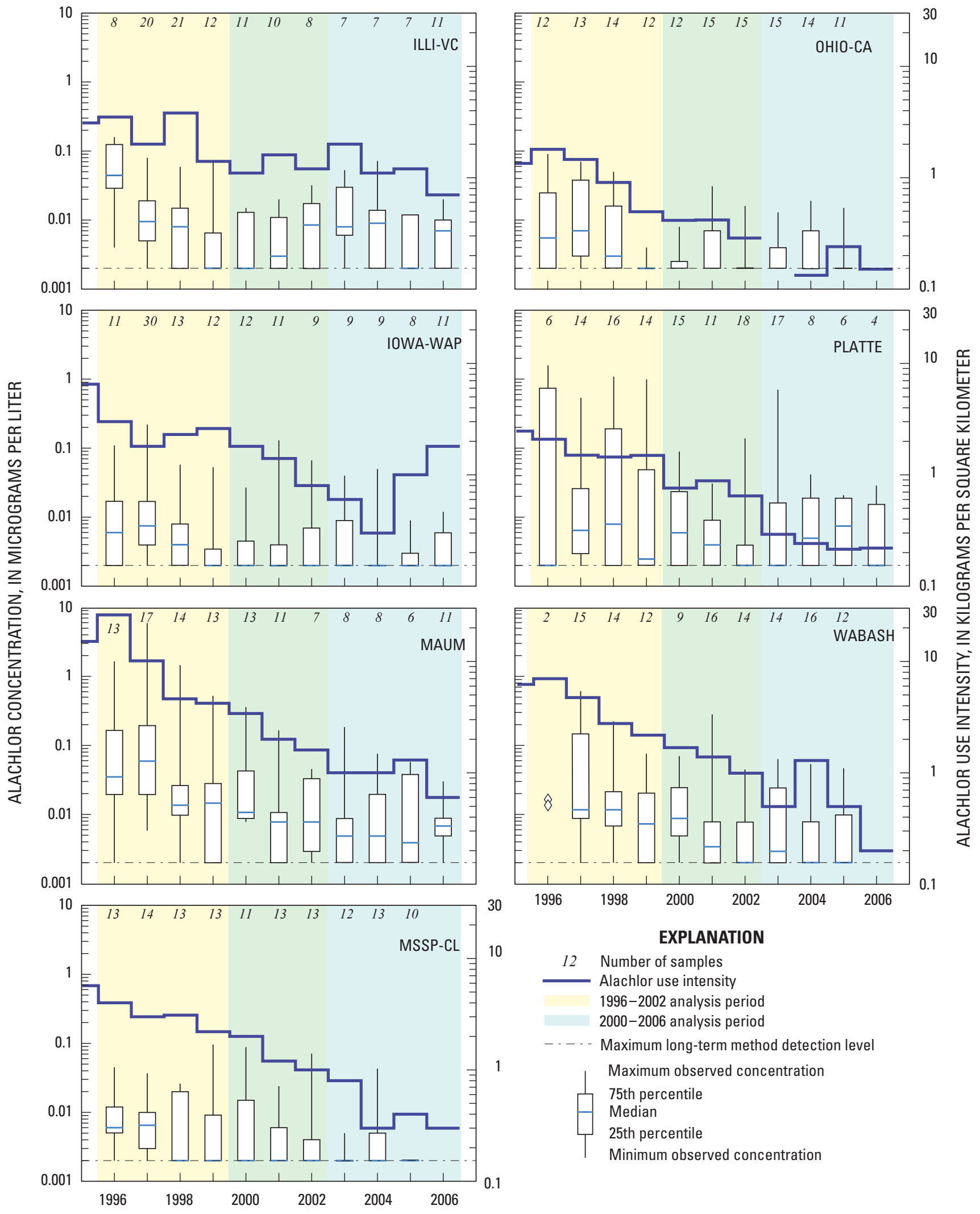

Figure 14. Alachlor use intensity and stream-water concentrations for selected trend sites in the Corn Belt, 1996-2006. 


\section{Cyanazine}

Trends in cyanazine concentrations during 1996-2002 were the greatest magnitude of all the pesticides evaluated for this study. There were highly significant downtrends at all 25 sites with sufficient data, and most (18 of 25) were larger than $40 \mathrm{pct} / \mathrm{yr}$ (fig. 15). The smallest trend magnitudes occurred for the Great Lakes and upper Mississippi River Basin sites (sites 8-16), where 5 of the downtrends were less than $40 \mathrm{pct} / \mathrm{yr}$. During 2000-2006 few sites had sufficient detections for trend testing, but large and highly significant downtrends occurred at eight of the ten sites with sufficient data, and smaller though still significant downtrends occurred for the remaining two sites.

\section{Trends in Relation to Changes in Use Intensity}

Cyanazine phaseout began in the mid-1990s as a result of environmental concerns about frequent detections in surface water and ground water. In 1992, more than 9 million $\mathrm{kg}$ of cyanazine were applied on corn acreage in the Corn Belt; by
2002 only about 4,500 $\mathrm{kg}$ were reported, and none was applied in 2005 or thereafter (proprietary pesticide use data obtained from DMRKynetec, St. Louis, Missouri).

Changes in cyanazine use within watersheds of the 11 use-trend sites (table 15, fig. l6) ranged from a decrease of $51.2 \mathrm{pct} / \mathrm{yr}$ for PLATTE during 1996-2002 to a decrease of $77.4 \mathrm{pct} / \mathrm{yr}$ for MAUM during 1996-2002. Because cyanazine use was essentially zero for the latter years, changes in use could not be computed for the 2000-2006 time period. There were strong downtrends in concentration for all of the sites during 1996-2002, and the trend magnitudes were similar to the use downtrends. 


\section{Cyanazine}

Average daily

flow, 1996-2006

$\left(\mathrm{m}^{3} / \mathrm{s}\right)$

$<80$

- 800

8,000
Average annual

flux, 1996-2006

$(\mathrm{kg} / \mathrm{yr})$

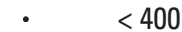

- 4,000

? 40,000

NA is not analyzed; > is greater than; $<$ is less than

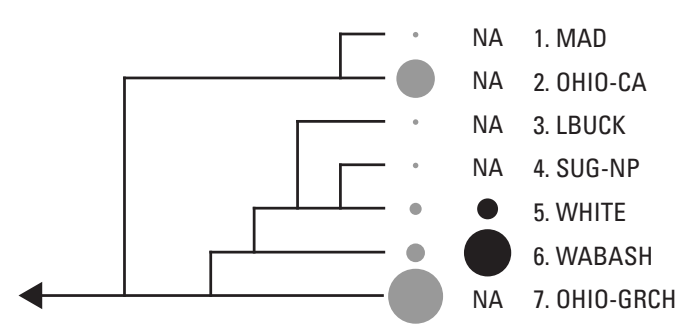

4 - 8. DUCK

$\longleftarrow$ NA 9. MILW

$\longleftarrow$ NA 10. CLINT

$\begin{array}{llll}\square & \text { NA } & \text { 11. STJOS } \\ & - & \bullet & \text { 12. AUGL } \\ & \bullet & \text { 13. MAUM }\end{array}$
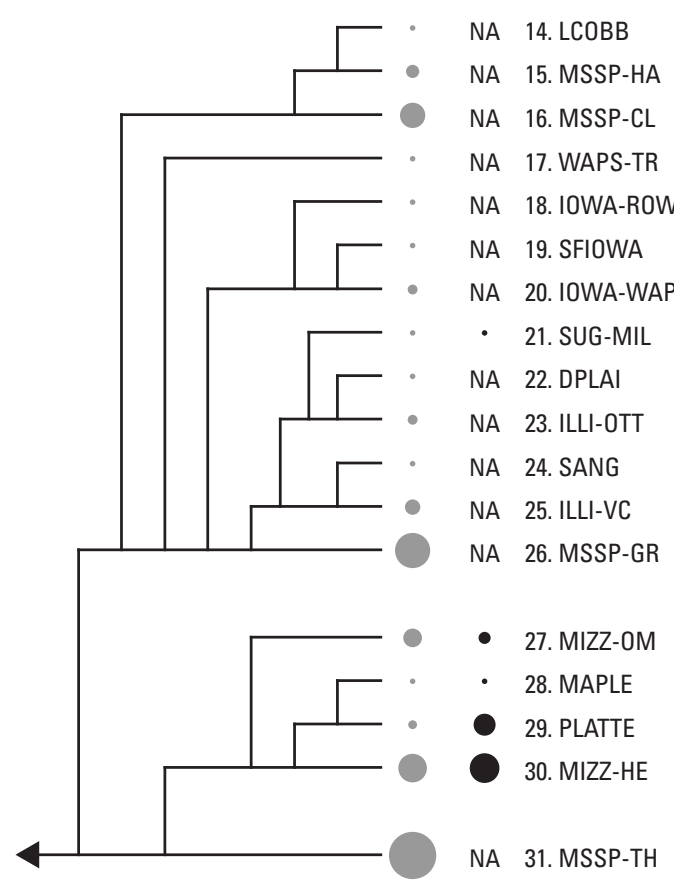

NA 31. MSSP-TH

Flow-adjusted trends in concentration

Estimated value

I

90-percent confidence limits

Nonsignificant

( $p>0.1)$

Significant

$(p<0.1)$

Highly significant

$(p<0.01)$

1996-2002
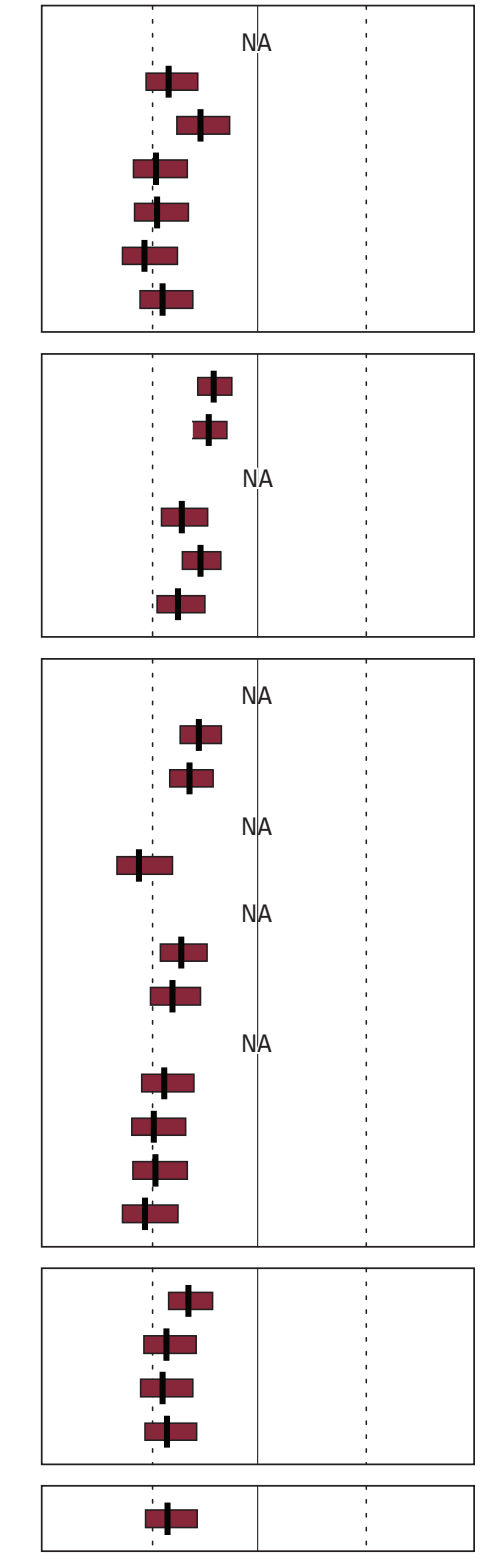

$+120-120$
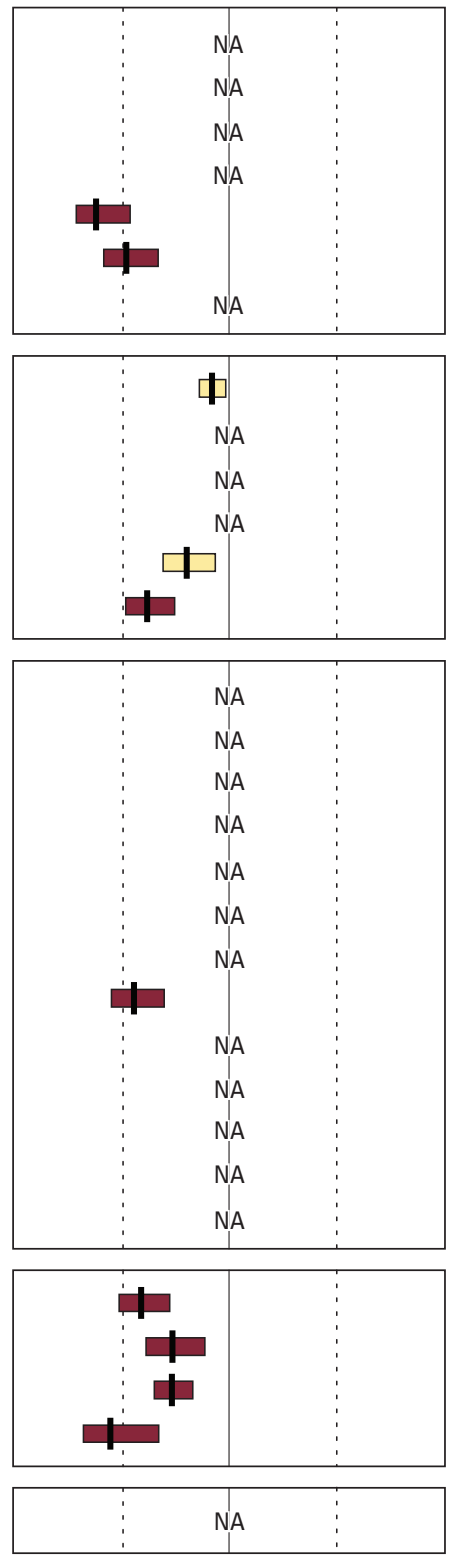

0

$+120$

TREND, IN PERCENT PER YEAR

Figure 15. Flow-adjusted trends in cyanazine concentration for 1996-2002 and 2000-2006 analysis periods. 
Table 15. Flow-adjusted trends in cyanazine concentration and changes in cyanazine use intensity for selected sites for the $1996-2002$ and 2000-2006 trend analysis periods.

[Bold type indicates significant $(p \leq 0.10)$ trends or changes in use intensity; na, not analyzed]

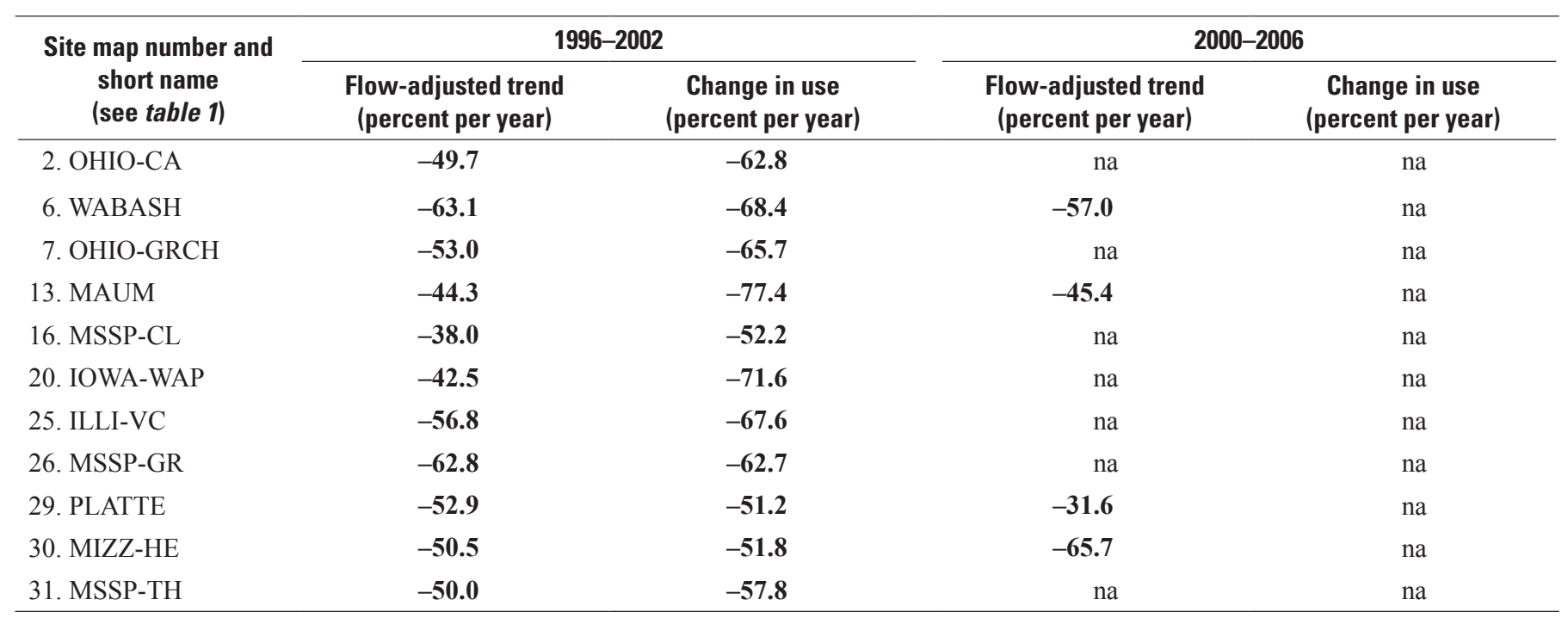




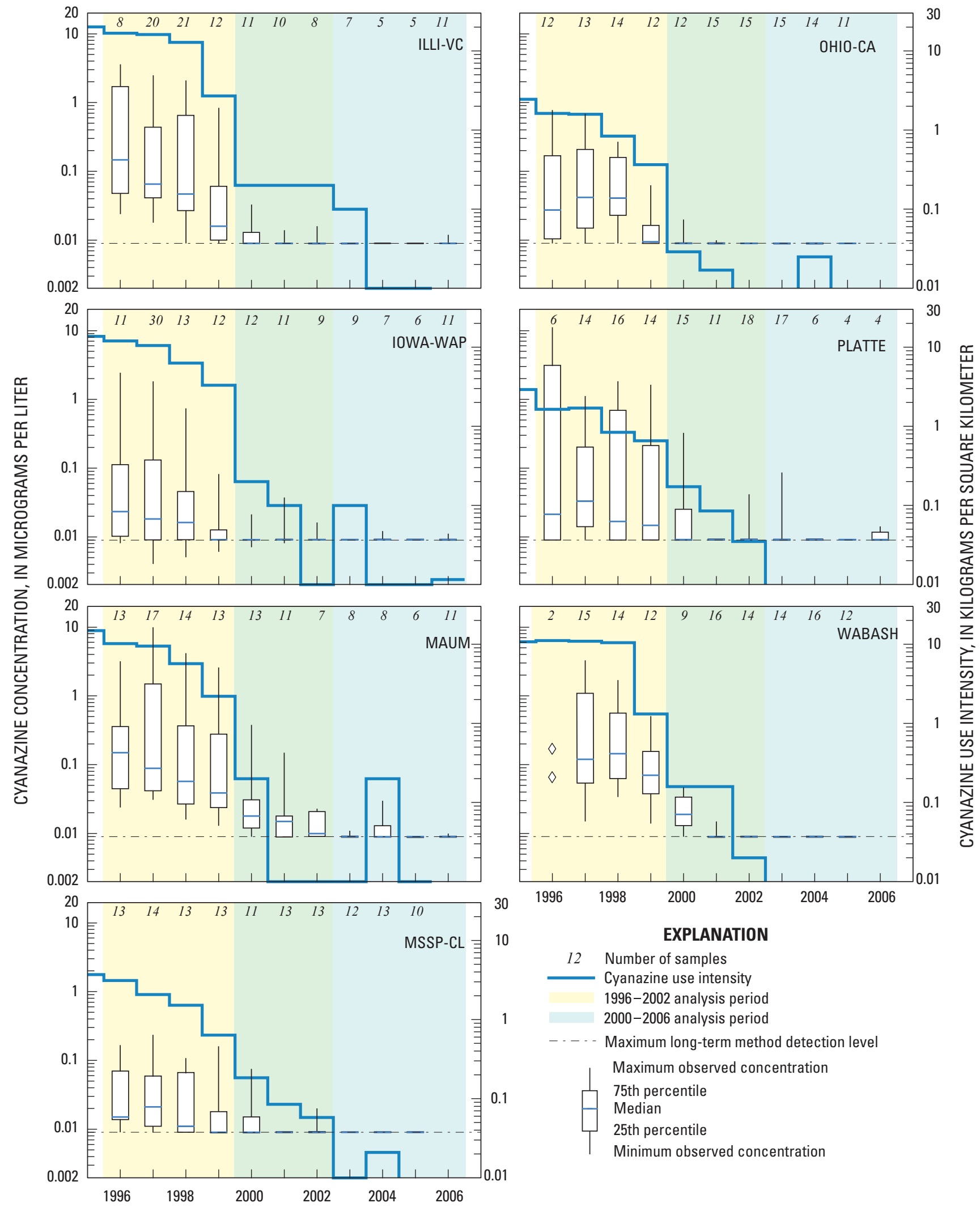

Figure 16. Cyanazine use intensity and stream-water concentrations for selected trend sites in the Corn Belt, 1996-2006. 


\section{EPTC}

Most of the sites had too few concentrations above detection limits to analyze trends in EPTC (table 3). Of ten sites that could be analyzed during the 1996-2002 period, eight had downtrends in EPTC concentrations, including significant downtrends at ILLI-VC, MIZZ-OM, and PLATTE (sites 25, 27, and 29) and a highly significant downtrend at MSSP-CL (site 16) (fig. 17). During 2000-2006, of two sites that could be analyzed, there was a highly significant downtrend at MIZZ-OM (site 27). There were no significant uptrends for any of the sites during either analysis period.

\section{Trends in Relation to Changes in Use Intensity}

Use of EPTC for weed control on corn fields declined over the study period as it was replaced by newer herbicides. In 1992, over 4.5 million $\mathrm{kg}$ of EPTC were applied in the Corn Belt, but this declined steadily to under 400,000 kg by 2005 .

Although use intensity for the use-trend sites generally declined (fig. 18), there were only five sites for which comparisons could be made between trends in EPTC concentration and use intensity, all for the 1996-2002 analysis period (table 16). For all five sites, the downtrends in EPTC concentration were similar in magnitude to the decreases in use intensity, although not all were individually significant. 
EPTC

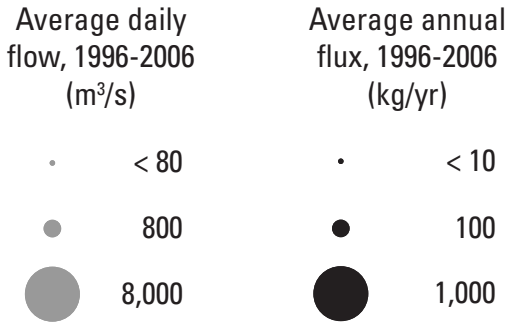

NA is not analyzed; > is greater than; $<$ is less than
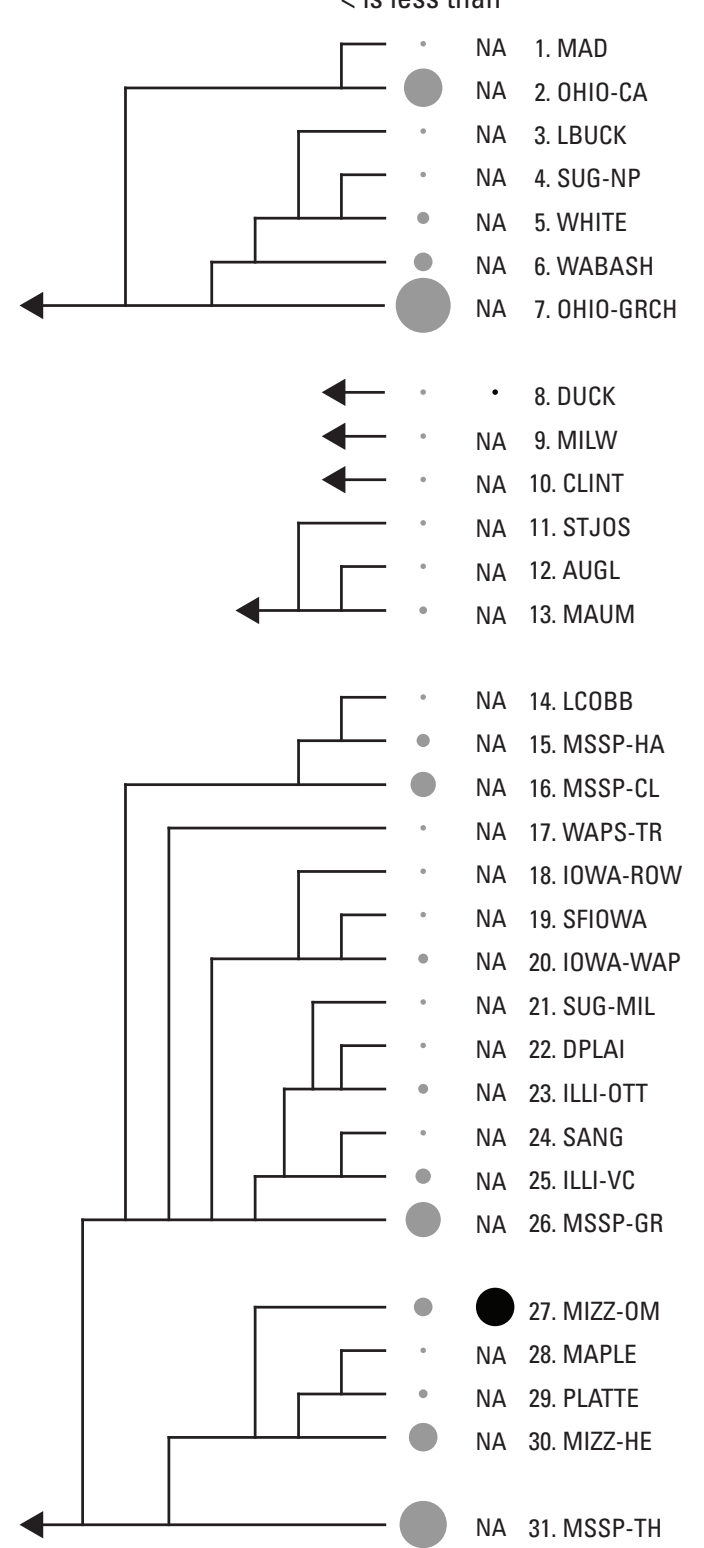

Flow-adjusted trends in concentration

Estimated value

I

90-percent confidence limits

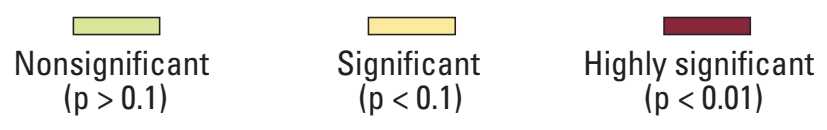

1996-2002
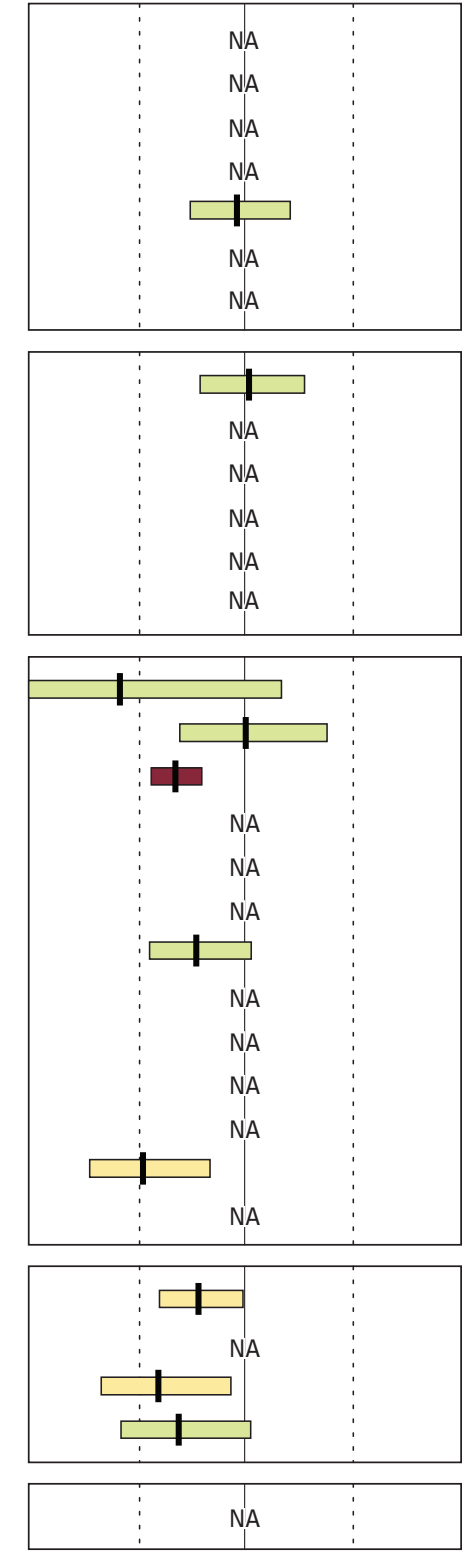

$+60-60$
$2000-2006$
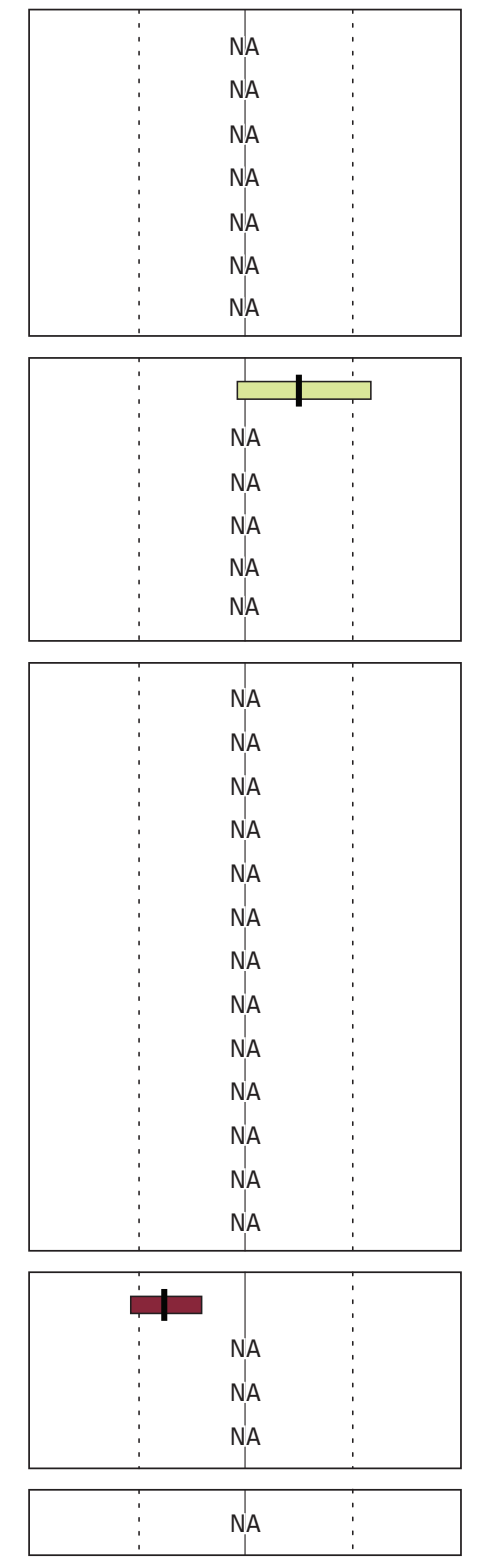

0

Figure 17. Flow-adjusted trends in EPTC concentration for 1996-2002 and 2000-2006 analysis periods. 


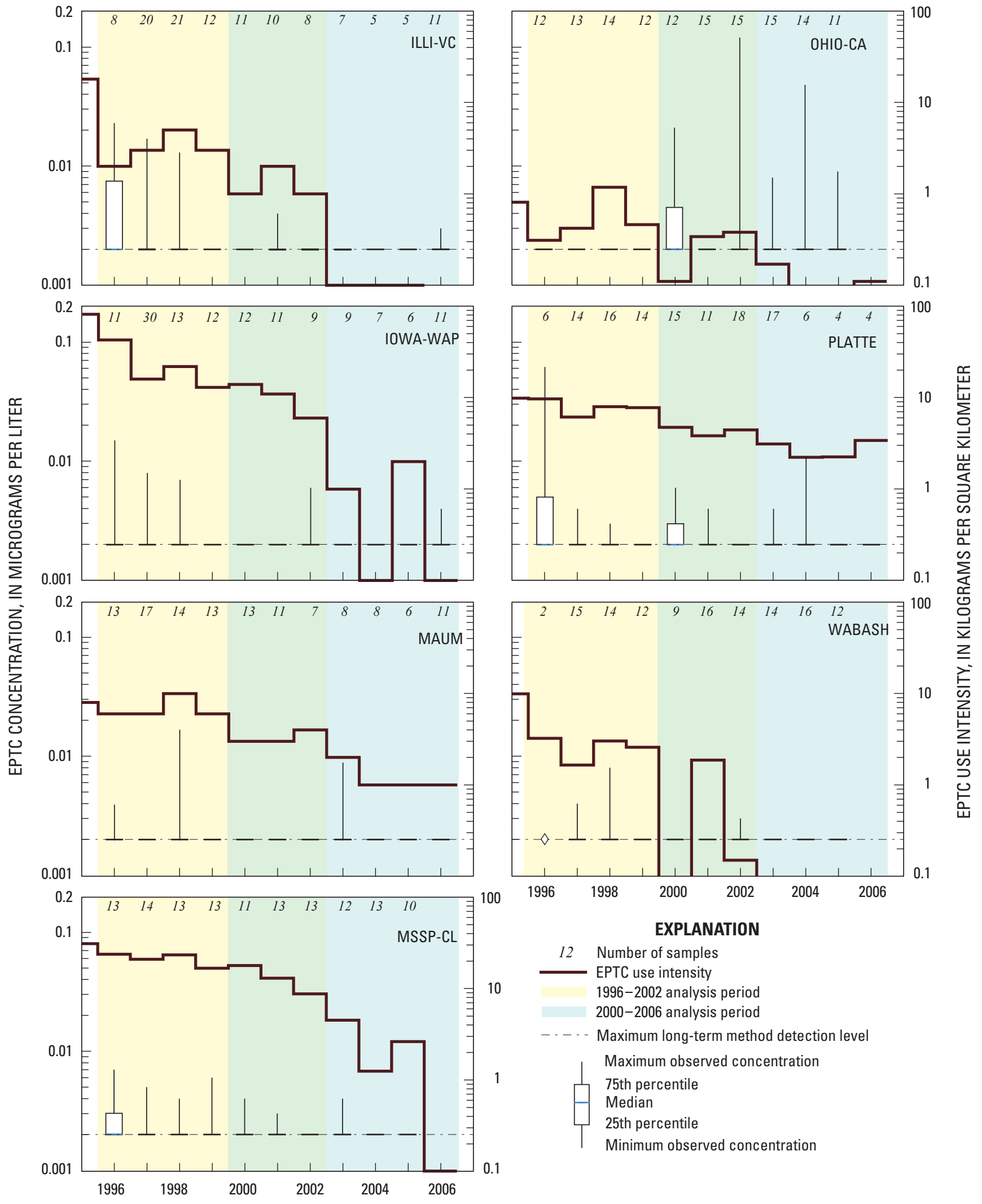

Figure 18. EPTC use intensity and stream-water concentrations for selected trend sites in the Corn Belt, 1996-2006. 
Table 16. Flow-adjusted trends in EPTC concentration and changes in EPTC use intensity for selected sites for the 1996-2002 and 2000-2006 trend analysis periods.

[Bold type indicates significant $(p \leq 0.10)$ trends or changes in use intensity; na, not analyzed]

\begin{tabular}{|c|c|c|c|c|}
\hline $\begin{array}{l}\text { Site map number } \\
\text { and short name } \\
\text { (see table 1) }\end{array}$ & \multicolumn{2}{|c|}{ 1996-2002 } & \multicolumn{2}{|c|}{ 2000-2006 } \\
\hline 20. IOWA-WAP & -13.5 & -20.8 & na & -57.5 \\
\hline 25. ILLI-VC & -28.3 & -26.0 & na & -38.4 \\
\hline
\end{tabular}




\section{Simazine}

Of the 28 sites analyzed, 21 had uptrends in simazine concentrations during 1996-2002, including 7 sites that had highly significant uptrends and 7 sites that had significant uptrends (fig. 19). There were 7 sites with downtrends during 1996-2002, four of which were significant or highly significant, but almost all were for sites with small basins that represent local conditions. Most (21 out of 27) of the trends for 2000-2006 also were uptrends, but the trends were smaller and less significant than the uptrends during the earlier time period. There only were five significant uptrends during the latter period. All 6 downtrends during 2000-2006 were relatively small (less than $12 \mathrm{pct} / \mathrm{yr}$ ) and only one downtrend was significant.

\section{Ohio River and Great Lakes Basins (sites 1-13)}

During 1996-2002, a highly significant uptrend in simazine concentration of about $12 \mathrm{pct} / \mathrm{yr}$ occurred for the downstream Ohio River Basin site OHIO-GRCH (site 7) (fig. 19). This was consistent with uptrends at two tributaries to OHIO-GRCH during that time: a highly significant uptrend of about $27 \mathrm{pct} / \mathrm{yr}$ at WABASH (site 6) and a smaller, but significant, uptrend of $8.5 \mathrm{pct} / \mathrm{yr}$ at $\mathrm{OHIO}-\mathrm{CA}$ (site 2). There also were significant uptrends at MAUM (site 13) and a tributary to MAUM, STJOS (site 11) during 1996-2002. There were highly significant downtrends only for two small tributary sites: LBUCK (site 3) in the Wabash River Basin, and DUCK (site 8) in the Great Lakes Basins. During 2000-2006, 11 of 13 trends were nonsignificant.

\section{Mississippi and Missouri River Basins (sites 14-31)}

Uptrends in simazine concentrations were found at 11 of 15 sites with sufficient data during 1996-2002, including highly significant uptrends at MSSP-GR (site 26) and a major tributary to MSSP-GR, ILLI-VC (site 25), as well as significant uptrends for four tributaries to ILLI-VC. However, other major tributaries to MSSP-GR-MSSP-CL and IOWA-WAP (sites 16 and 20) — had small and nonsignificant trends. The trend magnitude for MSSP-GR (about $37 \mathrm{pct} / \mathrm{yr}$ ) was larger than the magnitude at ILLI-VC (about $19 \mathrm{pct} / \mathrm{yr}$ ), despite the lack of uptrend at IOWA-WAP and a very small, nonsignificant uptrend for MSSP-CL. This may indicate that simazine sources from other tributaries contributed to the uptrend at MSSP-GR, or that the Illinois River is the major influence and the differences in trend magnitude primarily reflect uncertainty in trend estimates.

The highly significant uptrend for MSSP-TH (site 31) is consistent with the large uptrend for MSSP-GR, combined with a smaller uptrend at MIZZ-HE (site 30). Upstream of MIZZ-HE, there was no significant trend for MIZZ-OM (site 27), which contributes proportionally more streamflow than simazine flux, and the PLATTE (site 29) had a significant downtrend. The uptrend for MIZZ-HE may have been caused, at least in part, by sources downstream of the major tributaries to that site.

During 2000-2006, MSSP-GR and MIZZ-HE, as well as the Mississippi River site downstream of these sites (MSSP$\mathrm{TH}$ ), continued to have significant uptrends despite relatively weak and variable trends in upstream tributaries.

\section{Trends in Relation to Changes in Use Intensity}

Simazine is a commonly used herbicide that has lower total use and higher proportions of nonagricultural use when compared to the previously discussed herbicides (Gilliom and others, 2006). Simazine is used on a wider variety of crops relative to atrazine, acetochlor, alachlor, and metolachlor. During 1996-2002, significant uptrends occurred in both concentration and use for 5 of the 11 use-trend sites, three sites had significant concentration uptrends with nonsignifcant use trends, and two sites had nonsignificant trends for both concentration and use (table 17, fig. 20). During 2000-2006, 6 of the 11 sites had nonsignificant trends for both concentration and use. Four sites (IOWA-WAP, MSSP-GR, MIZZ-HE, and MSSP-TH) had significant concentration uptrends, despite nonsignificant decreases in use during that time. Concentration uptrends at these four sites may reflect increasing nonagricultural use of simazine in these basins. 


\section{Simazine}

Average daily

flow, 1996-2006

$\left(\mathrm{m}^{3} / \mathrm{s}\right)$

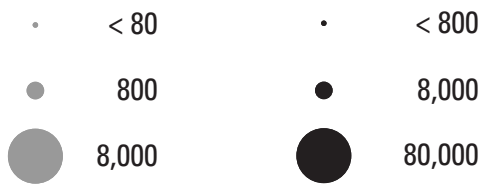

NA is not analyzed; > is greater than; $<$ is less than

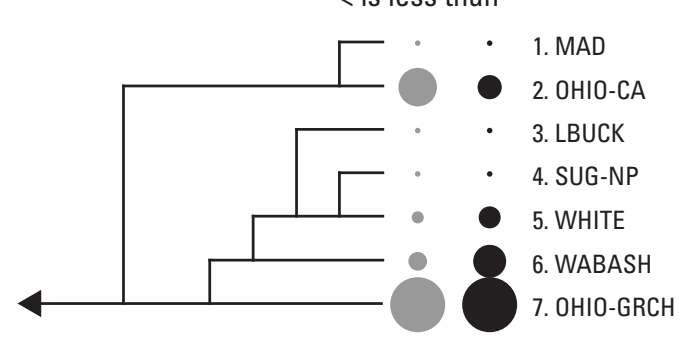

$\leftarrow \cdot$ 8. DUCK

$\leftarrow$ - 9. MILW

$\longleftarrow \cdot 10$. CLINT

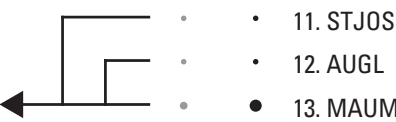
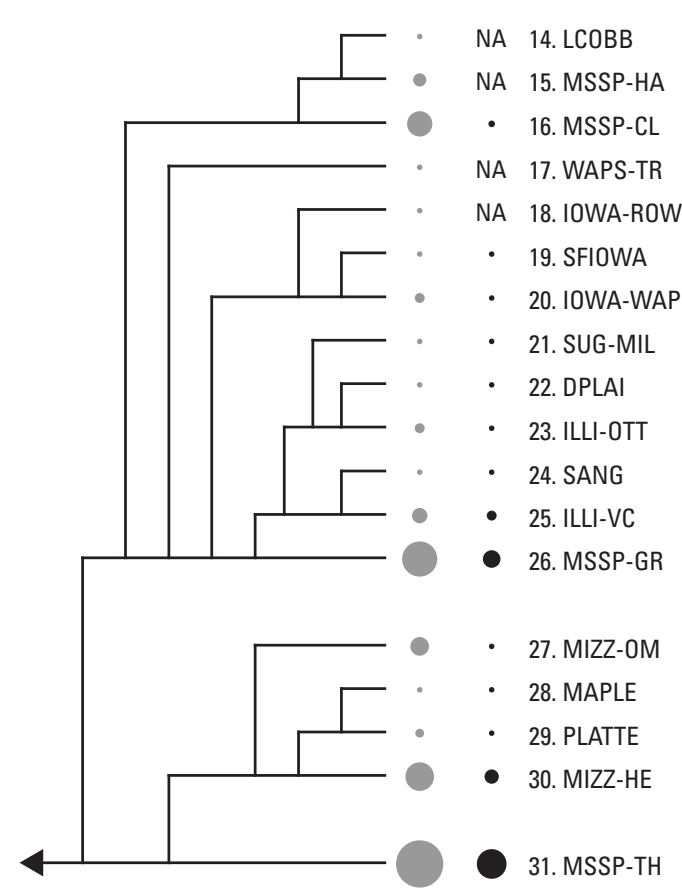

Flow-adjusted trends in concentration

Estimated value

I

90-percent confidence limits

$\begin{array}{ccc}\begin{array}{c}\text { Nonsignificant } \\ (p>0.1)\end{array} & \text { Significant } & \text { Highly significant } \\ & (p<0.1) & (p<0.01)\end{array}$

1996-2002
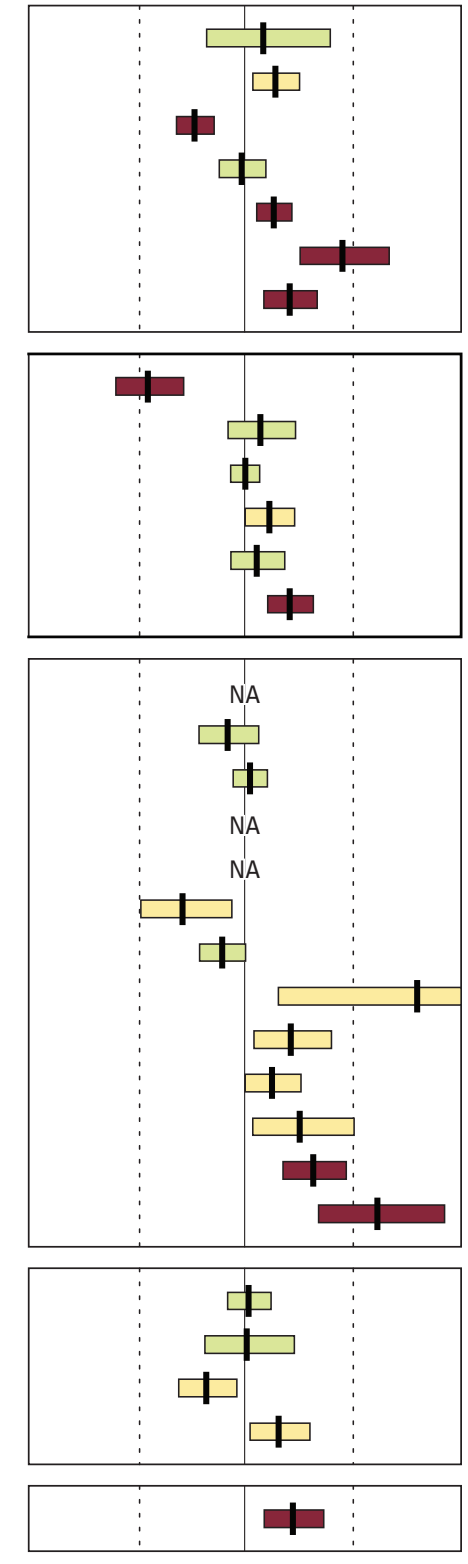

$+60-60$
2000-2006
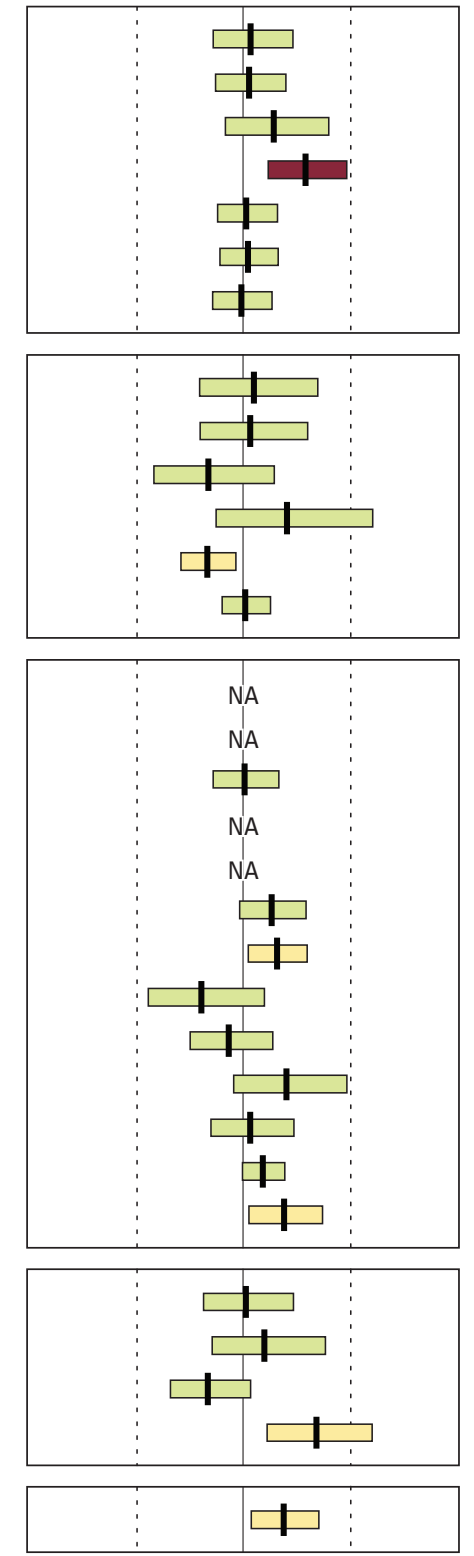

0

Figure 19. Flow-adjusted trends in simazine concentration for 1996-2002 and 2000-2006 analysis periods. 


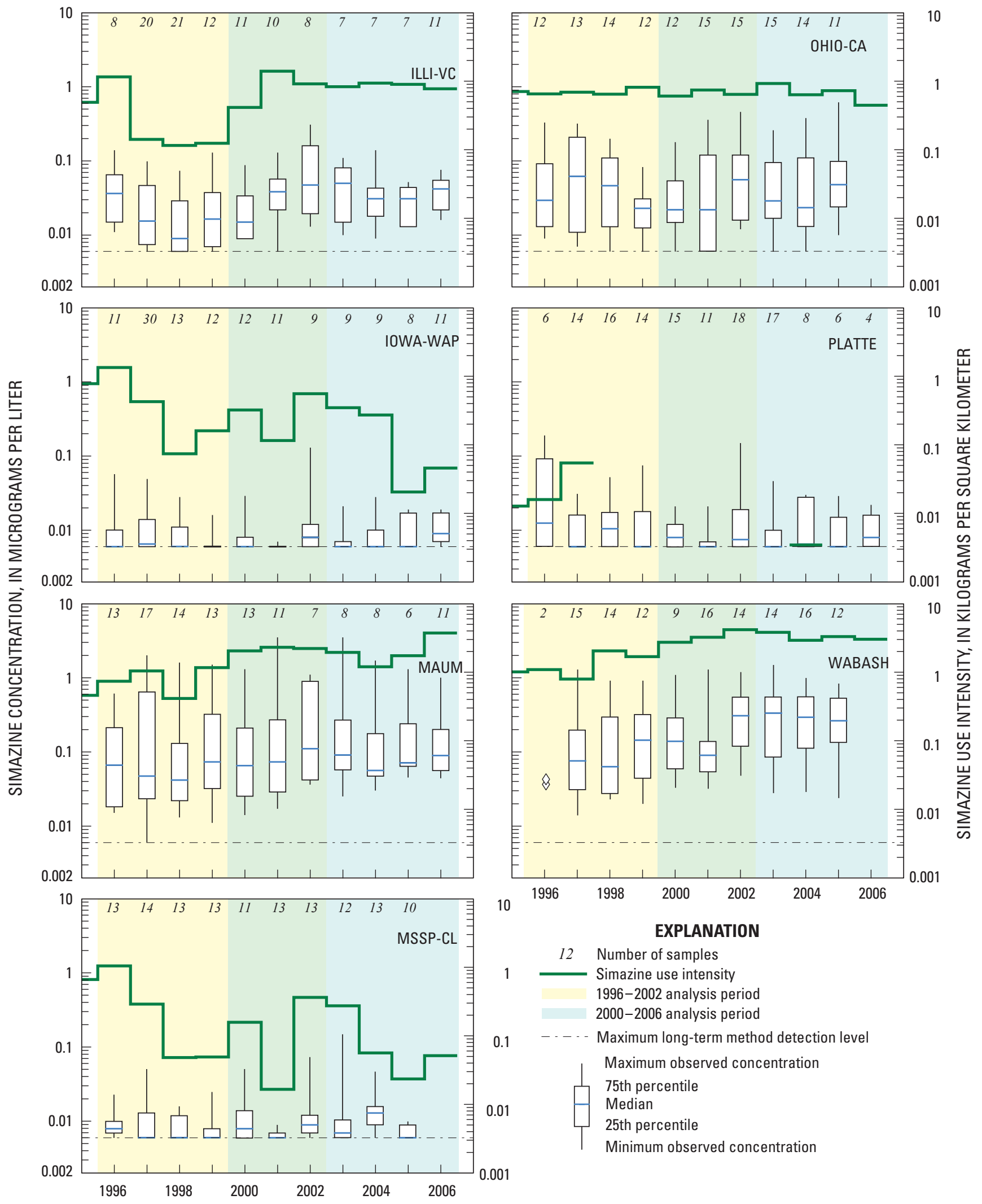

Figure 20. Simazine use intensity and stream-water concentrations for selected trend sites in the Corn Belt, 1996-2006. 
Table 17. Flow-adjusted trends in simazine concentration and changes in simazine use intensity for selected sites for the 1996-2002 and 2000-2006 trend analysis periods.

[Bold type indicates significant $(p \leq 0.10)$ trends or changes in use intensity; na, not analyzed]

\begin{tabular}{|c|c|c|c|c|}
\hline \multirow{2}{*}{$\begin{array}{l}\text { Site map number } \\
\text { and short name } \\
\text { (see table 1) }\end{array}$} & \multicolumn{2}{|c|}{ 1996-2002 } & \multicolumn{2}{|c|}{ 2000-2006 } \\
\hline & $\begin{array}{l}\text { Flow-adjusted trend } \\
\text { (percent per year) }\end{array}$ & $\begin{array}{c}\text { Change in use } \\
\text { (percent per year) }\end{array}$ & $\begin{array}{l}\text { Flow-adjusted trend } \\
\text { (percent per year) }\end{array}$ & $\begin{array}{c}\text { Change in use } \\
\text { (percent per year) }\end{array}$ \\
\hline 6. WABASH & 27.1 & 29.1 & 1.4 & 0.0 \\
\hline 7. OHIO-GRCH & 12.4 & 11.7 & -0.5 & -2.4 \\
\hline 20. IOWA-WAP & -6.3 & -12.7 & 9.4 & -30.2 \\
\hline 25. ILLI-VC & 19.1 & 20.3 & 5.6 & 3.7 \\
\hline 26. MSSP-GR & 36.9 & -1.8 & 11.5 & -9.7 \\
\hline 29. PLATTE & -10.7 & na & -9.7 & na \\
\hline
\end{tabular}

\section{Metribuzin}

Analysis of metribuzin concentration trends was limited during both analysis periods due to the large number of censored values (table 3). During 1996-2002, 14 sites had sufficient data, and all 14 sites had downtrends in concentrations (fig. 21). Downtrends were significant at four sites and highly significant at eight sites, including SUG-NP, WABASH, OHIO-GRCH, STJOS, AUGL, MAUM, ILLI-VC, and MSSPTH (sites 4, 6, 7, 11, 12, 13, 25, and 31). Only eight sites could be analyzed during 2000-2006 and all but WABASH (site 6) had nonsignificant trends (fig. 21). There were no significant uptrends for any of the sites during either analysis period.

\section{Trends in Relation to Changes in Use Intensity}

In the corn and soybean areas of the Midwest, metribuzin use was more common on soybeans than corn in the early part of the study period; in Wisconsin and Michigan metribuzin also is used on a variety of vegetable crops. Over 700,000 $\mathrm{kg}$ of metribuzin was applied in 1992 (fig. 2); by 2006, use had decreased to just over $100,000 \mathrm{~kg}$. The decrease in use primarily was because glyphosate became the herbicide of choice for soybeans. Low-level use on corn continued at similar levels throughout the study.

Use intensity for the use-trend sites generally was decreasing during both analysis periods (fig. 22). During 1996-2002, 7 of the 8 use-trend sites with adequate data for trend analysis had similar and significant downtrends in both concentration and use (table 18). The PLATTE also had a significant decline in concentration and the use trend was downward but not significant. During 2000-2006, only three sites had adequate data for evaluating concentration trends, all with significant or nonsignificant downtrends in both concentration and use. In all cases, downtrends in metribuzin concentration were similar in magnitude to decreases in use intensity - changes in use intensity for the 11 cases ranged from decreases of 9.3 to $21.6 \mathrm{pct} / \mathrm{yr}$ and the downtrends ranged from 2.6 to $25.1 \mathrm{pct} / \mathrm{yr}$. 


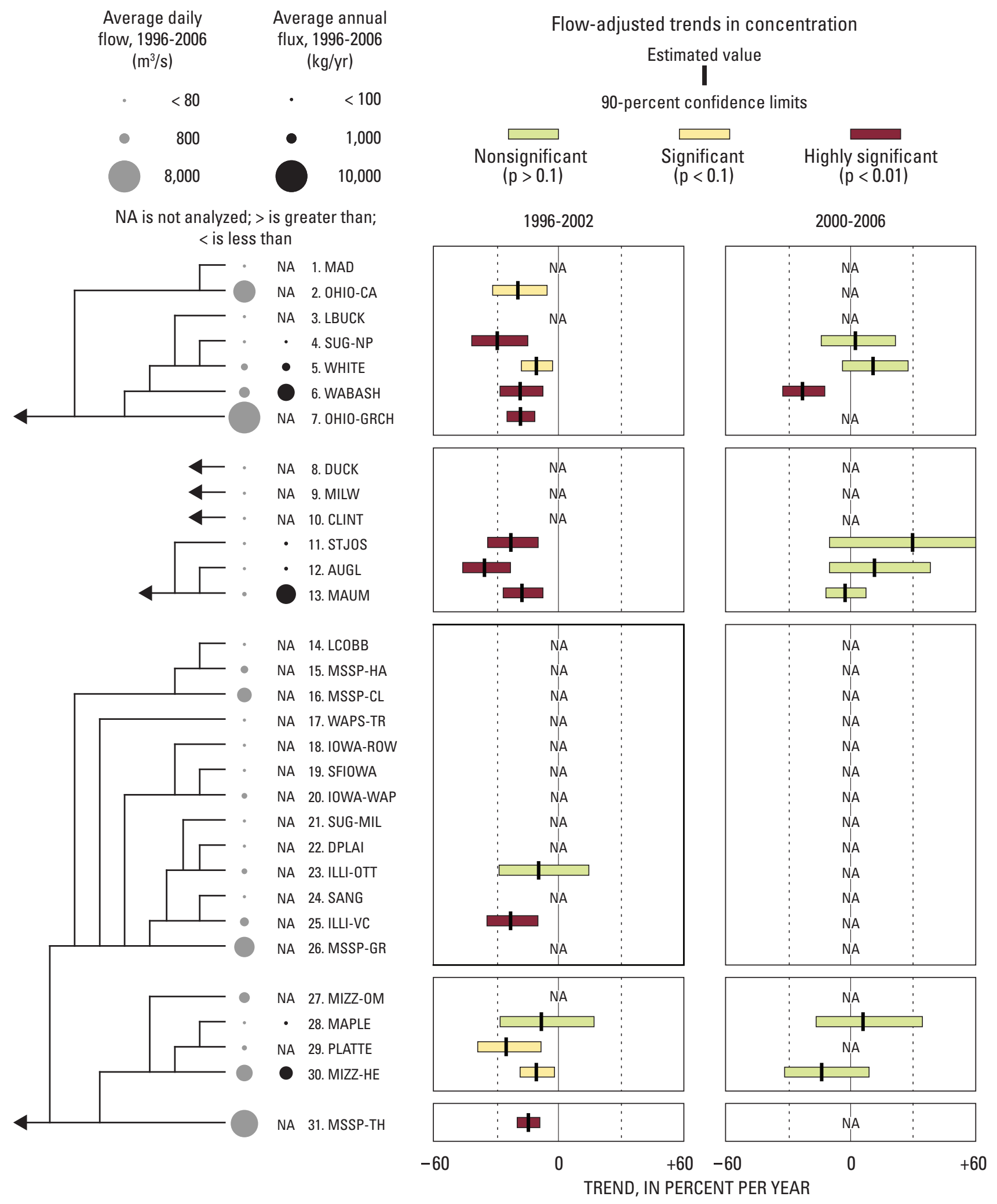

Figure 21. Flow-adjusted trends in metribuzin concentration for 1996-2002 and 2000-2006 analysis periods. 


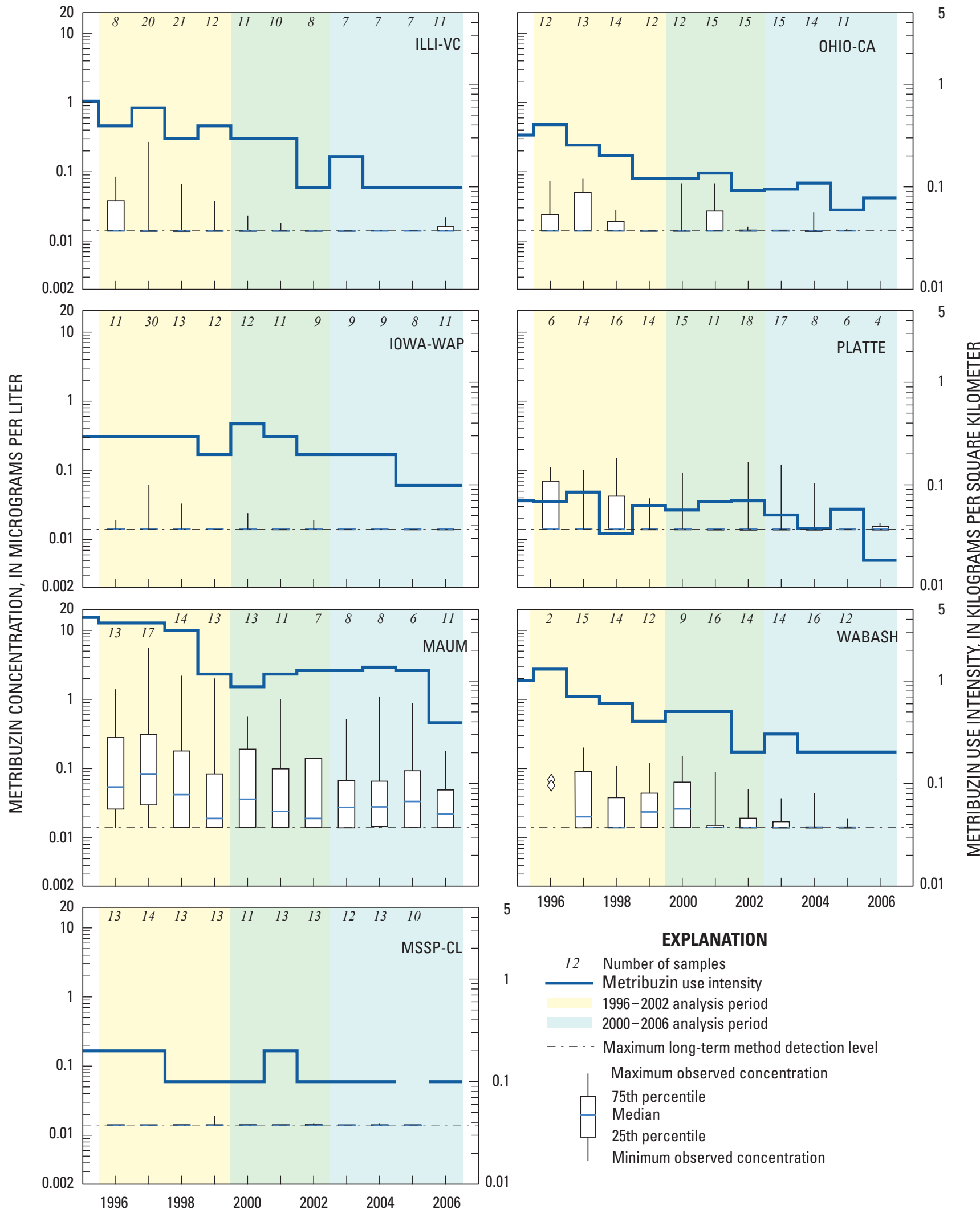

Figure 22. Metribuzin use intensity and stream-water concentrations for selected trend sites in the Corn Belt, 1996-2006. 
Table 18. Flow-adjusted trends in metribuzin concentration and changes in metribuzin use intensity for selected sites for the 19962002 and 2000-2006 trend analysis periods.

[Bold type indicates significant $(\mathrm{p} \leq 0.10)$ trends or changes in use intensity; na, not analyzed]

\begin{tabular}{|c|c|c|c|c|}
\hline \multirow{2}{*}{$\begin{array}{l}\text { Site map number } \\
\text { and short name } \\
\text { (see table 1) }\end{array}$} & \multicolumn{2}{|c|}{ 1996-2002 } & \multicolumn{2}{|c|}{ 2000-2006 } \\
\hline & $\begin{array}{l}\text { Flow-adjusted trend } \\
\text { (percent per year) }\end{array}$ & $\begin{array}{c}\text { Change in use } \\
\text { (percent per year) }\end{array}$ & $\begin{array}{l}\text { Flow-adjusted trend } \\
\text { (percent per year) }\end{array}$ & $\begin{array}{l}\text { Change in use } \\
\text { (percent per year) }\end{array}$ \\
\hline 2. OHIO-CA & -19.5 & -20.0 & na & -9.5 \\
\hline 6. WABASH & -18.4 & -19.5 & -23.3 & -16.3 \\
\hline 7. OHIO-GRCH & -18.3 & -19.9 & na & -12.3 \\
\hline 13. MAUM & -17.5 & -21.6 & -2.6 & -9.3 \\
\hline 25. ILLI-VC & -23.0 & -16.5 & na & -19.1 \\
\hline 29. PLATTE & -25.1 & -9.5 & na & -14.4 \\
\hline 30. MIZZ-HE & -10.5 & -14.7 & -13.7 & -14.2 \\
\hline 31. MSSP-TH & -14.4 & -12.5 & na & -15.9 \\
\hline
\end{tabular}

\section{Prometon}

All significant trends in prometon concentration during 1996-2002 were downward (fig. 23). Of the 29 sites analyzed, 27 had downtrends, including 10 sites that were highly significant and 4 sites that had significant downtrends. In contrast, during 2000-2006 uptrends outnumbered downtrends almost 2 to 1 (18 uptrends, 10 downtrends), but most (22 of 28) were not significant. The six significant or highly significant trends included uptrends (4) and downtrends (2). Because prometon is a nonselective herbicide used primarily for nonagricultural purposes (but in both urban and agricultural areas), accurate use data are not available and it is unknown whether downtrends in stream concentrations are the result of decreased use or some other factor(s).

\section{Ohio River and Great Lakes Basins (sites 1-13)}

During 1996-2002, there was a small (about 4 pct/yr) but significant downtrend at OHIO-GRCH (site 7), which is consistent with all of the upstream sites (with sufficient data for analysis) also having downtrends, including a highly significant downtrend at LBUCK (site 3), which is a small and rapidly urbanizing basin. There also were highly significant downtrends at Great Lakes tributary sites MILW and STJOS (sites 9 and 11). During 2000-2006, only two significant trends were found; a highly significant downtrend at MILW and a significant uptrend at SUG-NP.

\section{Mississippi and Missouri River Basins (sites 14-31)}

During 1996-2002, there was a highly significant downtrend in prometon concentrations at MSSP-GR (site 26) and significant or highly significant downtrends at its major upstream tributaries, ILLI-VC (site 25) and IOWA-WAP (site 20). Significant or highly significant downtrends also were found at several smaller sites in the Illinois and Iowa River Basins (IOWA-ROW, SFIOWA, DPLAI, ILLI-OTT, and SANG; sites 18, 19, 22, 23, and 24). There were no significant trends for the Missouri River Basin sites (sites 27-30), but a highly significant downtrend at MSSP-TH (site 31) was consistent with the downtrend at the upstream site, MSSPGR. During 2000-2006, however, there was a highly significant uptrend in prometon concentrations at MSSP-GR, and a significant uptrend downstream at MSSP-TH. As during 1996-2002, there were no significant trends at any of the four sites in the Missouri River Basin during 2000-2006. 
Prometon

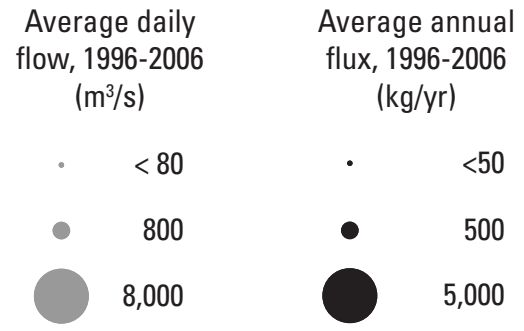

NA is not analyzed; > is greater than; $<$ is less than
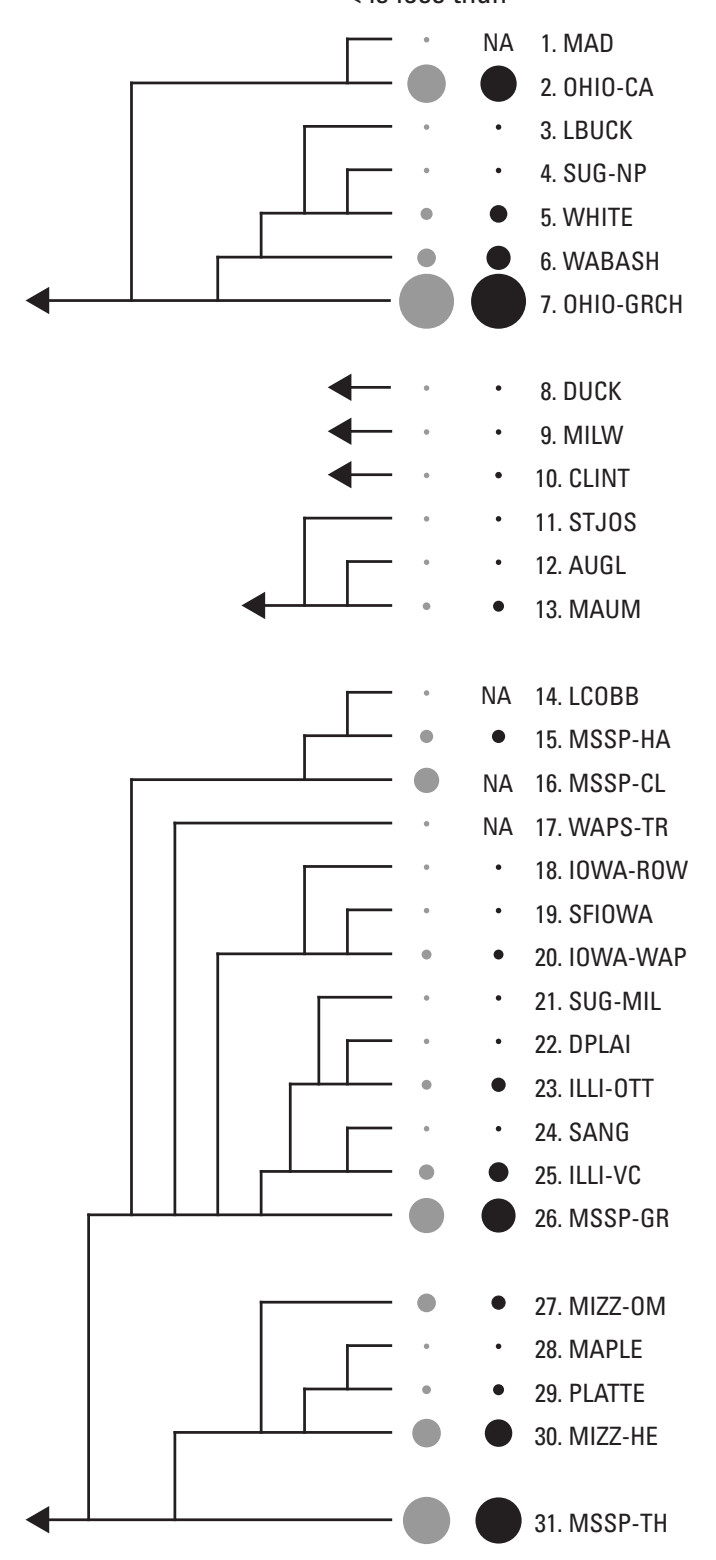

Flow-adjusted trends in concentration Estimated value I

90-percent confidence limits

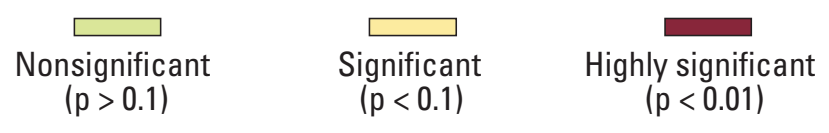

1996-2002

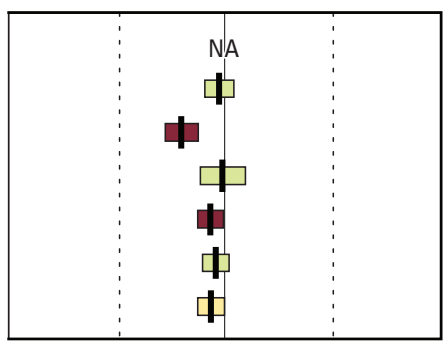
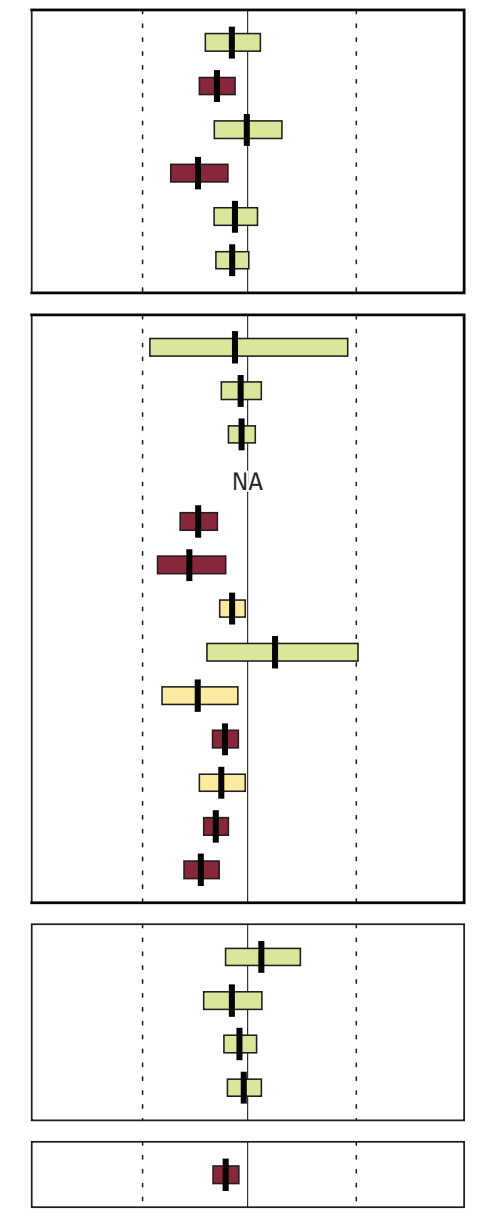

$+60-60$
2000-2006
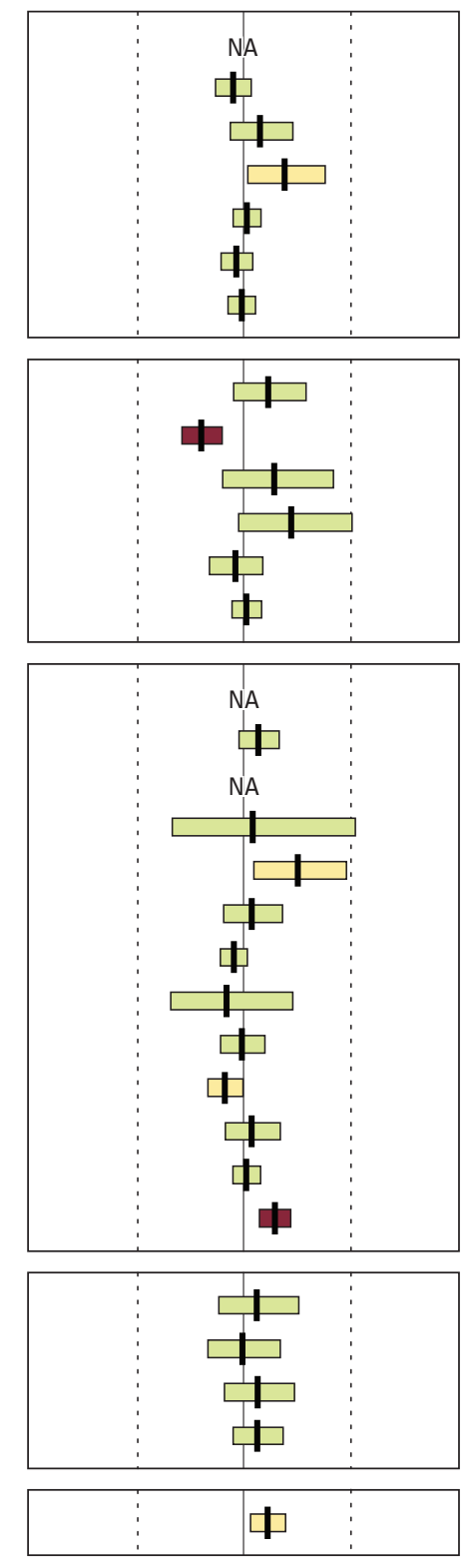

0

Figure 23. Flow-adjusted trends in prometon concentration for 1996-2002 and 2000-2006 analysis periods. 


\section{Chlorpyrifos}

Most sites had too few concentrations above detection limits to analyze for trends in chlorpyrifos (table 3). At the 11 sites for which flow-adjusted trends could be analyzed during 1996-2002, all had downtrends in chlorpyrifos concentrations, including significant downtrends at 2 sites and highly significant downtrends at 5 sites (fig. 24). Only three sites could be analyzed during 2000-2006, and there was a highly significant downtrend at WABASH (site 6) and a highly significant uptrend at MAPLE (site 28), a small agricultural stream. As indicated in table 3, MAPLE was one of few sites for which the percentage of uncensored chlorpyrifos concentrations was higher during 2000-2006 (25 percent) than during 1996-2002 (15 percent).

\section{Trends in Relation to Changes in Use Intensity}

Slightly more than half of all chlorpyrifos used for insect control in agriculture is on corn acreage (U.S. Environmental Protection Agency, 2002). Most residential uses were cancelled as of 2001. Agricultural use data (fig. 25) suggest that chlorpyrifos use may be declining somewhat, although patterns were not uniform at all sites.
Chlorpyrifos use for the use-trend sites generally was stable or decreasing during both trend analysis periods (fig. 25). There were only four sites and six cases for which comparisons could be made between trends in chlorpyrifos concentration and changes in use intensity (table 19). During 1996-2002, three of four sites had significant and substantial downtrends in concentrations, despite nonsignificant trends in use (OHIO-CA, OHIO-GRCH, and MAUM). Possible explanations for the steeper downtrends in concentrations compared to agricultural use include improved erosion control practices, which could have a particularly great effect on chlorpyrifos because of its hydrophobic nature, and the possibility that major reductions in nonagricultural use of chlorpyrifos accounted for most of the concentration reduction (this would not be apparent in the agricultural use trends). During 20002006, agricultural use trends were all downward, with three of the four sites significant. Three of the four sites had unassessable or nonsignificant concentration trends, while WABASH had a strong significant downtrend of $-30.5 \mathrm{pct} / \mathrm{yr}$. 


\section{Chlorpyrifos}

Average daily

flow, 1996-2006

$\left(\mathrm{m}^{3} / \mathrm{s}\right)$

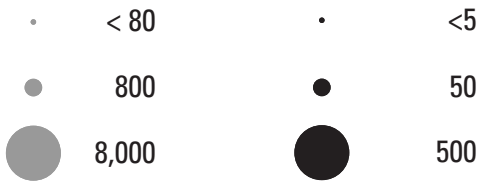

NA is not analyzed; $>$ is greater than; $<$ is less than

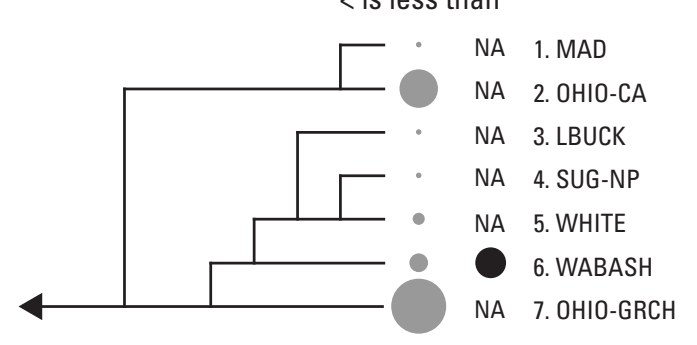

$4 \quad$ NA 8. DUCK

4 NA 9. MILW

4 NA 10. CLINT

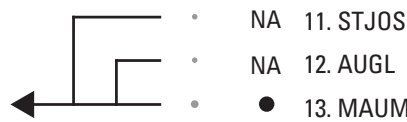

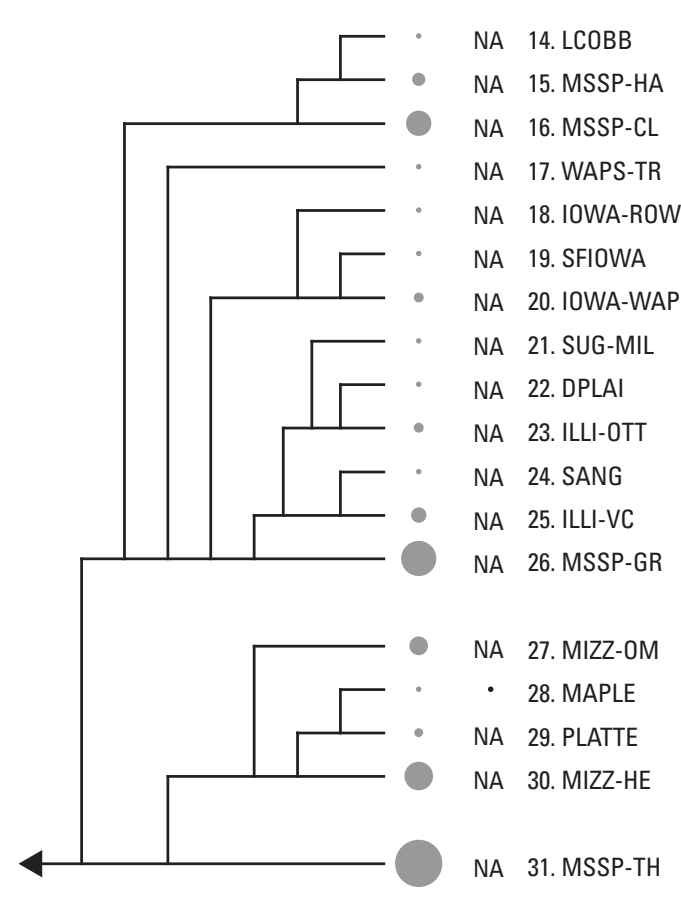

Flow-adjusted trends in concentration

Estimated value

I

90-percent confidence limits

$\begin{array}{ccc}\underset{N}{\text { Nonsignificant }}(p>0.1) & \text { Significant } & \text { Highly significant } \\ (p<0.1) & (p<0.01)\end{array}$

1996-2002
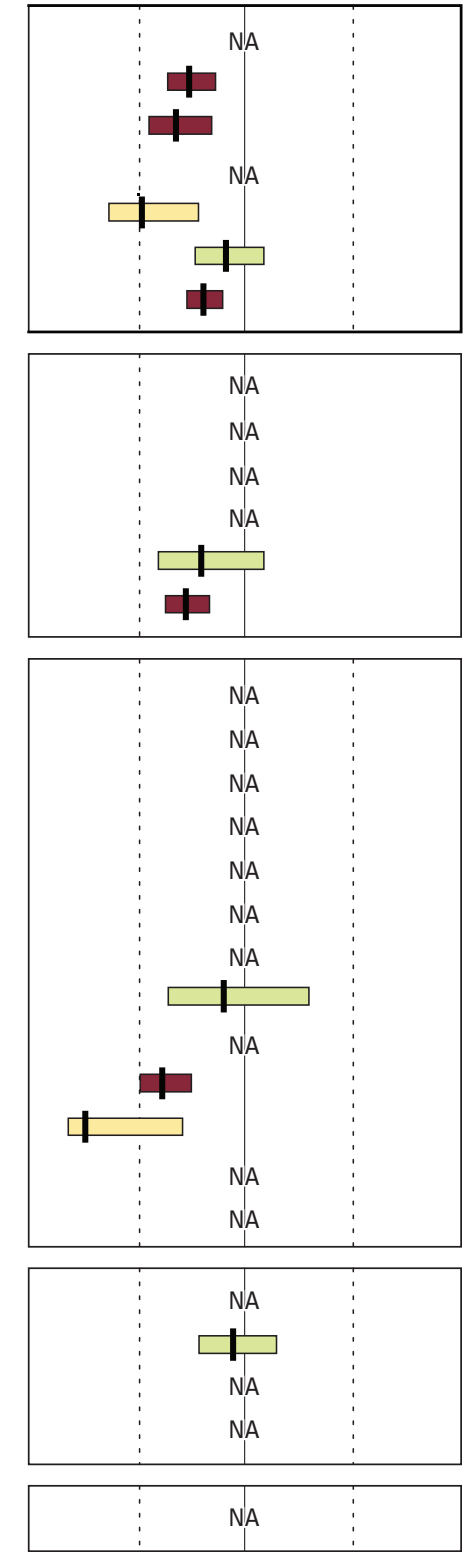

$+120-120$
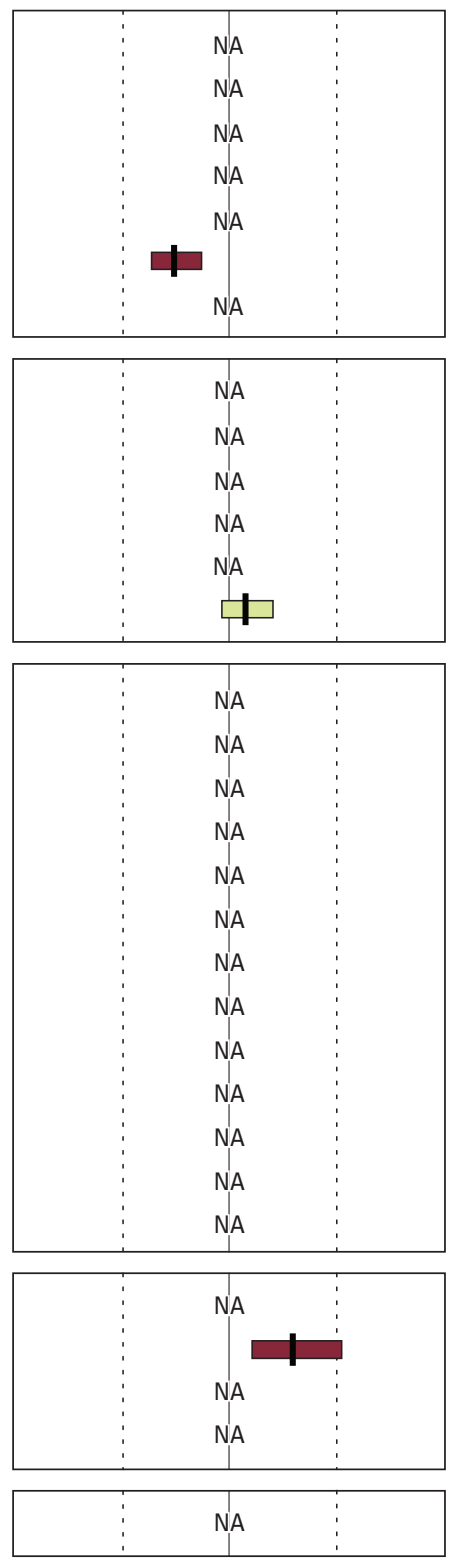

0

$+120$

TREND, IN PERCENT PER YEAR

Figure 24. Flow-adjusted trends in chlorpyrifos concentration for 1996-2002 and 2000-2006 analysis periods. 


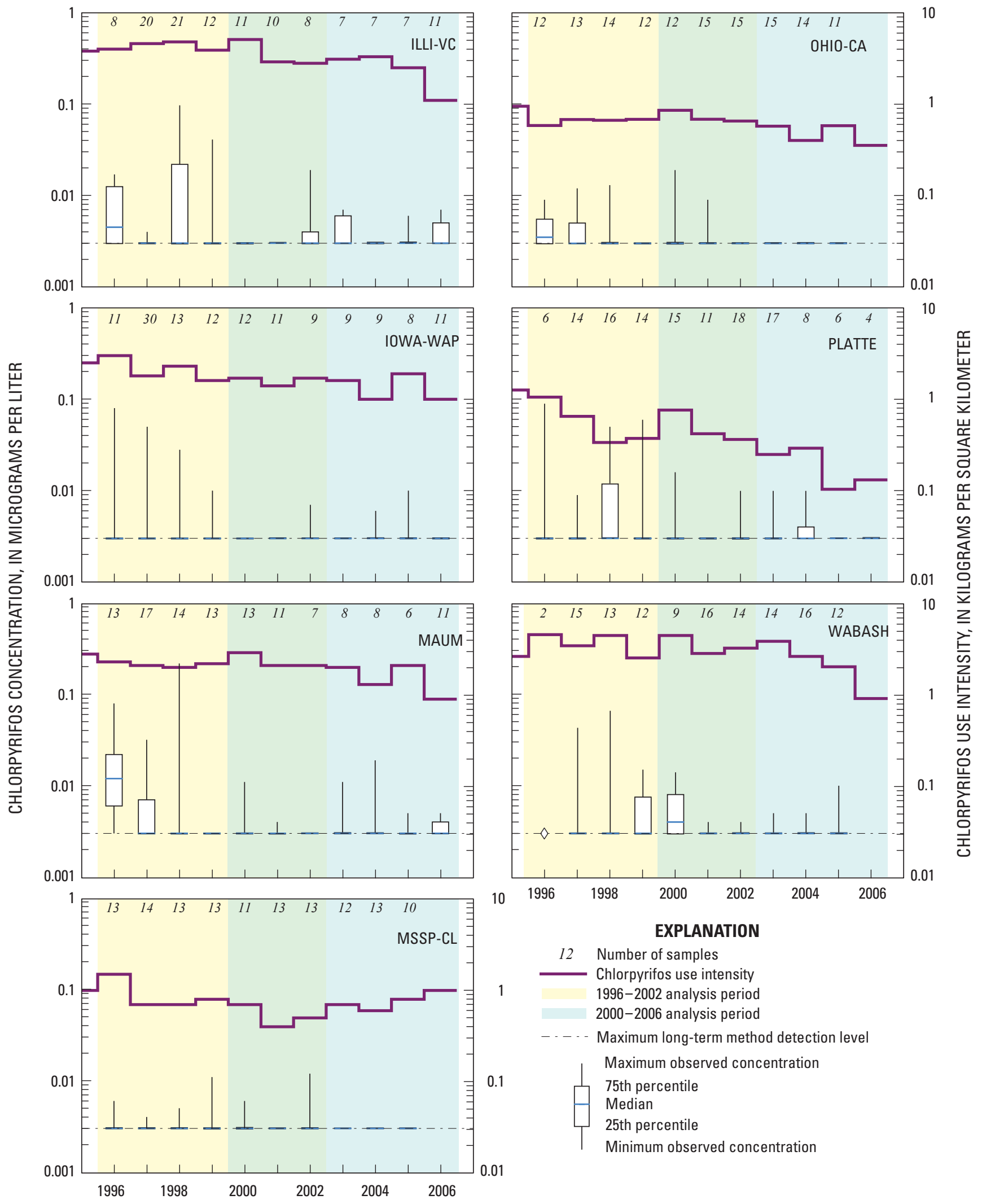

Figure 25. Chlorpyrifos use intensity and stream-water concentrations for selected trend sites in the Corn Belt, $1996-2006$. 
Table 19. Flow-adjusted trends in chlorpyrifos concentration and changes in chlorpyrifos use intensity for selected sites for the 1996-2002 and 2000-2006 trend analysis periods.

[Bold type indicates significant $(p \leq 0.10)$ trends or changes in use intensity; na, not analyzed]

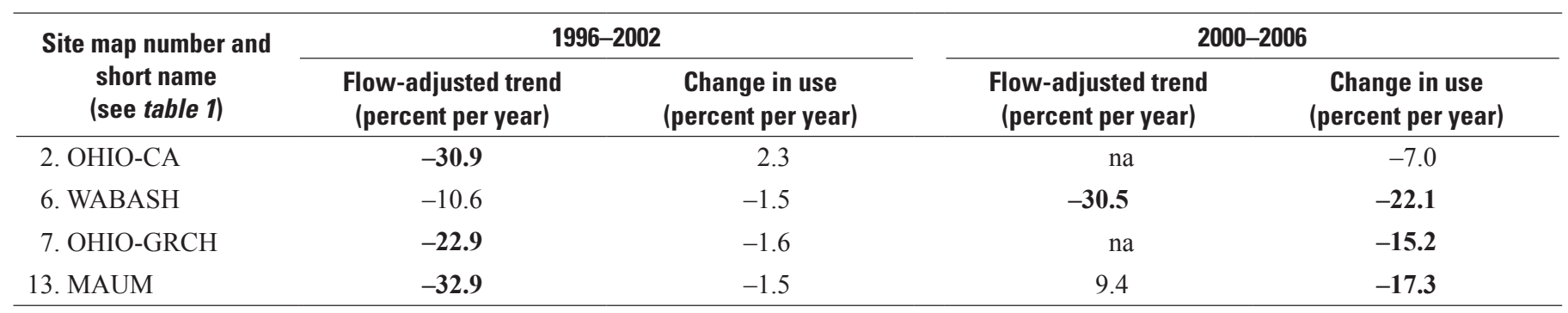

\section{Diazinon}

Flow-adjusted trends in diazinon concentration were mixed for 1996-2002 and broadly downward for 2000-2006 (fig. 26). Of 18 trends that could be analyzed for 1996-2002, 13 sites had nonsignificant trends, two sites had significant downtrends and 3 sites had significant uptrends, including highly significant uptrends for WABASH (site 6) and MILW (site 9). During 2000-2006, all 18 sites that could be analyzed had downtrends and 11 of the downtrends were highly significant. The downtrends were particularly strong for the Wabash River Basin (sites 3-6) and the Illinois River Basin (sites 22, 23 , and 25). There also were large (greater than $30 \mathrm{pct} / \mathrm{yr}$ ) and highly significant downtrends for the large Mississippi River and Missouri River mainstem sites, MSSP-GR (site 26), MIZZ-HE (site 30), and MSSP-TH (site 31). Small and nonsignificant downtrends for the two Ohio River mainstem sites (OHIO-CA and OHIO-GRCH; sites 2 and 7) were found during 2000-2006.

\section{Trends in Relation to Changes in Use Intensity}

A federally mandated phase out of non-agricultural uses of diazinon by 2004 (U.S. Environmental Protection Agency, 2008) resulted in significant decreases in urban streams and rivers in the northeastern and midwestern U.S. (Phillips and others, 2007). However, agricultural uses of diazinon continue (fig. 2) and the result is a mix of responses at sites in the Corn Belt.

Diazinon use intensities for the use-trend sites were much more variable from year to year than were use intensities for any of the previous pesticides (fig. 27). This variation in use partly reflects the fact that insecticides are applied on an as-needed basis and not as routinely as herbicides and, thus, application can be much higher during years of insect infestations and lower during years when few insect pests are observed. In addition, the effect of urban use of diazinon, not reflected in the agricultural use intensity shown in figure 27, likely masks relations between agricultural use and stream concentrations (table 20).

During 1996-2002, 3 of 10 use-trend sites with adequate data had significant downtrends in agricultural use in the range of 46 to 65 percent per year. Each of these sites, plus three others with substantial but nonsignificant downtrends (MAUM, IOWA-WAP, and MSSP-GR), had nonsignificant, mostly small downtrends in concentrations (table 20). ILL-VC had a significant downtrend in concentration and a large, but nonsignificant, downtrend in agricultulral use. During 2000-2006, there were substantial, but mostly nonsigificant, uptrends in use at most sites, which were accompanied by mostly significant downtrends in concentrations.

This apparent "disconnect" between concentration and use trends may result from the large proportional contribution of urban uses compared to agricultural uses prior to the 2004 phase out, such that agricultural use downtrends were offset or diminished by urban uses during 1996-2002. During 20002006, when the phase out of urban uses occurred, concentration trends generally were downward even though estimated agricultural use may have increased for several sites. Most sites with the largest decreasing trends during 2000-2006 also are those with the greatest urban influence. Results indicate that the diazinon phase-out for nonagricultural uses was effective in reducing river concentrations. 


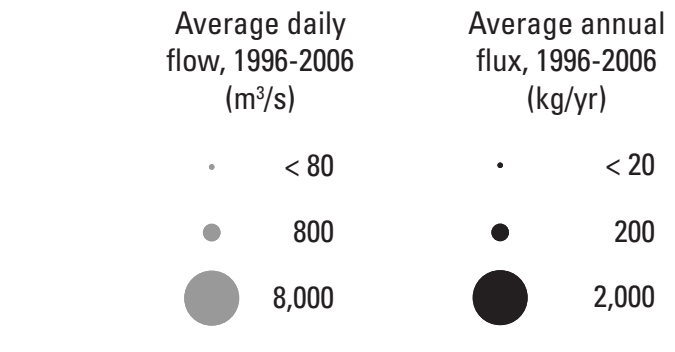

NA is not analyzed; > is greater than;
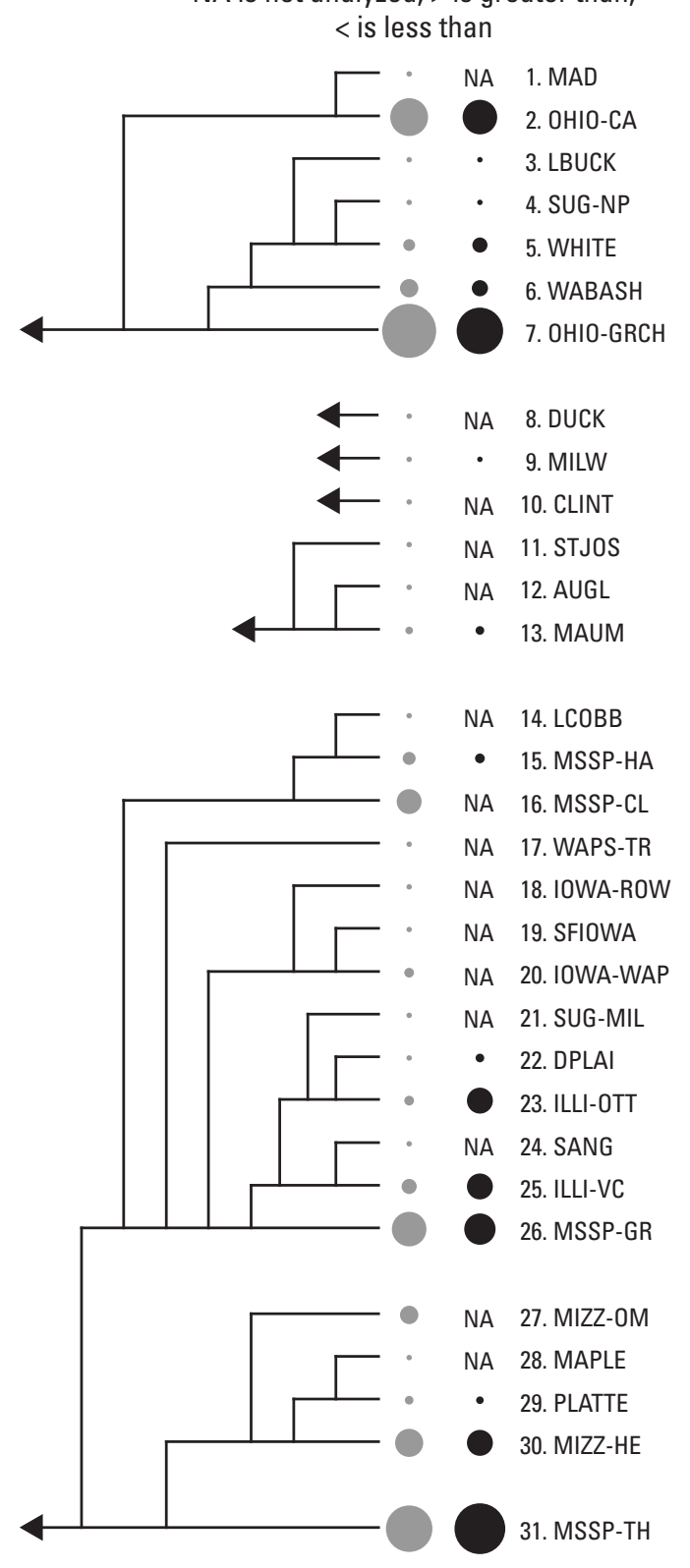

\section{Diazinon}

Flow-adjusted trends in concentration

Estimated value

I

90-percent confidence limits

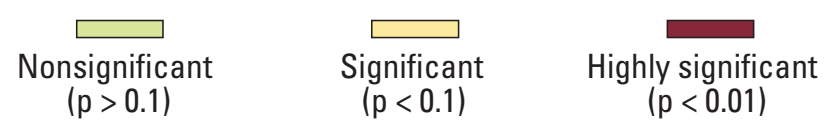

1996-2002
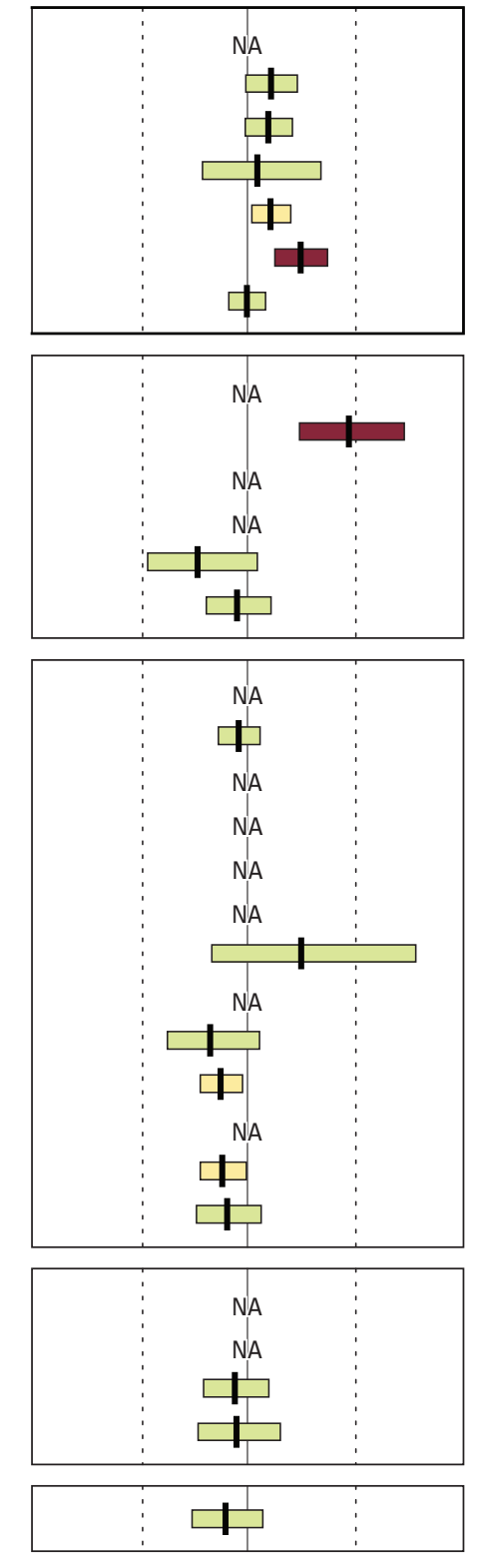

$+60-60$
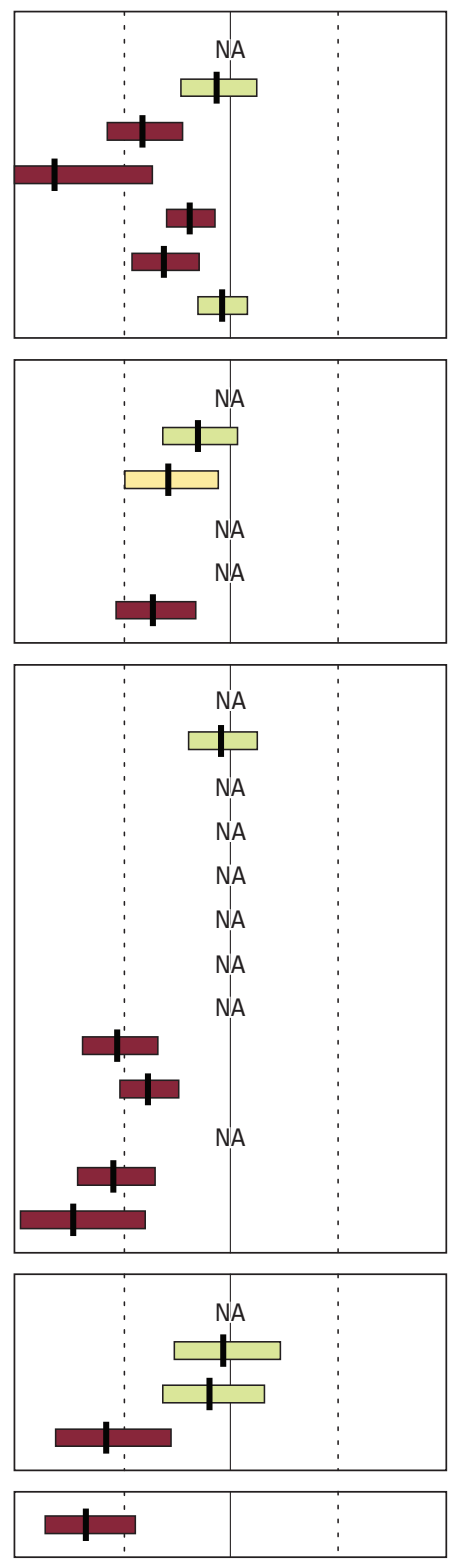

$-60$

0

TREND, IN PERCENT PER YEAR

Figure 26. Flow-adjusted trends in diazinon concentration for 1996-2002 and 2000-2006 analysis periods. 


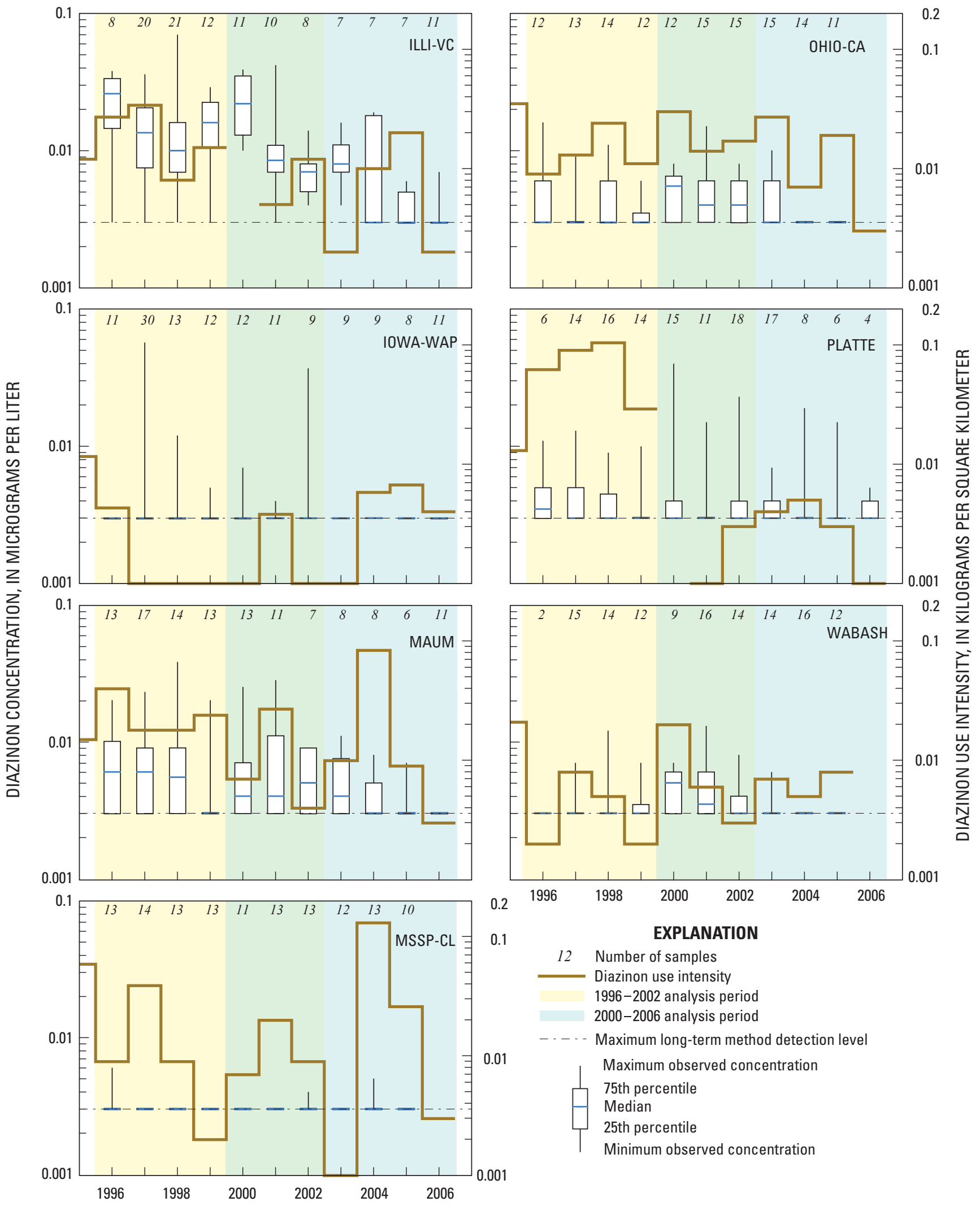

Figure 27. Diazinon use intensity and stream-water concentrations for selected trend sites in the Corn Belt, 1996-2006. 
Table 20. Flow-adjusted trends in diazinon concentration and changes in diazinon use intensity for selected sites for the $1996-2002$ and 2000-2006 trend analysis periods.

[Bold type indicates significant $(p \leq 0.10)$ trends or changes in use intensity; na, not analyzed]

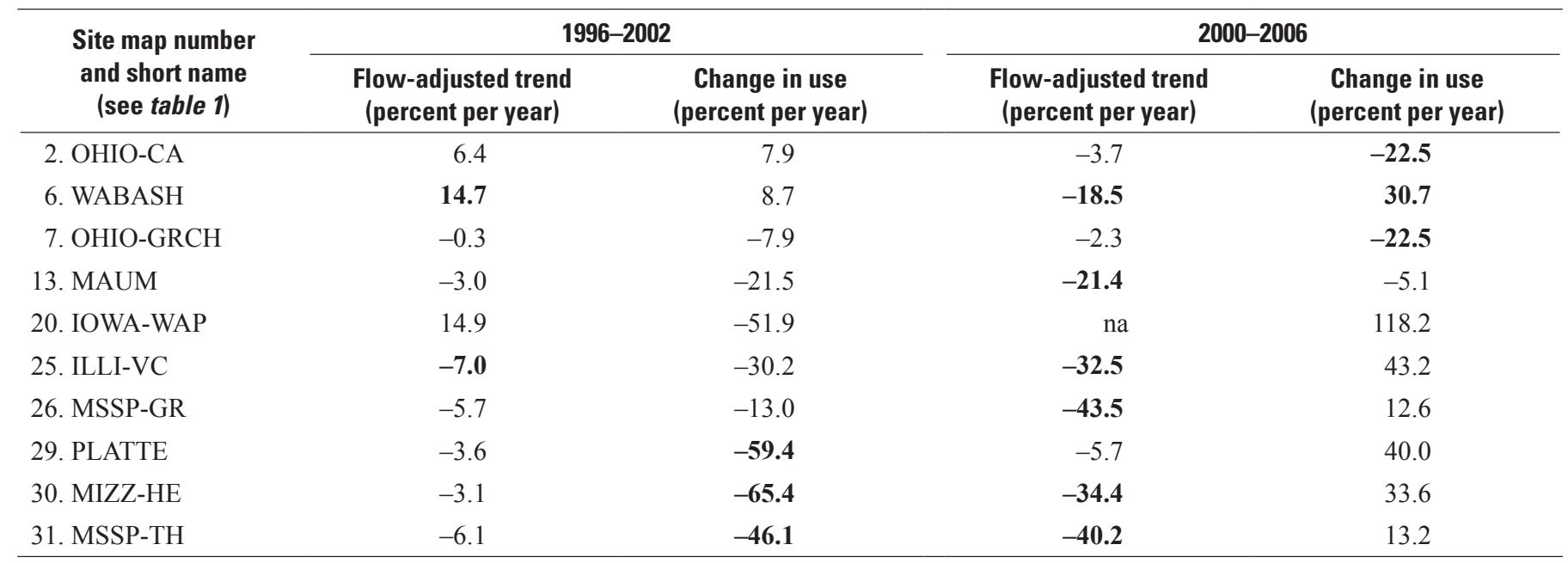




\section{Conclusions}

This study assessed trends in the concentrations of commonly occurring pesticides in selected streams in the Corn Belt, an agricultural region that accounts for a major proportion of pesticide use in the U.S., and evaluated the performance and application of statistical trend-assessment methods for subsequent application to other regions. Trends in the concentrations of 11 pesticides with sufficient data for trend assessment were assessed at up to 31 stream sites for two time periods: 1996-2002 and 2000-2006. Eleven of the 31 sites, referred to as "use-trend" sites, include 7 study sites that were selected as indicators of major subareas of the Corn Belt, plus four large river sites at the outlets of major drainage basins. These 11 sites have large enough drainage areas that reasonable estimates of agricultural use of pesticides are possible. Pesticides included in trend analyses are atrazine, acetochlor, metolachlor, alachlor, cyanazine, EPTC, simazine, metribuzin, prometon, chlorpyrifos, and diazinon.

The statistical methods applied and compared were (1) a modified version of the nonparametric seasonal Kendall test (SEAKEN), (2) a modified version of the Regional Kendall test, (3) a parametric regression model with seasonal wave (SEAWAVE), and (4) a version of SEAWAVE with adjustment for streamflow (SEAWAVE-Q). The SEAKEN test is a statistical hypothesis test for detecting monotonic trends in seasonal time-series data such as pesticide concentrations at a particular site. Trends across a region, represented by multiple sites, are evaluated using the regional seasonal Kendall test, which computes a test for an overall trend within a region by computing a score for each season at each site and adding the scores to compute the total for the region. The SEAWAVE model is a parametric regression model specifically designed for analyzing seasonal variability and trends in pesticide concentrations. The seasonal wave differs from a trigonometric function in that it is specifically designed to mimic the temporal behavior of pesticide concentrations in response to seasonal application rates, basin accumulation, and removal by processes such as degradation and runoff. Finally, the SEAWAVE-Q model accounts for the effect of changing flow conditions in order to separate changes caused by hydrologic trends from changes caused by other factors, such as pesticide use.

There was broad, general agreement between unadjusted trends (no adjustment for streamflow effects) identified by the SEAKEN and SEAWAVE methods, including the regional seasonal Kendall test. Only about 9 percent of the paired comparisons between SEAKEN and SEAWAVE indicated a difference in the direction of trend and only one of these had differences significant at the 10-percent significance level. This consistency of results supports the validity and robustness of all three approaches as trend-analysis tools. The SEAWAVE method is favored, however, because it has less restrictive data requirements, enabling analysis for more site/pesticide combinations, and can incorporate adjustment for streamflow (SEAWAVE-Q) with substantially fewer measurements than the flow-adjustment procedure used with SEAKEN.

Analysis of flow-adjusted trends is preferable to analysis of non-adjusted trends for evaluating potential effects of changes in pesticide use or management practices because flow-adjusted trends account for the influence of flow-related variability. If ignored, these influences of flow conditions may alter or disguise trends caused by changes in pesticide use or management practices. Flow adjustment affected the fitted trends to varying degrees. The flow-adjusted trends generally were smaller in magnitude than the unadjusted trends (whether up or down). Fitted trends for simazine and prometon concentrations for 1996-2002 were the most sensitive to flow adjustment of the 11 pesticides evaluated and, for the 2000-2006 period, flow adjustment had the most pronounced effect on prometon concentrations.

Analysis of flow-adjusted trends by SEAWAVE-Q shows that all of the pesticides assessed except for simazine (mostly uptrends) and acetochlor (mostly no trends) were dominated by varying degrees of concentration downtrends in one or both analysis periods. Atrazine, metolachlor, alachlor, cyanazine, EPTC, and metribuzin - all major corn herbicides - showed more prevalent concentration downtrends during 1996-2002 compared to 2000-2006. The downtrends in concentrations of these herbicides generally correspond to varying degrees of regional downtrends in their use resulting from a variety of regulatory, market, and new-product forces that reduced their use in the Corn Belt during all or part of the study period. The insecticide diazinon had no clear trends during 1996-2002, but the trends were predominantly downward during 2000-2006, most likely due to reductions in nonagricultural uses because of a regulatory phase-out. Acetochlor trends were mixed during 1996-2002 and slightly upward during 2000-2006, but most of the trends were not significant. Simazine concentrations trended upward at most sites during both 1996-2002 and 2000-2006, a pattern explained by increasing agricultural use at some sites, but also likely by extensive nonagricultural use in some of the watersheds.

More detailed qualitative comparisons of concentration and use trends at 11 sites with relatively large watersheds showed that concentration trends for atrazine, acetochlor, metolachlor, alachlor, cyanazine, EPTC, simazine, and metribuzin were generally similar to use trends for 50 percent or more of trend comparisons for use-trend sites evaluated (concentration and use trends were considered similar if both were significant and in the same direction or if both were nonsignificant). There were more frequent differences between concentration trends and agricultural use trends for chlorpyrifos and diazinon, which had substantial nonagricultural use during part of the study period and which are both insecticides with more erratic year-to-year use than most herbicides. 
Overall, combined study results indicate that trends in pesticide concentrations in Corn Belt streams and rivers during 1996-2006 were largely explained by corresponding trends in annual use and that major reductions in the use of some pesticides resulting from regulatory actions or market forces generally resulted in corresponding declines in stream and river concentrations. To further address the degree to which trends in watershed use of pesticides control concentration trends, more quantitative comparisons are needed that evaluate the significance of differences, given the uncertainty in trend estimates. In addition, watershed-scale information is needed on the timing of changes in factors other than annual use, such as conservation tillage and implementation of buffer strips.

\section{References Cited}

Aspelin, A.L., 2003, Pesticide usage in the United States: trends during the $20^{\text {th }}$ century: CIPM Technical Bulletin 105 (not paginated).

Barbash, J.E., Thelin, G.P., Kolpin, D.W., and Gilliom, R.J., 2001, Major herbicides in ground water: Results from the National Water-Quality Assessment: Journal of Environmental Quality, v. 30, no. 3, p. 831-845.

Cleveland, W.S., and McGill, Robert, 1985, Graphical perception and graphical methods for analyzing scientific data: Science, v. 229, p. 828-833.

Edwards, T.K., and Glysson, G.D., 1999, Field methods for measurement of fluvial sediment: U.S. Geological Survey Techniques of Water-Resources Investigations, book 3, chapter C2, 89 p. Available at http://pubs.er.usgs.gov/ usgspubs/twri/twri03C2

EXTOXNET, Pesticide information profiles: A cooperative effort of University of California-Davis, Oregon State University, Michigan State University, Cornell University, and the University of Idaho, accessed June 16, 2008, at http:// extoxnet.orst.edu/pips/ghindex.html

Fawcett, R.S. 2008, Environmental benefits of triazine use in convervation tillage in LeBaron, H.M., McFarland, J.E., and Burnside, O.C., eds., The Triazine herbicides -50 years revolutionizing agriculture: San diego, California, Elsevier Press, p. 519-526.

Gilliom, R.J., Barbash, J.E., Crawford, C.G., Hamilton, P.A., Martin, J.D., Nakagaki, Naomi, Nowell, L.H., Scott, J.C., Stackelberg, P.E., Thelin, G.P., and Wolock, D.M., 2006, The quality of our Nation's waters-Pesticides in the Nation's streams and ground water, 1992-2001: U.S. Geological Survey Circular 1291, 172 p., accessed April 1, 2008, at http://pubs.er.usgs.gov/usgspubs/cir/cir1291
Helsel, D.R., 2005, Nondetects and data analysis-Statistics for censored environmental data: Hoboken, New Jersey, John Wiley \& Sons, 266 p.

Helsel, D.R., and Frans, L.M., 2006, Regional Kendall test for trend: Environmental Science \& Technology, v. 40, no. 13, p. 4066-4073.

Helsel, D.R., and Hirsch R.M., 2002, Statistical methods in water resources: U.S. Geological Survey Techniques of Water-Resources Investigations, book 4, chap. A3, 510 p., available at $h t t p: / / p u b s . e r . u s g s . g o v / u s g s p u b s / t w r i / t w r i 04 A 3$

Hirsch, R.M., and Slack, J.R., 1984, A nonparametric trend test for seasonal data with serial dependence: Water Resources Research, v. 20, no. 6, p. 727-732.

Hirsch, R.M., Slack, J.R., and Smith, R.A., 1982, Techniques of trend analysis for monthly water quality data: Water Resources Research, v. 18, no. 1, p. 107-121.

Homer, C., Huang, C., Yang, L., Wylie, B., and Coan, M., 2004, Development of a 2001 national land cover database for the United States: Photogrammetric Engineering and Remote Sensing v. 70, no. 7, p. 829-840. Available at http:// www.mrlc.gov/pdf/July_PERS.pdf

Larson, S.J., Gilliom, R.J., and Capel, P.D., 1999, Pesticides in streams of the United States-Initial results from the National Water-Quality Assessment Program: U.S. Geological Survey Water-Resources Investigations Report 98-4222, 99 p., accessed January 30, 2009, at http://water.usgs.gov/ nawqa/pnsp/pubs/wrir984222/

Lindley, C.E., Stewart, J.T., and Sandstrom, M.W., 1996, Determination of low concentrations of acetochlor in water by automated solid-phase extraction and gas chromatography with mass-selective detection: Journal of AOAC International, v. 79, no. 4, p. 962-966.

Ma, Q., Rahman, A., Holland, P.T., James, T.K., and McNaughton, D.E., 2004a, Field dissipation of acetochlor in two New Zealand soils at two application rates: Journal of Environmental Quality, v. 33, p. 930-938.

Ma, Q.L., Rahman, A., James, T.K., Holland, P.T., McNaughton, D.E., Rojas, K.W., and Ahuja, L.R., 2004b, Modeling the fate of acetochlor and terbuthylazine in the field using the Root Zone Water Quality Model: Soil Science Society of America Journal, v. 68, p. 1491-1500.

Mackay, D., Shiu, W-Y., and Ma, K-C, 1997, Illustrated handbook of physical-chemical properties and environmental fate for organic chemicals, Volume V. Pesticide Chemicals: New York, New York, Lewis Publishers, 812 p. 
Mackay, D.M., Shiu, W.Y. and Ma, K.C., 2000, Henry’s law constant, in Boethling, R.S. and Mackay, D., eds., Handbook of property estimation methods for chemicals-Environmental and Health Sciences: New York, New York, Lewis Publishers, p. 69-87.

Martin, J.D., 2009, Sources and preparation of data for assessing trends in concentrations of pesticides in streams of the United States, 1992-2006: U.S. Geological Survey Scientific Investigations Report 2009-5062, 41 p. Available at http://pubs.usgs.gov/sir/2009/5062/

Martin, J.D., Stone, W.W., Wydoski, D.S., and Sandstrom, M.W., 2009, Adjustment of pesticide concentrations for temporal changes in analytical recovery, 1992-2006: U.S. Geological Survey Scientific Investigations Report 20095189, 24 p., plus appendixes. Available at http://pubs.usgs. gov/sir/2009/5189/

Mueller, D.K., Martin, J.D., and Lopes, T.J., 1997, Qualitycontrol design for surface-water sampling in the National Water-Quality Assessment Program: U.S. Geological Survey Open-File Report 97-223, 17 p., accessed April 1, 2008, at http://pubs.usgs.gov/of/1997/223/

Nakagaki, N., Price, C.P., Falcone, J.A., Hitt, K.J., and Ruddy, B.C., 2007, Enhanced National Land Cover Data 1992 (NLCDe 92), Edition 1.0, [digital map], accessed December 1, 2007, at http://water.usgs.gov/lookup/getspatial?nlcde92

Phillips, P.J., Ator, S.W., and Nystrom, E.A., 2007, Temporal changes in surface-water insecticide concentrations after the phase out of diazinon and chlorpyrifos: Environmental Science \& Technology, v. 41, p. 4246-4251.

Pickett, J.P., and others, ed., 2000, The American Heritage Dictionary of the English Language ( $4^{\text {th }}$ ed.): Boston, Mass., Houghton Mifflin Company, 2,074 p.

Schertz, T.L., Alexander, R.B., and Ohe, D.J., 1991, The computer program estimate trend (ESTREND), a system for the detection of trends in water-quality data: U.S. Geological Survey Water-Resources Investigations Report 91-4040, 63 p., available at http://pubs.er.usgs.gov/usgspubs/wri/ wri914040

Shelton, L.R., 1994, Field guide for collecting and processing stream-water samples for the National Water-Quality Assessment Program: U.S. Geological Survey Open-File Report 94-455, 42 p., accessed April 1, 2008, at http://pubs. er.usgs.gov/usgspubs/ofr/ofr 94455

Shiu, W.Y., Ma, K.C., Mackay, D., Seiber, J.N., and Wauchope, R.D., 1990, Solubilities of pesticide chemicals in water Part II: Data compilation: Reviews of Environmental Contamination and Toxicology, v. 116, p. 15-187.
Sprague, L.A., and Lorenz, D.L., 2009, Regional nutrient trends in streams and rivers of the United States, 1993 to 2003: Environmental Science and Technology, v. 43, no. 10, p. 3430-3435.

Staudinger, J., and Roberts, P.V., 2001, A critical compilation of Henry's law constant temperature dependence relations for organic compounds in dilute aqueous solutions: Chemosphere, v. 44, p. 561-576.

Timmons, F.L., 2005, A history of weed control in the United States and Canada: Journal of Weed Science, v. 53, no. 6, p. 748-761.

Turnbull, B.W., 1974, Nonparametric estimation of a survivorship function with doubly censored data: Journal of the American Statistical Association, v. 69, no. 345, p. 169-173.

Turnbull, B.W., 1976, The empirical distribution function with arbitrarily grouped, censored, and truncated data: Journal of the Royal Statistical Society (Series B), v. 38, p. 290-295.

U.S. Department of Agriculture, National Agricultural Statistics Service, 1997, Usual planting and harvesting dates for U.S. field crops: Agricultural Handbook 628, accessed June 7, 2007, at http://usda.mannlib.cornell.edu/usda/nass/ planting/uph97.pdf

U.S. Department of Agriculture, 2005, Agricultural Research Service (ARS), Pesticide Properties Database, accessed August 22, 2005, at http://www.ars.usda.gov/Services/docs. htm? docid $=14199$

U.S. Environmental Protection Agency, 1994, Pesticide environmental fate database one-line summary-Acetochlor: U.S. Environmental Protection Agency, Office of Pesticide Programs, Environmental Fate and Effects Division, Washington, D.C. (Last updated 9/9/94.)

U.S. Environmental Protection Agency, 2002, Chlorpyrifos facts: U.S. Environmental Protection Agency, EPA 738-F01-006., accessed October 29, 2008, at http://www.epa.gov/ oppsrrd1/REDs/factsheets/chlorpyrifos_fs.htm

U.S. Environmental Protection Agency, 2005, Ag 101-Major crops grown in the United States, accessed November 27, 2006, at http://www.epa.gov/agriculture/ag101/cropmajor. html

U.S. Environmental Protection Agency, 2008, Diazinon: Phase out of all residential uses of the insecticide, accessed October 27, 2008, at http:/www.epa.gov/opp00001/factsheets/ chemicals/diazinon-factsheet.htm

U.S. Geological Survey, 2006a, National Water-Quality Assessment (NAWQA) Program, accessed October 2, 2006, at http://water.usgs.gov/nawqa/ 
U.S. Geological Survey, 2006b, NASQAN-National Stream Quality Accounting Network, accessed December 14, 2006, at http://water.usgs.gov/nasqan/

Vecchia, A.V., Martin, J.D., and Gilliom, R.J., 2008, Modeling variability and trends in pesticide concentrations in streams: Journal of the American Water Resources Association, v. 44, no. 5 , p. 1308-1324.

Vogelmann, J.E., Howard, S.M., Yang, L., Larson, C.R., Wylie, B.K., and Van Driel, N., 2001, Completion of the 1990's national land cover data set for the conterminous United States from Landsat Thematic Mapper data and ancillary data sources: Photogrammetric Engineering and Remote Sensing, v. 67, p. 650-662.
Zaugg, S.D., Sandstrom, M.W., Smith, S.G., and Fehlberg, K.M., 1995, Methods of analysis by the U.S. Geological Survey National Water Quality Laboratory-Determination of pesticides in water by $\mathrm{C}-18$ solid-phase extraction and capillary-column gas chromatography/mass spectrometry with selected-ion monitoring: U.S. Geological Survey Open-File Report 95-181, 49 p., accessed April 1, 2008, at http://nwql.usgs.gov/Public/pubs/OFR95-181/OFR95-181. html

Zimdahl, R.L. and Clark, S.K., 1982, Degradation of three acetanilide herbicides in soil: Weed Science, v. 30, p. 545-548. 


\section{Appendixes}

\section{Appendix 1. Left-Censored Seasonal Kendall Trend Test and Approach for Estimating Trend Slope}

The left-censored seasonal Kendall trend test is based on the seasonal Kendall trend test described in Hirsch and Slack (1984). The seasonal Kendall trend test described in Hirsch and Slack (1984) gives unbiased test results for singly censored data, when simple substitution is for the censored values, however, the estimated trend is affected by the choice of the substitution value. Modifications to that test to provide unbiased test results for multiply censored data are described in this appendix. Consider a sequence of observations collected at regular intervals over a period of years, with no ties in the values. Let the matrix

$$
X=\left[\begin{array}{ccc}
x_{11} & \cdots & x_{1 p} \\
\vdots & \ddots & \vdots \\
x_{n 1} & \cdots & x_{n p}
\end{array}\right]
$$

denote a sequence of observations sampled over $p$ seasons for $n$ years. The null hypothesis is that the $n$ observations for each of the $p$ seasons are ordered randomly. The alternative hypothesis is a monotonic trend in one or more seasons. The Mann-Kendall test statistic for each season is

$$
S_{g}=\sum_{i<j} \operatorname{sgn}\left(x_{j g}-x_{i g}\right), g=1,2, \ldots, p,
$$

where the $s g n$ function is defined for censored and uncensored values in equations 2 through 5 . For these equations, a censored value is indicated by preceding the symbol with $<$, the upper limit is indicated by preceding the symbol with '.

If both are detected values:

$$
\operatorname{sgn}\left(x_{m}-x_{s}\right)=\left\{\begin{array}{l}
1 \text { if } x_{m}-x_{s}>0 \\
0 \text { if } x_{m}-x_{s}=0 \\
-1 \text { if } x_{m}-x_{s}<0
\end{array}\right\}
$$

If both are censored:

$$
\operatorname{sgn}\left(<x_{m}-<x_{s}\right)=0
$$

If only the minuend is censored:

$$
\operatorname{sgn}\left(<x_{m}-x_{s}\right)=\left\{\begin{array}{l}
0 \text { if }{ }^{\prime} x_{m}-x_{s}>0 \\
-1 \text { if }{ }^{\prime} x_{m}-x_{s} \leq 0
\end{array}\right\}
$$

If only the subtrahead is consored:

$$
\operatorname{sgn}\left(x_{m}-<x_{s}\right)=\left\{\begin{array}{l}
1 \text { if } x_{m}-' x_{s} \geq 0 \\
0 \text { if } x_{m}-x_{s}<0
\end{array}\right\}
$$

If either value is missing, the result is 0 .

The seasonal Kendall test statistic is

$$
S^{\prime}=\sum_{g} S_{g}
$$

and is asymptotically normal with mean 0 and variance

$\operatorname{Var}\left(S^{\prime}\right)=\sum_{g} \sigma_{g}^{2}+\sum_{g h \quad g !=h} \sigma_{g h}$,

where $\sigma^{2}$ is $\operatorname{Var}\left(S_{g}\right)$ and $\sigma_{g h}$ is $\operatorname{Cov}\left(S_{g} S_{h}\right)$. Equations 6 to 8 describe the proposed method for computing the adjustment to the $p$-value to account for serial dependence between seasons.

Equation 6 in Hirsch and Slack (1984) estimates the covariance:

$$
\sigma_{g h}=K_{g h} / 3+\left(n^{3}-n\right) r_{g h} / 9
$$

Equation 7 in Hirsch and Slack (1984) describes the computation of $K_{g h}$ :

$$
K_{g h}=\sum_{i<j} \operatorname{sgn}\left[\left(x_{j g}-x_{i g}\right)\left(x_{j h}-x X_{i h}\right)\right]
$$

Equation 8 in Hirsch and Slack (1984) describes the computation of $r_{g h}$ :

$$
r_{g h}=3 /\left(n^{3}-n\right) \sum_{i, j, k} \operatorname{sgn}\left[\left(X_{j g}-X_{i g}\right)\left(X_{j h}-X_{k h}\right)\right]
$$

The covariance can be computed using the same rules as for computing the variance of $\mathrm{S}$.

For computational purposes, the sign of the product of two values is equal to the product of the signs of each value (eq. 9):

$$
\operatorname{sgn}(A B)=\operatorname{sgn}(A) \operatorname{sgn}(B)
$$


This reduces the computation of equations 7 and 8 to a simple look-up table (eq. 2 through 5) on the basis of the values of minuend $\left(X_{m}\right)$ and subtrahend $\left(X_{s}\right)$.

For missing data, the same procedure as in Hirsch and Slack (1984) is used. Define $\operatorname{sgn}(\mathrm{A}-\mathrm{B})$ to be zero if either A or $\mathrm{B}$ is missing. Equation 8 then becomes:

$$
r_{g h}=3 /\left(n\left(n_{g}+1\right)\left(n_{h}+1\right)\right) \sum_{i, j, k} \operatorname{sgn}\left[\left(x_{j g}-x_{i g}\right)\left(x_{j h}-x_{k h}\right)\right]
$$

and equation 6 becomes:

$$
\sigma_{g h}=K_{g h} / 3+\left(n\left(n_{g}+1\right)\left(n_{h}+1\right)\right) r_{g h} / 9
$$

The modifications described in this appendix result in no change for left-censored data when there is a single censoring value and no observed values less than the censoring value. There also is no difference when there are missing values. However, these modifications provide a method to estimate the significance of a trend, when there are multiple reporting limits.

\section{Computing Slope}

Slope is an estimate of the magnitude of the trend. The method used in the left-censored seasonal Kendall trend test modifies the procedure presented by Helsel (2005, p. 210-212) from a general regression between $\mathrm{X}$ and censored $\mathrm{Y}$ to a seasonal slope estimate. This method describes the relation between $\mathrm{T}$ and censored $\mathrm{Y}$, where $\mathrm{Y}$ is observed on a regular basis throughout a given period of time (T). The estimate of slope is made by computing the median slope of all withinseason comparisons. For example, if water-quality samples were taken on a monthly basis, slopes would be computed for all values taken in January, but not between January and February, as is described in Hirsch and Slack (1984).

The key to this method is that water-quality data are interval-censored data. That is, a concentration that is reported as $<\mathrm{Y}$ actually is a concentration that probably lies between 0 and $\mathrm{Y}$. Thus, the slope between two observations, one censored and one uncensored, is expressed as a range. For example, assume that at time 1 the concentration is $<1$ and that at time 2 the concentration is 2 . The slope (rate of change in concentration between time 1 and time 2$)$ is between $(2-1) / 1=1$ and $(2-0) / 1=2$. The median slope can be estimated using Turnbull's method for the Kaplan-Meier survival analysis (Turnbull, 1974, 1976) using estimated seasonal slopes as input.
Turnbull's method requires three values, a maximum value $\left(S_{\max }\right)$, a minimum value $\left(S_{\min }\right)$, and an indicator value $\left(S_{\text {ind }}\right)$, (1 for known event (maximum = minimum), 2 for interval censored (maximum $>$ minimum), for example). Equations $12-15$ describe computing slope.

$Y_{t}$ and $Y_{t+n}$ are uncensored:

$$
\begin{gathered}
S_{\max }=\left(Y_{t+n}-Y_{t}\right) / n \\
S_{\min }=S_{\text {max }} \\
S_{\text {ind }}=1
\end{gathered}
$$

$Y_{t}$ censored and $Y_{t+n}$ uncensored:

$$
\begin{gathered}
S_{\max }=\left(Y_{t+n}-0\right) / n \\
S_{\text {min }}=\left(Y_{t+n}-Y_{t}\right) / n \\
S_{\text {ind }}=2
\end{gathered}
$$

$Y_{t}$ uncensored and $Y_{t+n}$ censored:

$$
\begin{gathered}
S_{\max }=\left(Y_{t+n}-Y_{t}\right) / n \\
S_{\min }=\left(0-Y_{t}\right) / n \\
S_{\text {ind }}=2
\end{gathered}
$$

$Y_{t}$ and $Y_{t+n}$ are censored:

$$
\begin{gathered}
S_{\max }=\left(Y_{t+n}-0\right) / n \\
S_{\min }=\left(0-Y_{t}\right) / n \\
S_{\text {ind }}=2
\end{gathered}
$$

If either $Y_{t}$ or $Y_{t+n}$ are missing, no slope is computed. For computational purposes, if $\mathrm{Y}$ is censored at a value $\mathrm{D}$, then a value of $D-\varepsilon$ is used for that value, where $\varepsilon$ is about $1 / 1000$ the resolution of the data (the smallest range between sorted data). All possible slopes are computed for each season and the median is computed for the aggregated slopes for each season. 


\section{Appendix 2. Methods for Fitting SEAWAVE and SEAWAVE- 0 models}

The methods used to fit the SEAWAVE model (eq. 2) and SEAWAVE-Q model (eq. 3) are similar to those described in Vecchia and others (2008), with some minor modifications, described in this appendix, to accommodate the specific sites and pesticides analyzed in this study.

The seasonal wave, $W_{(t)}$, is the solution to the following differential equation,

$$
\begin{aligned}
& \frac{d}{d t} W(t)=\lambda(t)-\phi W(t) \quad[0 \leq t \leq 1, W(0)=W(1)] \\
& \lambda(t)=\sum_{k=1}^{12} \omega_{k} I\left(\frac{k-1}{12} \leq t<\frac{k}{12}\right)
\end{aligned}
$$

where

$t$ is decimal time, in years, with respect to an arbitrary origin;

$\lambda(t)$ is an instantaneous input function describing seasonal variability of pesticide application rates;

$\phi$ is a positive constant;

$\left\{\omega_{\mathrm{k}}, \mathrm{k}=1,2, \ldots, 12\right\}$ are specified non- negative constants; and $I()=$.$I if t$ lies in the given interval and $I()=$.0 otherwise.

As described in Vecchia and others (2008), the input function consisted of seven choices with either 1 or 2 pesticide application periods of specified length and constant application rates within each period. For this report, 14 choices for the input function were used (table A2-1), including the 7 choices from
Vecchia and others (2008) plus 7 additional choices. See Vecchia and others (2008) for figures that show examples of the seasonal waves. The parameter $\phi$ controls the rate at which the seasonal wave decays during periods of no input. If input ceases at some time $t^{*}\left(\lambda(t)=0\right.$ for $\left.t>t^{*}\right), W(t)$ decays at a rate of $\exp (-\phi / 12)$ per month, corresponding to an approximate half-life of $(12 / \phi)$ months. In this report, four choices were used for $\phi-3,4,6$, and 12 - corresponding with half-lives of 4, 3, 2, or 1 month. In Vecchia and others (2008), only two choices for $\phi$ (4 or 12) were used.

For each pesticide/site combination, there were 56 choices for the seasonal wave, corresponding with the 14 choices for the input function and 4 choices for $\phi$ described previously. In addition, since the origin used to compute the seasonal wave was arbitrary, a phase shift needed to be applied to make the maximum of each wave line up as closely as possible with the timing of the maximum concentration. In Vecchia and others (2008), the time of the maximum concentration was selected by locating the center of the 1-month interval for which the mean of the log-transformed concentration data were maximized. However, for this report, a more robust method was used for fixing the time of the maximum concentration. Namely, the S-plus function, supsmu, was used to fit a smooth line to a plot of season ( $t$ minus the greatest integer in $t$ ) versus concentration and the time was selected at which the line reached its maximum.

The regression parameters for either eq. 3 or eq. 7 were estimated using Gaussian maximum likelihood estimation with censored data, as described in Vecchia and others (2008). Parameters were estimated for each of the 56 choices for the seasonal wave, and the wave with the highest value for the likelihood function for a given site/pesticide combination was selected as the best wave.

Table A2-1. Choices for the input function describing seasonal variability of pesticide application rates (equation A2-1).

\begin{tabular}{cllllllllllll}
\hline $\begin{array}{c}\text { Choice } \\
\text { number }\end{array}$ & $\omega_{1}$ & $\omega_{2}$ & $\omega_{3}$ & $\omega_{4}$ & $\omega_{\mathbf{5}}$ & $\omega_{6}$ & $\omega_{7}$ & $\omega_{8}$ & $\omega_{9}$ & $\omega_{10}$ & $\omega_{11}$ & $\omega_{12}$ \\
\hline 1 & 0 & 0 & 1 & 0 & 0 & 0 & 0 & 0 & 0 & 0 & 0 & 0 \\
2 & 0 & 0 & 1 & 1 & 0 & 0 & 0 & 0 & 0 & 0 & 0 & 0 \\
3 & 0 & 0 & 1 & 1 & 1 & 0 & 0 & 0 & 0 & 0 & 0 & 0 \\
4 & 0 & 0 & 1 & 1 & 1 & 1 & 0 & 0 & 0 & 0 & 0 & 0 \\
5 & 0 & 0 & 1 & 1 & 1 & 1 & 1 & 1 & 0 & 0 & 0 & 0 \\
6 & 0 & 0 & 1 & 1 & 1 & 1 & 1 & 1 & 1 & 1 & 1 & 0 \\
7 & 0 & 0 & 1 & 1 & 1 & 0 & 0 & 0 & 1 & 0 & 0 & 0 \\
8 & 0 & 0 & 1 & 1 & 1 & 0 & 0 & 0 & 0 & 1 & 0 & 0 \\
9 & 0 & 0 & 1 & 1 & 1 & 0 & 0 & 0 & 0 & 0 & 1 & 0 \\
10 & 0 & 0 & 1 & 1 & 1 & 0 & 0 & 0 & 0 & 0 & 0 & 1 \\
11 & 0 & 0 & 1 & 1 & 1 & 0 & 0 & 0.75 & 0.75 & 0 & 0 & 0 \\
12 & 0 & 0 & 1 & 1 & 1 & 0 & 0 & 0 & 0.75 & 0.75 & 0 & 0 \\
13 & 0 & 0 & 1 & 1 & 1 & 0 & 0 & 0 & 0 & 0.75 & 0.75 & 0 \\
14 & 0 & 0 & 1 & 1 & 1 & 0 & 0 & 0 & 0 & 0 & 0.75 & 0.75 \\
\hline
\end{tabular}


Manuscript approved for publication, June 16, 2009

Prepared by the USGS Enterprise Publishing Network, Publishing Service Center, Sacramento, California

For more information concerning the research in this report, contact the California Water Science Center Director,

U.S. Geological Survey, 6000 J Street

Sacramento, California 95819

http://ca.water.usgs.gov 


\section{$\frac{\mathbb{2}}{3}$}

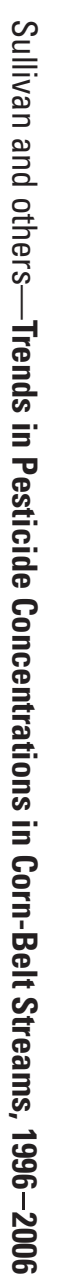

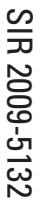

Printed on recycled paper 